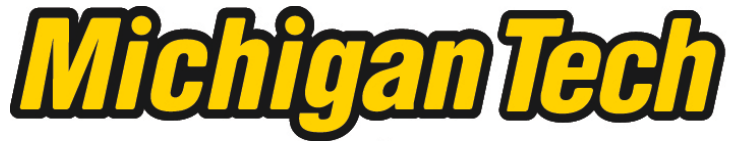 \\ Michigan Technological University Create the Future Digital Commons @ Michigan Tech
}

\section{Acute alcohol ingestion and sympathetic neural responses during orthostatic stress in humans}

Sarah F. Stream

Michigan Technological University

Follow this and additional works at: https://digitalcommons.mtu.edu/etds

Part of the Biology Commons

Copyright 2012 Sarah F. Stream

\section{Recommended Citation}

Stream, Sarah F., "Acute alcohol ingestion and sympathetic neural responses during orthostatic stress in humans", Master's Thesis, Michigan Technological University, 2012.

https://doi.org/10.37099/mtu.dc.etds/185

Follow this and additional works at: https://digitalcommons.mtu.edu/etds

Part of the Biology Commons 


\title{
ACUTE ALCOHOL INGESTION AND SYMPATHETIC NEURAL RESPONSES DURING ORTHOSTATIC STRESS IN HUMANS
}

\author{
By \\ Sarah F. Stream

\begin{abstract}
A THESIS
Submitted in partial fulfillment of the requirements for the degree of MASTER OF SCIENCE

(Biological Sciences)
\end{abstract}

MICHIGAN TECHNOLOGICAL UNIVERSITY

2012

(C)2012 Sarah F. Stream 
This thesis, "Acute Alcohol Ingestion and Sympathetic Neural Responses During Orthostatic Stress in Humans," is hereby approved in partial fulfillment of the requirements for the Degree of MASTER OF SCIENCE IN BIOLOGICAL SCIENCES.

Department of Biological Sciences

Signatures:

Thesis Advisor

Jason R. Carter, Ph.D.

Department Chair

Shekhar P. Joshi, Ph.D.

Date 


\section{Table of Contents}

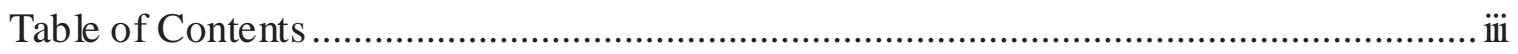

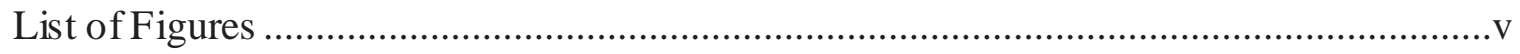

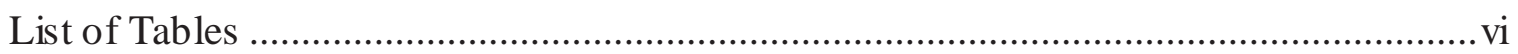

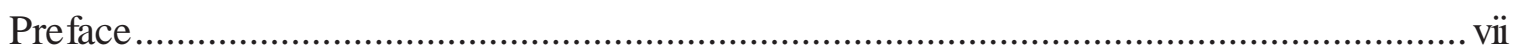

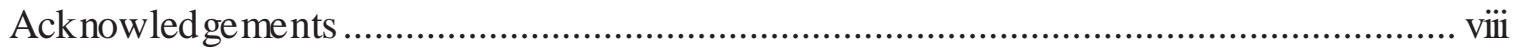

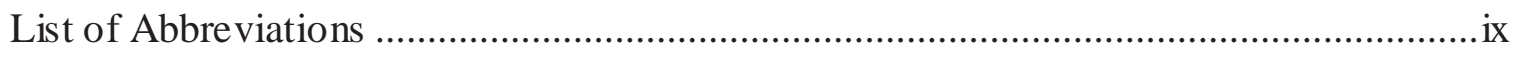

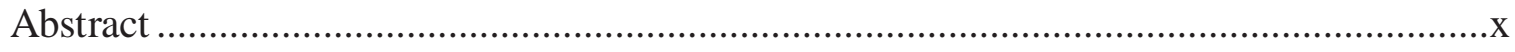

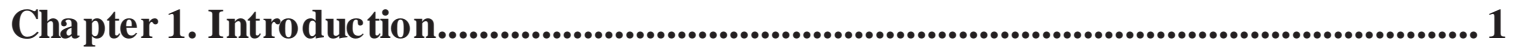

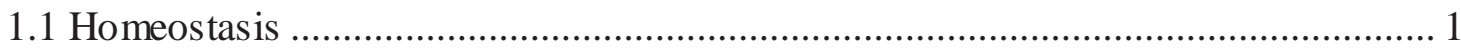

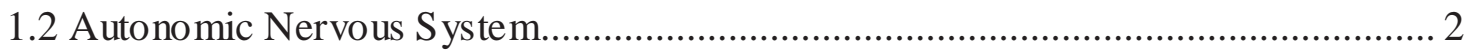

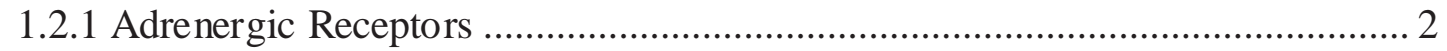

1.2.2 Muscle Sympathetic Nerve Activity ….................................................... 3

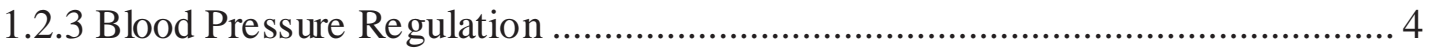

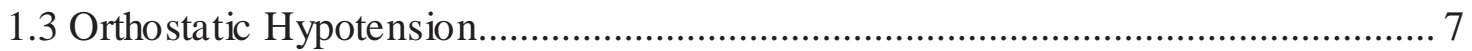

1.3.1 Methods for Inducing Orthostatic Stress ................................................ 9

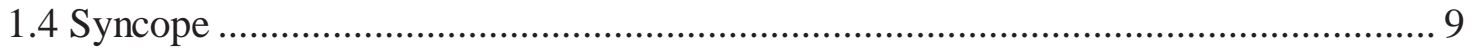

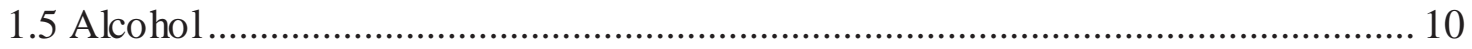

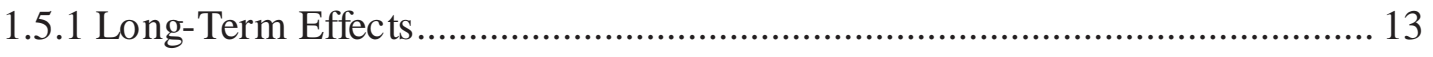

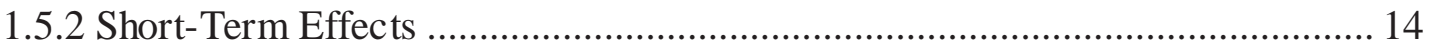

1.5.3 Acute Alcohol Consumption and an Orthostatic Challenge ............................ 15

Chapter 2. Methods .................................................................................................... 16

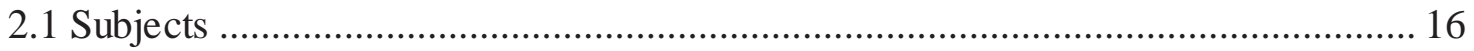

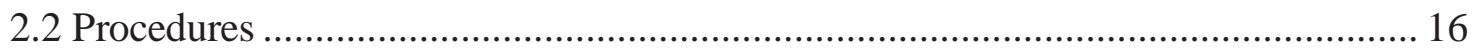

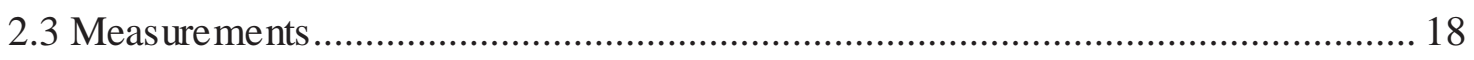

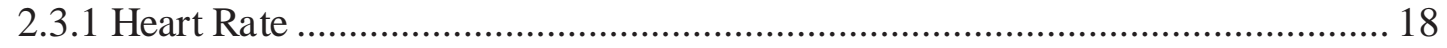

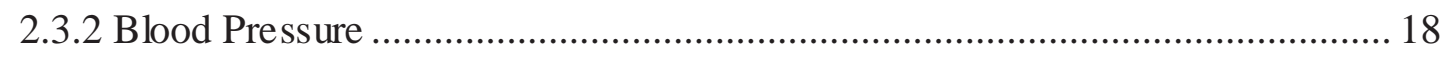

2.3.3 Muscle Sympathetic Nerve Activity ....................................................... 19

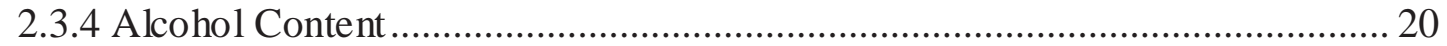




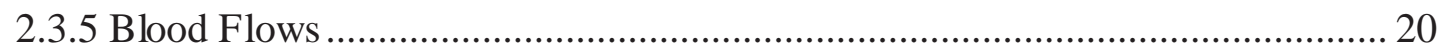

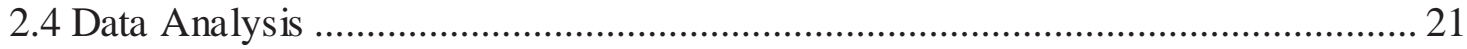

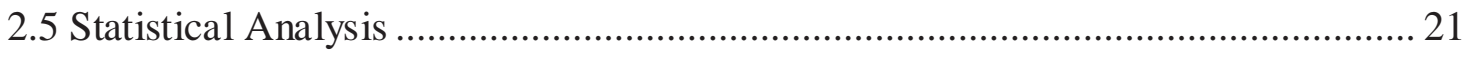

Chapter 3. Results ...................................................................................................................... 23

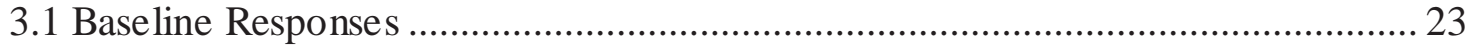

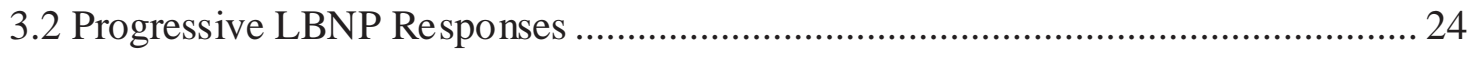

3.2.1 Hemodynamic Responses ........................................................................ 24

3.2.2 Sympathetic Responses ........................................................................... 26

3.2.3 Vasculature Responses .......................................................................... 28

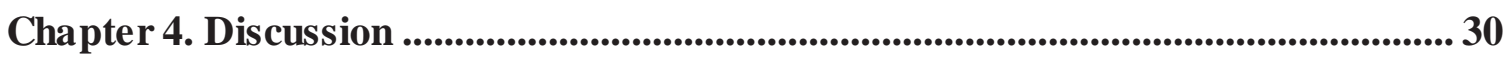

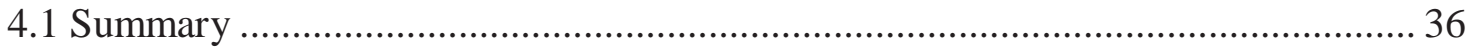

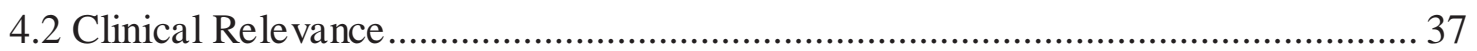

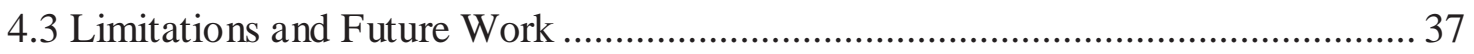

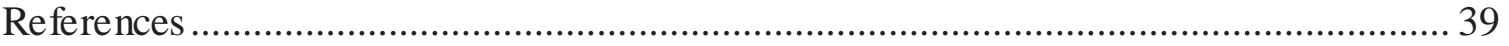

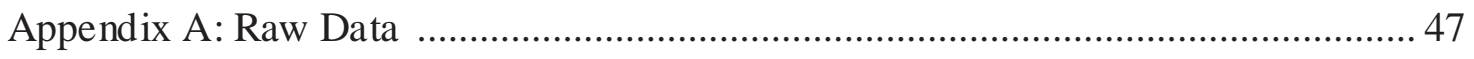

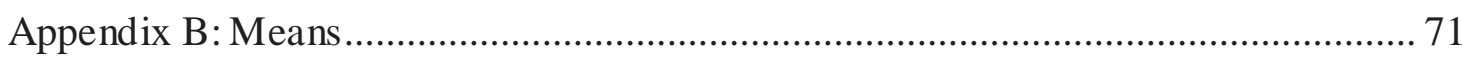

Appendix C: Repeated Measures ANOVA................................................................... 75

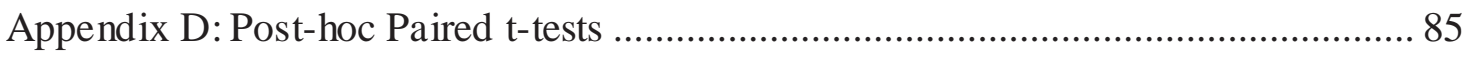

Appendix E: Copyright Clearance ………………................................................... 89 


\section{List of Figures}

Figure 1.1 A neurogram and the corresponding blood pressure .........................................

Figure 1.2 The body's short-term response to a decrease in blood pressure via the baroreflex...................................................................................................6

Figure 1.3 The body's long-term response to a decrease in blood pressure ........................6

Figure 1.4 The normal response to an orthostatic challenge, such as a postural change, and the ventricular theory describing how an orthostatic challenge may

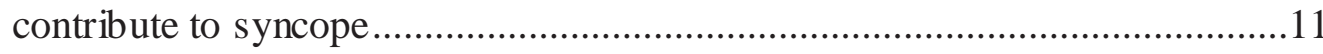

Figure 3.1 Changes in SAP, DAP, and MAP during progressive LBNP ..........................25

Figure 3.2 Changes in HR during progressive LBNP..................................................26

Figure 3.3 Changes in MSNA during progressive LBNP.................................................27

Figure 3.4 Changes in FBF, FVR, and FVC during progressive LBNP ..........................29

Figure 4.1 A screenshot of the American Physiological Society's copyright permission

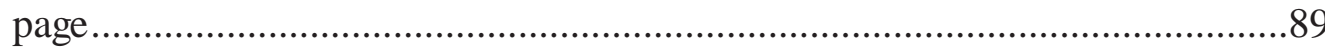

Figure 4.2 A screenshot of the American Physiological Society's copyright permission page stating the rights of authors to reuse published articles in theses ............89 


\section{List of Tables}

Table 2.1 Timeline of the experimental protocol........................................................ 18

Table 3.1 Pre-and post-treatment baseline values for alcohol and placebo groups ..........24 


\section{Preface}

Some of the text throughout this thesis, specifically a majority of the Abstract, Methods, and Results, along with all of the figures and the table in the Results section, are used with consent from the American Physiological Society as a concerted effort with co-authors Dr. Jason Carter, Dr. John Durocher, and Robert Larson. All data collection was performed in Dr. Jason Carter's laboratory at Michigan Tech University in Houghton, Michigan. My involvement included subject recruitment, data acquisition, data analysis and statistical analysis of the study. I also had an important part in authoring the Abstract and Results sections of the article, with a lesser, but still important role in the Introduction, Methods, and Discussion sections. Please see Appendix E for documentation relating to the permission to republish this material. 


\section{Acknowledgements}

Finishing this thesis was a rewarding experience and I would not have been able to do it without the help of so many wonderful people. First of all, thank you to my advisor, Dr. Jason Carter. Without your knowledge, patience, and support, none of this would have been possible. You have been a great mentor and role model and I am very appreciative of that. Next, thank you to all the members of my committee. Your enthusiasm in this research and your feedback was always valued. Also, thank you to the Department of Kinesiology and Integrative Physiology, Athletics, and Women's Basketball for all your support throughout the various stages of this work as well.

A very important thank you to all of my family and friends. Your love, support, and patience throughout these past few years have meant the world to me. Your positive attitude and encouragement never went unnoticed.

I've had the opportunity to work with a great group of lab members and I would like to thank you for not only all of your help, but also for making my graduate studies enjoyable: Dr. Chris Schwartz, Dr. John Durocher, Jenna Klein, Huan Yang, and Robert Larson. Also, a very big thank you to Terry Anderson for always being there for me. I am not sure where I would be without all of your assistance and positivity. Lastly, I would like thank the entire Michigan Tech community. I've had an amazing time here and I wouldn't trade my experiences at this university for anything. I am so grateful for everything I have learned and have had the chance to be a part of. No matter where I go or where I end up, it will always be a great day to be a Husky! 


\section{List of Abbreviations}

\begin{tabular}{|c|c|}
\hline ANS & Autonomic nervous system \\
\hline BAC & Blood alcohol content \\
\hline BMI & Body mass index \\
\hline $\mathrm{CO}$ & Cardiac output \\
\hline DAP & Diastolic arterial pressure \\
\hline $\mathrm{E}$ & Epinephrine \\
\hline FBF & Forearm blood flow \\
\hline FVC & Forearm vascular conductance \\
\hline FVR & Forearm vascular resistance \\
\hline $\mathrm{HB}$ & Heartbeat \\
\hline HR & Heart rate \\
\hline LBNP & Lower body negative pressure \\
\hline MAP & Mean arterial pressure \\
\hline MSNA & Muscle sympathetic nerve activity \\
\hline NE & Norepinephrine \\
\hline NTS & Nucleus tractus solitarii \\
\hline $\mathrm{OH}$ & Orthostatic hypotension \\
\hline SAP & Systolic arterial pressure \\
\hline SV & Stroke volume \\
\hline TPR & Total peripheral resistance \\
\hline
\end{tabular}




\section{Abstract $^{1}$}

Acute alcohol consumption has been reported to decrease mean arterial pressure (MAP) during orthostatic challenge, a response that may contribute to alcohol-mediated hypotension and eventually syncope. Muscle sympathetic nerve activity (MSNA) increases during orthostatic stress to help maintain MAP, yet the influence of alcohol on MSNA during orthostatic stress has not been determined. We hypothesized that alcohol ingestion would blunt arterial blood pressure and MSNA responses to progressive lower body ne gative pressure (LBNP). MAP, MSNA, and heart rate (HR) were recorded during progressive LBNP $(-5,-10,-15,-20,-30$, and $-40 \mathrm{mmHg} ; 3 \mathrm{~min} / \mathrm{stage}$ ) in 30 subjects (age $24 \pm 1 \mathrm{yrs}$ ). After an initial progressive LBNP protocol (pre-treatment), subjects were randomly assigned to consume alcohol $(0.8 \mathrm{~g}$ ethanol/kg body mass; $n=15)$ or placebo $(n=15)$ and then repeated the progressive LBNP protocol (post-treatment). Alcohol increased (drug $\times$ treatment, $\mathrm{P} \leq 0.05)$ resting HR $(59 \pm 2$ to $65 \pm 2$ beats $/ \mathrm{min})$ and MSNA (13 \pm 3 to $19 \pm 4$ bursts/min) when compared to placebo. While alcohol increased MAP ( $83 \pm 2$ to $87 \pm 2 \mathrm{mmHg}$ ), these increases were also observed with placebo $(82 \pm 2$ to $88 \pm 1 \mathrm{mmHg}$; treatment, $\mathrm{P}<0.05$; drug $\times$ treatment, $\mathrm{P}>0.05)$. During progres sive LBNP, a prominent decrease in MAP was observed after alcohol (drug $\times$ time $\times$ treatment, $\mathrm{P}<0.05)$, but not placebo. There was also a significant attenuated response in forearm vascular resistance $(\mathrm{FVR})$ during progressive LBNP (drug $\times$ time $\times$ treatment, $\mathrm{P}$ $<$ 0.05). MSNA and HR increased during all LBNP protocols, but there were no differences between treatments or groups (drugs). In summary, acute alcohol ingestion induces an attenuation in blood pressure response during an orthostatic challenge, possibly due to the effect that alcohol has on impairing peripheral blood vessel constriction.

\footnotetext{
${ }^{1}$ The material in this abstract was previously published in the American Journal of Physiology Endocrinology and Metabolism.

Carter JR, Stream SF, Durocher JJ \& Larson RA. (2011). Influence of acute alcohol ingestion on sympathetic neural responses to orthostatic stress in humans. American journal of physiology Endocrinology and metabolism 300, E771-778.
} 


\section{Chapter 1 \\ INTRODUCTION}

\subsection{Homeostasis}

The autonomic nervous system (ANS) is critical in preserving homeostasis throughout the body. Walter Cannon first coined this term in 1929, with "homeo" meaning like or similar and "stasis" meaning a condition. He described the human body as an open system that interacts with the environment, and hypothesized that those changes in the surrounding environment create internal disturbances of the system. "Such disturbances are normally kept within narrow limits, because autonomic adjustments within the system are brought into action, and thereby wide oscillations are prevented and the internal conditions are held fairly constant" (Cannon, 1929). This homeostas is is maintained by negative feedback. By comparing organisms to machines, Rosenblueth, Wiener, and Bigelow (1943), a physiologist, mathematician, and engineer, respectively, were able to recognize the importance of negative feedback in the living organism. "The behavior of some machines and some reactions of living organisms involve a continuous feed-back from the goal that modifies and guides the behaving object (Rosenblueth, 1943)."

When homeostasis is disrupted, the possibility of cardiovascular risks increase. Many lifestyle choices, such as alcohol consumption, contribute to this disruption of homeostasis. Alcohol has been shown to increase the incidence of both hypertension (Zilkens et al., 2005; Lichtenstein et al., 2006; Kloner \& Rezkalla, 2007; Saremi \& Arora, 2008; van de Wiel \& de Lange, 2008; Klatsky, 2009; Wakabayashi, 2009) and orthostatic hypotension (Fisher, 1979; Hollister, 1992; Narkiewicz et al., 2000; Medow et al., 2008; Freeman et al., 2011; Lanier et al., 2011). While the long-term effects of moderate alcohol consumption and hypertension have been well studied and are thought to be due to sympathoexcitation (Johnson et al., 1986; Grassi et al., 1989; Iwase et al., 1995; Randin et al., 1995; Kloner \& Rezkalla, 2007), the link between alcohol induced hypotension after an orthostatic stress is still unclear. 


\subsection{Autonomic Nervous System}

Unlike the somatic nervous system, which is voluntary, the ANS operates predominately without any conscious input or voluntary control. Its role is to innervate cardiac muscle, smooth muscle, and many exocrine and endocrine glands (Cannon, 1929). It is further subdivided into two divisions, the parasympathetic and the sympathetic nervous systems, which are both constantly active to some degree. The sympathetic nervous system is perhaps best known for Cannon's infamous "fight or flight" analogy, and is responsible for mobilizing the body's systems during physical or mental stress by increasing heart rate, increasing heart contractility, and constricting blood vessels. Cannon described how an animal responds to threats and that all of the changes that occur are "directly serviceable in making the organism more effective in the violent display of energy which fear or rage or pain may involve" (Cannon, 1915). The sympathetic nervous system is the main division of the ANS that is responsible for vascular tone (Cannon, 1929). The parasympathetic nervous system, also known as the "rest and digest" response, is responsible for conserving energy and is usually complementary of the sympathetic nervous system (Cannon, 1929).

\subsubsection{Adrenergic Receptors}

Adrenergic receptors are receptors that respond to both norepinephrine and epinephrine (Furchgott, 1959). The main neurotransmitter used to transmit information to the target tissue in the sympathetic nervous system via post-ganglionic fibers is norepinephrine (NE). NE can also be released in the bloodstream along with epinephrine (E) through stimulation of the adrenal medulla. There are two classes of $\alpha$ receptors and three classes of $\beta$ receptors (Bylund, 2007). $\alpha_{1}, \beta_{1}$, and $\beta_{2}$ receptors are important to the maintenance of blood pressure. $\alpha_{1}$ receptors are found in blood vessels and have a higher affinity for NE than E. Stimulation of these will cause vasoconstriction (Furchgott, 1959; Charkoudian \& Rabbitts, 2009). $\beta_{2}$ receptors are also found in many blood vessels and stimulation of these adrenergic receptors will result in vasodilation (Furchgott, 1959). These receptors have a greater affinity for epinephrine. $\beta_{1}$ receptors, which are found on the heart, have affinity for both epinephrine and norepinephrine. If these are stimulated, 
there is an increase in both heart rate and heart contractility (Furchgott, 1959). There are also $\alpha_{2}$ and $\beta_{3}$ receptors. $\alpha_{2}$ receptors are found in many membranes of adrenergic axon terminals and have the ability to inhibit NE release (Marieb \& Hoehn, 2008). $\beta_{3}$ receptors are found in adipose tissue and stimulation will result in lipolysis (Marieb \& Hoehn, 2008).

\subsubsection{Muscle Sympathetic Nerve Activity}

Microneurography is a technique used to record sympathetic neural traffic. It measures the post-ganglionic efferent sympathetic bursts to skeletal muscle beds, i.e. muscle sympathetic nerve activity (MSNA). Microneurography originated in Sweden in 1965-1966 by researchers Karl-Erik Hagbarth and Åke Vallbo who first developed the technique by inserting needles into their own ulnar nerves (Vallbo et al., 2004). In the late 1960s and early 70s, Gunnar Wallin and Göran Sundlöf learned the microneurography system from Hagbarth and made vast contributions to the development of not only the method, but of the role of the sympathetic nervous system in health and disease (Vallbo et al., 2004). This has especially played an important role in advancing our understanding of the pathophysiology of cardiovascular disease (Grassi \& Esler, 1999; Charkoudian \& Rabbitts, 2009). For more information about the technique itself, please refer to the muscle sympathetic nerve activity section in the methods of this thesis.

Although MSNA is a measurement of the sympathetic outflow to the vasculature of skeletal muscle, it appears to reasonably represent sympathetic activity to other vascular beds and thus be a good indicator of overall sympathetic activity . It has been demonstrated that there is a correlation between renal NE spillover and MSNA and also between cardiac NE spillover and MSNA (Wallin et al., 1992; Wallin et al., 1996). As outlined previously, with every sympathetic burst, NE is released by post-ganglionic sympathetic fibers and binds to vascular receptors (Morlin et al., 1983). This process elicits varying levels of vasoconstriction and beat-to-beat control of arterial blood pressure. These bursts represent a collection of action potentials of several nerve fibers (Wallin, 2006) and occur in rhythm with the cardiac cycle (Sundlof, 1978). MSNA is largely modulated via the baroreflex and has a negative correlation with blood pressure, 
specifically diastolic blood pressure (DAP) (Sundlof, 1978). If there is a decrease in blood pressure, there is typically an increase in MSNA which elicits vasoconstriction and a subsequent increase in blood pressure. If there is an increase in blood pressure, there will typically be a decrease in MSNA. As a result, there will be less sympathetic tone, which will decrease blood pressure (Sundlof, 1978). The relationship between MSNA and arterial blood pressure via the baroreflex is a classic example of a negative feedback system to aid in homeostasis.

\subsubsection{Blood Pressure Regulation}

Baroreceptors are mechanoreceptors with sensory afferent nerve endings located in blood vessels and the heart. They detect increases or decreases in blood pressure or volume by the change in stretch/deformation (Kirchheim, 1976). High-pressure arterial baroreceptors are located in the aortic arch and the carotid artery and low-pressure cardiopulmonary baroreceptors are located in the heart (Kirchheim, 1976; MosquedaGarcia et al., 2000; Freeman, 2006). If a change in blood pressure or volume is detected, the number of signals being sent to the nucleus tractus solitarii (NTS) in the medulla via afferent pathways changes, and there is a corresponding modification in sympathetic and parasympathetic outflow (Kirchheim, 1976). As a result, there is a change in sympathetic neural activity, heart rate, heart contractility, vascular tone, and total peripheral resistance, which results in a correction of blood pressure (Charkoudian \& Rabbitts, 2009).

Mean arterial pressure (MAP) is the product of cardiac output (CO) and total peripheral resistance (TPR) (Shepherd, 1987), and CO is the product of heart rate (HR) and stroke volume (SV) (Rushmer \& Smith, 1959). The most immediate regulation of arterial blood pressure is through the baroreflex (Sundlof, 1978). A summary of the shortterm events that take place if there is a decrease in MAP, including the ones that were already discussed, is outlined in Figure 1.2. 


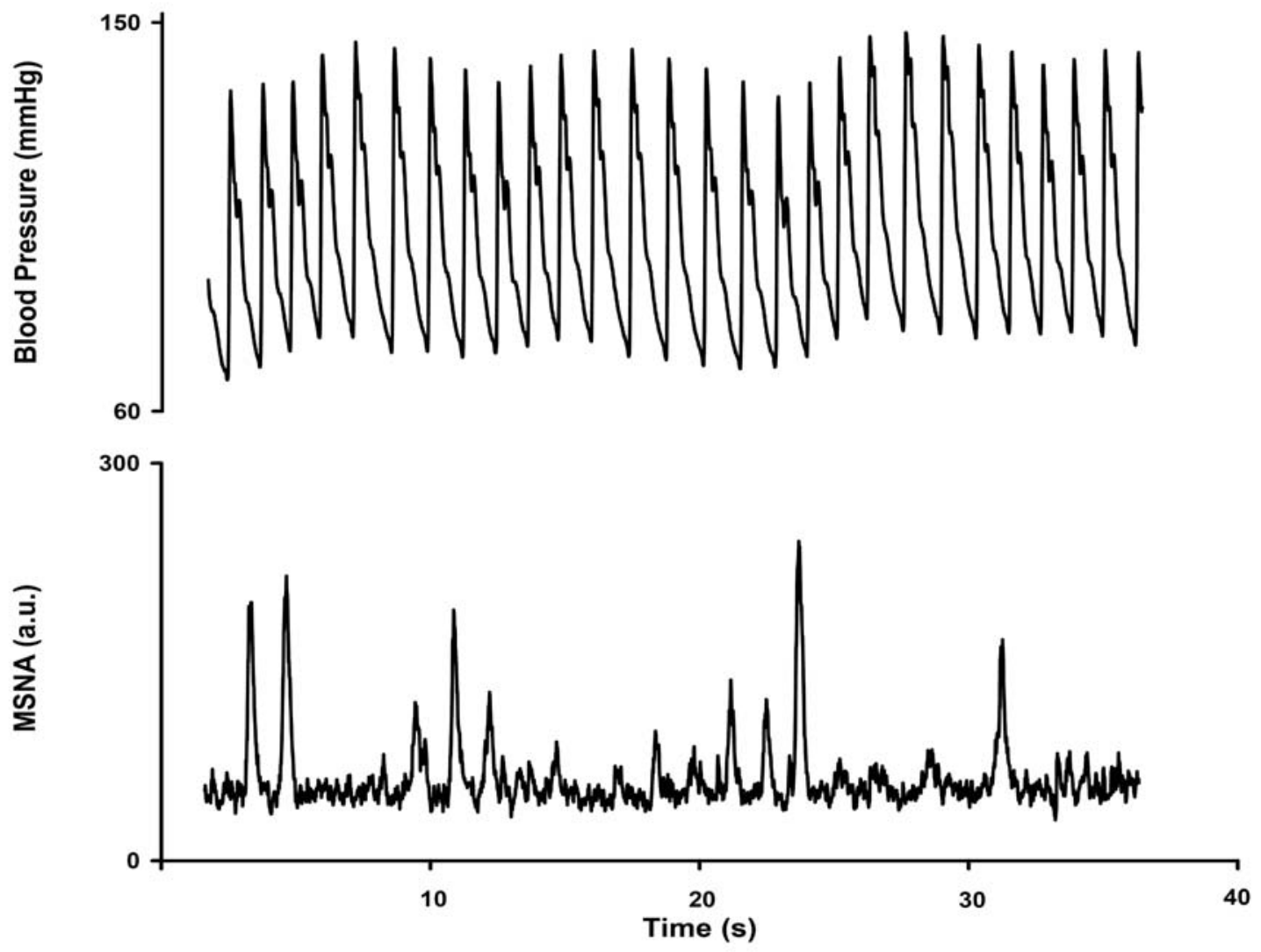

Figure 1.1 A neurogram and the corresponding blood pressure during an approximately 30 second period of baseline. Note the relationship between fluctuations in blood pressure and MSNA such that burst occur more frequently during reductions in blood pressure. MSNA, muscle sympathetic nerve activity; a.u., arbitrary units

There are several other methods the body uses to maintain a stable blood pressure, including the kidneys which participate predominantly in long-term control. The sympathetic nervous system can stimulate the kidneys to release renin, which activates the renin-angiontensin-aldosterone system (Rowell, 1993). When activated, this system can increase water and salt retention and thus, increase blood volume. Angiontensin II will also stimulate vasopressin release from the posterior pituitary gland, which can increase water and salt reabsorption. Angiontensin II and vasopressin are vasoconstrictors as well (Rowell, 1993). This is also diagrammed in Figure 1.3. Additionally, local factors can play a role in blood pressure regulation. Endothelial cells can release vasodilators 
such as nitric oxide (NO) and prostaglandins, which can decrease local sympathetic tone and therefore, TPR (Wolf et al., 1999).

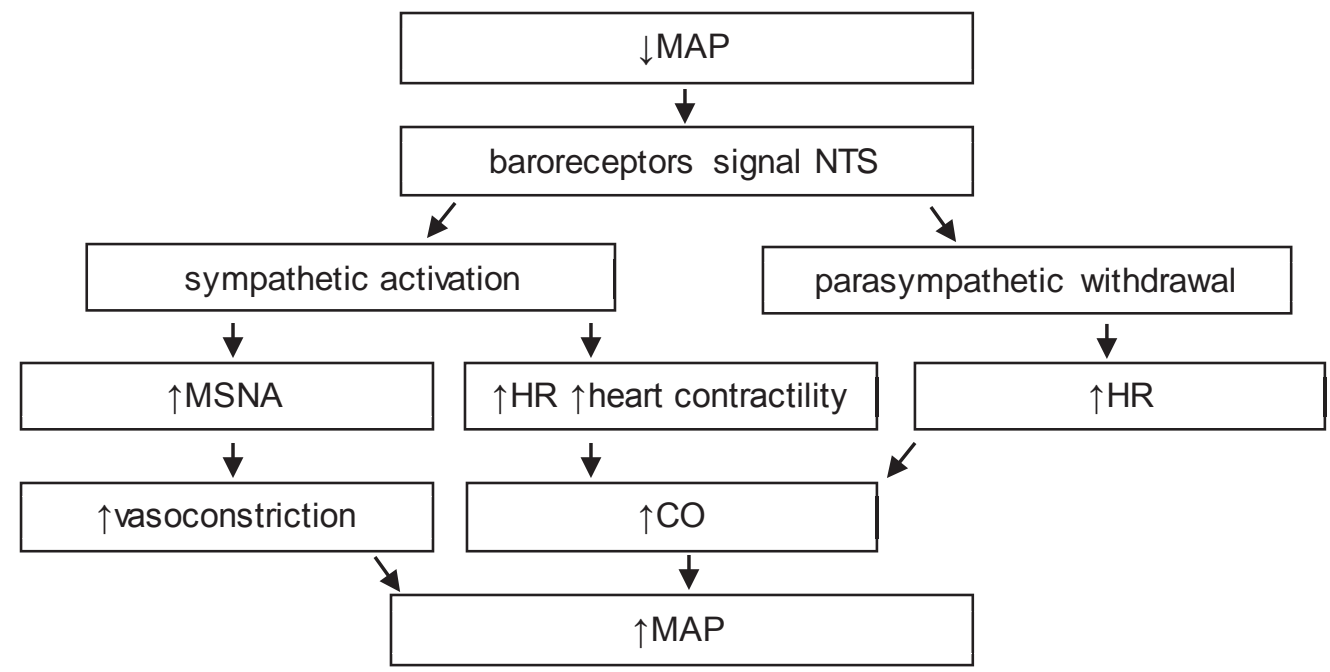

Figure 1.2 The body's short-term response to a decrease in blood pressure via the baroreflex. MAP, mean arterial pressure; NTS, nucleus tractus solitarii; MSNA, muscle sympathetic nerve activity; $\mathrm{HR}$, heart rate; $\mathrm{CO}$, cardiac output.

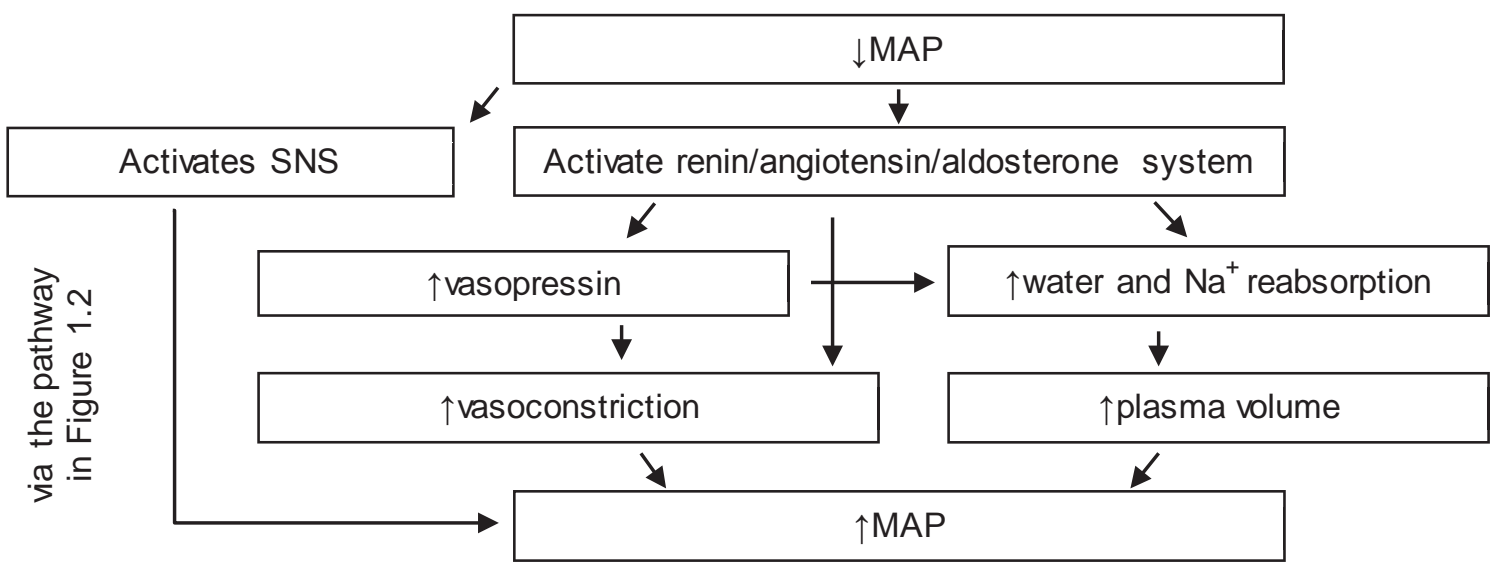

Figure 1.3 The body's long-term response to a decrease in blood pressure. MAP, mean arterial pressure; SNS, sympathetic nervous system. $\mathrm{NA}^{+}$, sodium. 


\subsection{Orthostatic Hypotension}

Orthostatic hypotension $(\mathrm{OH})$ often results after a postural change to the upright position. One of the first physiological accounts of this came from Thomas Lewis who was a medical doctor studying British soldiers in World War I. He noticed a drop of 30 $\mathrm{mmHg}$ or more in blood pressure as soldiers went from supine to erect (Lewis, 1920). This idea was expanded on by Swedish physicians, Bjure and Laurell, who in the late 1920s and 30s demonstrated that patients with orthostatic hypotension had reduced stroke volume and cardiac output (Streeten, 1999).

In the past, $\mathrm{OH}$ was used to describe an abnormal drop in blood pressure after standing up. However, the American Autonomic Society and the American Academy of Neurology defines $\mathrm{OH}$ as a decrease in SAP of at least $20 \mathrm{mmHg}$ or DAP of at least 10 mmHg within three minutes of standing ((NIAAA), 2012). It is more common in elderly (Vaddadi et al., 2007; Freeman et al., 2011), females (Ganzeboom et al., 2006), astronauts that return from space (Mano \& Iwase, 2003), and highly trained endurance athletes (Raven \& Pawelczyk, 1993). It occurs spontaneously in $0.5 \%$ of individuals (Medow et al., 2008) and is also a major risk factor for falls, which can lead to serious injuries (Naschitz \& Rosner, 2007).

When a person stands up, anywhere from $300-800 \mathrm{~mL}$ of blood redistributes to the lower part of the body such as the legs, buttocks, pelvis, and splanchnic region (Freeman, 2006). As a result, there is a drop in stroke volume (SV), cardiac output, and arterial blood pressure (Burke et al., 1977). The baroreceptors located in the carotid arteries, aorta, and the heart quickly detect the drop in blood volume and pressure (Bradley \& Davis, 2003). The heart rate increases almost immediately due to parasympathetic withdrawal and an increase in sympathetic activity (Burke et al., 1977; Freeman, 2006). There is also vasoconstriction in the splanchnic, renal, and skeletal muscle regions and a subsequent increase in TPR (Burke et al., 1977; Rowell, 1993; Freeman, 2006). Additionally, the contraction of the leg and abdominal muscles upon standing activates the skeletal and respiratory pumps and enhances venous return to the heart (Bradley \& Davis, 2003; Medow et al., 2008). An orthostatic challenge has also 
been shown to increase plasma NE levels (Mosqueda-Garcia et al., 2000), as well as renin, angiotensin II, aldosterone, and vasopressin (Tid gren et al., 1990; Norsk, 1992), all of which help to maintain blood pressure. As a result of all the above mechanisms, arterial blood pressure is generally well maintained during orthostasis (Burke et al., 1977; Sundlof \& Wallin, 1978; Mano \& Iwase, 2003; Freeman, 2006; Ichinose et al., 2006).

$\mathrm{OH}$ is due to a drop in $\mathrm{CO}$ and/or insufficient vasoconstriction (Sharpey-Schafer, 1956; Medow et al., 2008; Freeman et al., 2011). It is associated with primary and secondary autonomic disorders, postural tachycardia syndrome, or reflex syncope (Medow et al., 2008). OH is often exacerbated by many factors like alcohol, medications (e.g. vasodilators, diuretics, antidepressants), hypovolemia (e.g. hemorrhage, diarrhea, vomiting), eating a large meal, exercise, prolonged bed rest, time of day (i.e. morning), a warm environment, or having poor respiratory or skeletal pump functioning (Fisher, 1979; Medow et al., 2008; Moya et al., 2009; Freeman et al., 2011). It can be symptomatic or asymptomatic (Bradley \& Davis, 2003; Freeman et al., 2011). It may result in presyncopal symptoms, such as dizziness, lightheadedness, blurred vision, weakness, fatigue, and nausea (Medow et al., 2008) or syncope itself if there is a transient loss of consciousness (Moya et al., 2009; Lanier et al., 2011). If syncope results it is often neurally-mediated, with a sympathetic withdrawal and parasympathetic activation (Medow et al., 2008; Moya et al., 2009).

There are a few variants of $\mathrm{OH}$ that have recently been discussed in the literature. Initial $\mathrm{OH}$ is a drop in SAP of at least $40 \mathrm{mmHg}$ and/or DAP of $20 \mathrm{mmHg}$ within 15 seconds of standing (Wieling et al., 2007; Freeman et al., 2011). If often happens in young, asthenic subjects or the elderly (Moya et al., 2009). In delayed $\mathrm{OH}$, there is a fall in BP beyond three minutes of a postural change (Moya et al., 2009). There is a decrease in venous return over time and this causes a reduced CO. It is mostly seen in older individuals (Freeman et al., 2011). 


\subsubsection{Methods for Inducing Orthostatic Stress}

Lower body negative pressure (LBNP) and head-up tilt (HUT) are two common ways to elicit an orthostatic challenge. During LBNP, a pressure gradient is created by placing the lower body into an air-tight chamber with a negative pressure compared to the surrounding air. As a result, blood is displaced from the upper body to the lower body and limbs. If done progressively in discrete stages, this action gradually unloads the baroreceptors (Freeman, 2006). The head-up tilt is similar in that the subjects lay supine and then their head is tilted, usually $60-80$ degrees for up to $60 \mathrm{~min}$ to unload the baroreceptors (Freeman, 2006). The main difference between these two applications is that splanchnic volume increases with head up tilt whereas it decreases with LBNP (Taneja et al., 2007). If done properly, these passive orthostatic challenges do not substantially activate the skeletal muscle pump (Freeman, 2006). For more information on the LBNP protocol that we used, please see the procedures section in the methods description of this thesis.

\subsection{Syncope}

An early French physician, Pierre Piorry described syncope in 1826 as "the heart continues to beat, but the beats have not force enough to overcome the resistance which is given by gravity" (Hill, 1894). Syncope is a short-lived event with rapid onset. It is due to a decrease in cerebral perfusion, which causes a brief loss of consciousness, followed by a spontaneous recovery (Mosqueda-Garcia et al., 2000; Vaddadi et al., 2007; Chen et al., 2008; Costantino et al., 2008; Moya et al., 2009).

Syncope is a common problem, and has been reported to account for up to $1 \%$ of all emergency department visits and up to 3\% of hospital admissions (Morichetti \& Astorino, 1998; Blanc et al., 2002). The Framingham Study examined over 5,000 subjects over 26 years and showed that 3\% of men and 3.5\% of women had at least one syncopal episode throughout that time period (Savage et al., 1985), and another study showed that syncope has a lifetime incidence of 35\% (Ganzeboom et al., 2006). It is estimated that expenses related to syncope are approximately $\$ 2$ billion a year (Sun et al., 
2005). Syncope is related to a higher increase in fractures, injuries, depression, and decreased quality of life (Moya et al., 2009).

Syncope is not a disease itself, but often an outcome due to another underlying cause (Zaidi \& Fitzpatrick, 2000). Ganzeboom et al. (2006) reported that the lifetime incidence of syncope in the general public were caused by everyday situations that affected the maintenance of orthostatic blood pressure, such as a postural changes, people taking certain medications, and people suffering from hypovolemia (Ganzeboom et al., 2006). All of these situations can cause a decreased CO and/or TPR. If the systolic blood pressure drops below $50 \mathrm{mmHg}$, cerebral hypoperfusion will likely result in syncope (Sharpey-Schafer, 1956).

The most common kind of syncope that occurs due to orthostatic hypotension is vasovagal syncope, which is a type of neurally-mediated syncope (NMS). For being so common, the pathophysiology behind this type of syncope is still not fully understood (Ayd in et al., 2010), but it is often a result of a combination of parasympathetic activation and sympathetic withdrawal (Mosqueda-Garcia et al., 2000). Figure 1.4 depicts how orthostatic stress might cause vaso vagal syncope, a conceptual model commonly referred to as the ventricular theory (Mosqueda-Garcia et al., 2000). It was first popularized by Sharpey-Schafer as he noticed a reflex mechanism that can overcome the baroreflex (Sharpey-Schafer, 1956). The abrupt loss of MSNA is often the last physiological incident that sets off orthostatic responses (Wallin \& Sundlof, 1982; Mano \& Iwase, 2003). However, this statement has recently been challenged by Cooke et al. (2009) who has shown that in some presyncopal subjects there was no withdrawal of MSNA immediately preceding syncope despite decreases in blood pressure. More research in this area is needed.

\subsection{Alcohol}

As mentioned previously, there are many triggers for syncope. The consumption of alcohol has been shown to attenuate blood pressure responses after a lower body negative pressure protocol (Eisenhofer et al., 1984; Narkiewicz et al., 2000) and this 


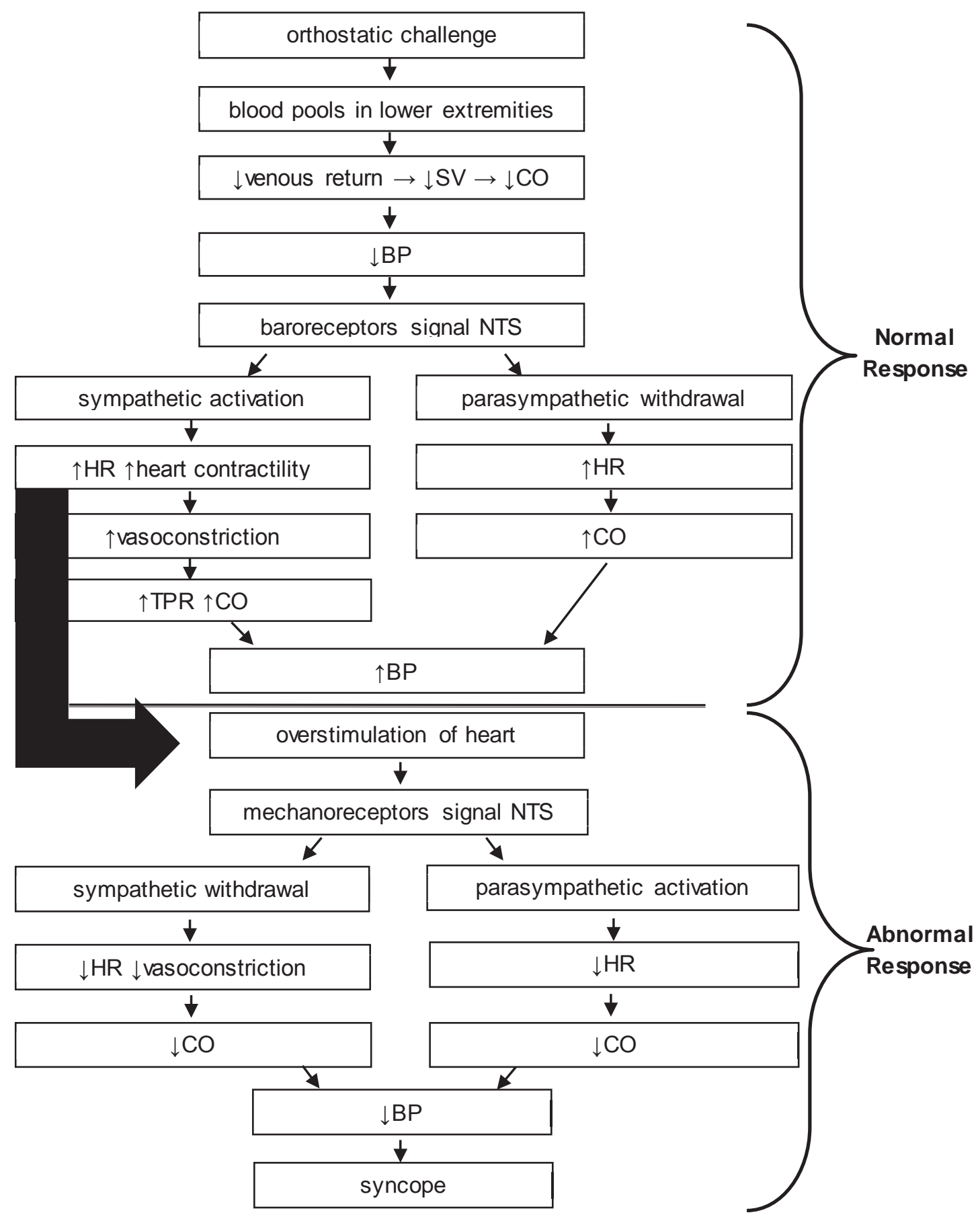

Figure 1.4 The normal response to an orthostatic challenge, such as a postural change, and the ventricular theory describing how an orthostatic challenge may contribute to syncope (abnormal response). In the abnormal response, there is a sympathetic withdrawal and a parasympathetic activation, causing a decrease in vascular tone, heart rate, and blood pressure. SV, stroke volume; CO, cardiac output; BP, blood pressure; NTS, nucleus tractus solitarii; HR, heart rate. 
could theoretically result in orthostatic hypotension and eventually syncope. Ganzeboom et al. (2006) reported that almost 3\% of the people who had a syncopal episode had ingested alcohol prior to losing consciousness.

Alcohol is generally regarded as the most abused drug in the United States (Wolf et al., 1999) and it has been noted that its overall harm is greater than heroin, cocaine, and methamphetamine (Nutt et al., 2010). It can be a huge personal, family, social, and economical burden. Each year in the United States, alcohol plays a role in over 100,000 lives lost and has an economic toll over \$184.6 billion (United States. Dept. of Health and Human Services. Office of the Secretary. \& National Institute on Alcohol Abuse and Alcoholism (U.S.), 2000). At any given point, approximately 20-40\% of patients in urban hospitals are admitted as a result of an alcohol-related incident (United States. Dept. of Health and Human Services. Office of the Secretary. \& National Institute on Alcohol Abuse and Alcoholism (U.S.), 2000). A standard drink is considered to be a 12 ounce bottle of beer, a 5 ounce glass of wine, or a 1.5 ounce shot of 80-proof spirits ((NIAAA), 2012). It is recommended that males not consume more than two drinks per day and females not consume more than one drink per day ((NIAAA), 2012). Any more than this "moderate drinking" over an extended period of time and negative side effects are most likely to occur.

Alcohol is classified as a depressant, because it decreases the excitatory actions of the neurotransmitter glutamate and increases the inhibitory actions of the neurotransmitter gamma-aminobutyric acid (GABA) (United States. Dept. of Health and Human Services. Office of the Secretary. \& National Institute on Alcohol Abuse and Alcoholism (U.S.), 2000). Once it is consumed, roughly $20-25 \%$ of it is absorbed by the stomach, and $75-80 \%$ by the small intestine (Tateoka et al., 2007). Alcohol dehydrogenase, an enzyme found in the liver, converts most of the ethanol to acetaldehyde and then aldehyde dehydrogenase converts acetaldehyde to acetate (Diamond \& Messing, 1994). If the alcohol is ingested on an empty stomach it only takes one hour for $90 \%$ of it to be absorbed and for the individual to reach his or her peak alcohol level (Wolf et al., 1999; Tateoka et al., 2007). Alcohol readily crosses the blood- 
brain barrier and intoxication can develop starting at levels 50 to $150 \mathrm{mg}$ per dl (Diamond \& Messing, 1994), which is roughly equivalent to readings by a portable breath test of $0.05 \%$ to $0.15 \%$.

\subsubsection{Long-Term Effects}

Alcohol has been suggested to play a key role in the development of certain cardiovascular diseases. In the United States, cardiovascular diseases contributes to more deaths annually than any other groups of diseases (United States. Dept. of Health and Human Services. Office of the Secretary. \& National Institute on Alcohol Abuse and Alcoholism (U.S.), 2000). The long-term effects of alcohol consumption are well documented. Moderate to heavy drinking (i.e. greater than one drink a day for women and greater than two drinks a day for men) leads to hypertension (Zilkens et al., 2005; Lichtenstein et al., 2006; Kloner \& Rezkalla, 2007; Saremi \& Arora, 2008; van de Wiel \& de Lange, 2008; Klatsky, 2009; Wakabayashi, 2009), and this is likely caused, in part, by overstimulation of the sympathetic nervous system (Johnson et al., 1986; Grassi et al., 1989; Iwase et al., 1995; Randin et al., 1995; Kloner \& Rezkalla, 2007). Moderate to heavy drinking can also lead to cancer, stroke, and cardiomyopathy among other health risks (Kloner \& Rezkalla, 2007; Saremi \& Arora, 2008; Klatsky, 2009). However, light drinking (i.e. not more than one drink a day for women and not more than 2 drinks a day for men) may lower the risk of several diseases. More specifically, cardiovascular risk associated with alcohol appears to have a J-shaped curve for mortality, coronary heart disease, blood pressure, and other cardiovascular events (Sun \& Reis, 1996; Di Castelnuovo et al., 2002; Kloner \& Rezkalla, 2007; van de Wiel \& de Lange, 2008; Klatsky, 2009). Light drinking lowers the risk for several of these cardiovascular diseases, but any more than this recommended amount and risks appear to increase. The benefits of alcohol, no matter what the type, could be due to the anticoagulant and antiinflammatory properties they contains, as well as the ability to increase HDL levels (Sun \& Reis, 1996; Di Castelnuovo et al., 2002; Kloner \& Rezkalla, 2007; van de Wiel \& de Lange, 2008; Klatsky, 2009). 


\subsubsection{Short-Term Effects}

Whereas the negative effects of the long-term consumption of alcohol are well documented, the short-term effects of moderate alcohol consumption remain controversial. Most results investigating the influence of short-term alcohol ingestion are documented after subjects reach mild intoxication levels. Results from these studies demonstrate that acute alcohol consumption generally increases MSNA (Zsoter \& Sellers, 1977; Grassi et al., 1989; Iwase et al., 1995; Randin et al., 1995; van de Borne et al., 1997; Spaak et al., 2008), along with heart rate (Giles et al., 1982; Kupari, 1983; Stott et al., 1987; Grassi et al., 1989; Iwase et al., 1995; Randin et al., 1995; van de Borne et al., 1997; Narkiewicz et al., 2000; Yoda et al., 2005; Takahashi et al., 2008).

The relationship between acute alcohol consumption and blood pressure is not as clear as the MSNA studies. Many studies showed that after ingestion, resting MAP remains unchanged (Chaudhuri et al., 1994; Tomaszewski et al., 1995; van de Borne et al., 1997; Narkiewicz et al., 2000; Tateoka et al., 2007; Spaak et al., 2008; Takahashi et al., 2008) or increases (Grassi et al., 1989; Nixon et al., 1989; Iwase et al., 1995; Randin et al., 1995)

The effect that alcohol consumption has on the vasculature is also unclear. Most studies have demonstrated that at rest, alcohol ingestion results in peripheral vasodilation (Altura et al., 1979; Kupari, 1983; Johnson et al., 1986; Malpas et al., 1990; van de Borne et al., 1997), greater increases in skin blood flow (Fewings et al., 1966; Gillespie, 1967; Iwase et al., 1995; Wolf et al., 1999; Yoda et al., 2005), and a decrease in peripheral resistance (Kupari, 1983; van de Borne et al., 1997). However, other studies report no changes in flow mediated dilation after alcohol consumption (Chaudhuri et al., 1994; Spaak et al., 2008) and no change in forearm vascular resistance (Narkiewicz et al., 2000). It may be that alcohol consumption results in variable effects depending on which vascular beds are being examined (Johnson et al., 1986).

Several studies report an increase in blood flow to the splanchnic region after alcohol consumption (Carmichael et al., 1988; Orrego et al., 1988; Chaudhuri et al., 1994; Israel et al., 1994), as well as an augmentation to gastrointestinal blood flow and a 
drop in systemic vascular resistance (Tateoka et al., 2007). The vasculature of the splanchnic region has an critical role in the maintenance of blood pressure because it has the greatest volume of blood of all the regional beds (Chaudhuri et al., 1994) (Taneja et al., 2007).

Alcohol has also been shown to alter plasma hormone levels (Johnson et al., 1986), but the results are not conclusive. Many studies have reported that acute ingestion increases plasma NE (Eisenhofer et al., 1984; Ireland et al., 1984; Randin et al., 1995) and inhibits vasopressin release (Eisenhofer \& Johnson, 1982). Alcohol may also increase plasma E (Ireland et al., 1984) and has shown to have contradictory effects on plasma cortisol (Jenkins \& Connolly, 1968; Linkola et al., 1979; Ireland et al., 1984).

\subsubsection{Acute Alcohol Consumption and an Orthostatic Challenge}

Previous studies have demonstrated that acute alcohol consumption leads to a decreased blood pressure response during a progressive lower body negative pressure protocol (Eisenhofer et al., 1984; Narkiewicz et al., 2000). Narkiewicz et al. (2000) also reported a blunted forearm vascular resistance (FVR) response in the alcohol group during progressive LBNP. These responses may be due to a lack of blood vessel constriction (Eisenhofer et al., 1984; Narkiewicz et al., 2000). However, it was not determined if the blunted vasoconstriction was due to a decreased sympathetic response during the orthostatic challenge (Narkiewicz et al., 2000), or whether the sympathetic response was still present, but the dilator effect of alcohol suppresses the vasoconstriction (van de Borne et al., 1997; Wolf et al., 1999; Narkiewicz et al., 2000).

To date, no studies have examined the influence of acute alcohol ingestion and direct neural recordings of MSNA during an orthostatic stress. It is possible that a decrease in MSNA could contribute to alcohol-mediated hypotension during an orthostatic challenge. The purpose of this study was to understand the role that MSNA may have in the regulation of the blood pressure during lower body negative pressure (LBNP) after acute alcohol consumption. We hypothesized that alcohol ingestion would blunt arterial blood pressure and MSNA responses to progressive LBNP. 


\section{Chapter 2 METHODS $^{2}$}

\subsection{Subjects}

Thirty subjects (23 males, 7 females) from the local community of Houghton, Michigan volunteered to participate in this study. There were 15 subjects in the alcohol group (12 males, 3 females: age $23 \pm 1$ yrs, height $180 \pm 3 \mathrm{~cm}$, weight $86 \pm 3 \mathrm{~kg}$, BMI 27 $\pm 1 \mathrm{~kg} / \mathrm{m}^{2}$ ) and 15 subjects in the placebo group (11 males, 4 females: age $25 \pm 1$ yrs, height $175 \pm 2 \mathrm{~cm}$, weight $76 \pm 3 \mathrm{~kg}$, BMI $25 \pm 1 \mathrm{~kg} / \mathrm{m}^{2}$ ). Subjects were randomly assigned to either the alcohol or placebo group. All participants had no personal or family history of substance abuse or cardiovascular disease. Subjects had to be at least 21 years of age. All females were tested in the early follicular phase of their menstrual cycle, since it has been shown that MSNA can vary depending on the phase of the menstrual cycle (Carter et al., 2009; Fu et al., 2009). This study was approved by the Michigan Technological University Institutional Review Board (M0472) and all subjects provided written consent prior to the study.

\subsection{Procedures}

Subjects arrived at the laboratory at 7:30 AM after undergoing an overnight fast and from abstaining from alcohol for a minimum of 72 hours and from caffeine and exercise for at least 12 hours. Upon arrival, subjects were given two granola bars (Nature Valley, General Mills Sales) to eat and water if needed in an attempt to control for the amount of food in the gastrointestinal tract during testing. Subjects filled out the subject information sheet and consent form and took a preliminary breath test. Their height and weight were then recorded. Following a five minute resting period, three blood pressures

\footnotetext{
${ }^{2}$ The material in this chapter was previously published in the American Journal of Physiology Endocrinology and Metabolism.

Carter JR, Stream SF, Durocher JJ \& Larson RA. (2011). Influence of acute alcohol ingestion on sympathetic neural responses to orthostatic stress in humans. American journal of physiology Endocrinology and metabolism 300, E771-778.
} 
were taken with an automated sphygmomanometer in the seated position with each measurement separated by a minute. After these measurements, the participants were asked to use the restroom to void their urine and to change into shorts. Subjects were then instructed to lay supine in the LBNP chamber with their lower torso inside the chamber. All participants wore a neoprene skirt that created a vacuum right below the subjects' iliac crest, which would allow venous blood to be shifted from the upper torso to the lower extremities (Mano \& Iwase, 2003; Freeman, 2006). This simulates an orthostatic stress. Subjects were then prepped to record heart rate, blood pressure, blood flow, and MSNA.

Subjects underwent five minutes of resting baseline data, followed by a progressive LNBP protocol that consisted of three minutes each at $-5,-10,-15,-20,-30$, and $-40 \mathrm{mmHg}$ (pre-treatment). Following this treatment, subjects remained supine and consumed either the alcohol or placebo through a straw, depending on what group they were randomly assigned to. Participants had 15 minutes to drink at which time their heads were supported at an incline to make it easier to ingest the liquid. Following this 15 minutes, there was a 30 minute waiting period to allow for blood alcohol levels to reach their peak. After this 45 minute period in which no measurements were recorded, subjects repeated the 5 minute baseline and the progressive LBNP protocol (posttreatment). Table 2.1 outlines the experimental timeline. Subjects were carefully monitored for presyncopal symptoms and continuously asked for feedback. If any signs did occur such as a drop in systolic blood pressure less than $80 \mathrm{mmHg}$, profuse sweating, light headedness, or nausea, the experiment was stopped immediately.

The participants were blinded to as which treatment they would be receiving. The alcohol group consumed $2.5 \mathrm{~mL} / \mathrm{kg}$ body mass of $40 \%$ vodka $(0.8 \mathrm{~g}$ ethanol $/ \mathrm{kg}$ body mass) diluted in a 1:4 mixture of Crystal Light (Kraft Foods Global, Inc.) and the placebo group ingested $12.5 \mathrm{~mL} / \mathrm{kg}$ body mass of Crystal Light. The amount of liquid was the same whether the subject drank the alcohol or placebo. Crystal light was chosen to mask 
Table 2.1

Timeline of the experimental protocol.

\begin{tabular}{|c|c|c|c|c|}
\hline Baseline & $\begin{array}{c}\text { Progressive } \\
\text { LBNP }\end{array}$ & $\begin{array}{c}\text { Treatment } \\
\text { (Alcohol } \\
\text { or } \\
\text { Placebo) }\end{array}$ & Baseline & $\begin{array}{c}\text { Progressive } \\
\text { LNBP }\end{array}$ \\
\hline $18 \mathrm{~min}$ & $\begin{array}{c}15 \mathrm{~min} \\
\text { ingestion } \\
30 \mathrm{~min} \\
\text { rest }\end{array}$ & $5 \mathrm{~min}$ & $18 \mathrm{~min}$ \\
\hline
\end{tabular}

the taste of the alcohol and at the same time be low in sugar. The rims of all the glasses were also wiped with vodka in another attempt to disguise the drink. The amount of alcohol used in this experiment would be roughly equivalent to four or five drinks for the average participant, considering that 1.5 ounces of vodka is equivalent to one standard drink (Lichtenstein et al., 2006; (NIAAA), 2012). This was consistent with what other studies had used.

\subsection{Measurements}

\subsubsection{Heart Rate}

Heart rate was measured using a three-lead electrocardiogram. Two electrodes were placed on the shoulders and one was placed on the lower left rib cage. Baseline heart rates were successfully recorded on all 30 subjects for both pre- and post-treatment. However, one placebo subject reached presyncope during the post-treatment LBNP protocol, making our heart rate measurements for the entire study (baseline plus LBNP), $n=15$ for alcohol and $n=14$ for placebo.

\subsubsection{Blood Pressure}

After an initial five minute resting period when subjects first arrived to the laboratory, three blood pressures each separated by a minute, were recorded in the seated position using an automated sphygmomanometer (Omron HEM-907XL; Omron Health Care). The automated sphygmomanometer was also used to record three supine blood pressures (each separated by a minute) immediately before the pre-treatment and post- 
treatment protocols. The average of these three blood pressures was used to determine baseline values. Beat-to-beat blood pressure was also recorded throughout the entire experiment using the Finometer (Finapres Medical Systems, Amsterdam, The Netherlands). The Finometer is a noninvasive blood pressure acquisition. It was used to precisely record the relative changes in the blood pressure and the readings from the automated sphygmomanometer were used for absolute baseline measurements. Blood pressures were recorded as systolic, diastolic, and mean arterial pressures. Mean arterial pressures were calculated as DAP plus one-third of the pulse pressure (SAP minus DAP). All blood pressures were taken on the right limbs of the subjects. Baseline measurements were obtained on all 30 subjects for both pre-and post-treatment. For the entire study (baseline plus LBNP), $n=15$ for alcohol and $n=14$ for placebo (due to the presyncopal participant).

\subsubsection{Muscle Sympathetic Nerve Activity}

Microneurography is a technique that allows direct measurement of autonomic function, more specifically, the sympathetic nerve activity to the vasculature of muscle beds (Freeman, 2006). Microneurography was performed on the right leg of each subject. Multifiber recordings of MSNA were obtained by inserting a sterilized tungsten microelectrode into the superficial peroneal nerve located in the popliteal region behind the knee. A reference electrode was placed roughly two centimeters from this recording electrode. The nerve signal was amplified (80,000 gain), band-pass filtered (700-2,000 $\mathrm{Hz}$ ), and integrated at a time constant of 0.1 seconds to obtain a mean voltage display of nerve activity. This signal has a latency period of approximately 1.3 seconds after an Rwave occurs. MSNA recordings were considered satisfactory when spontaneous pulse synchronous bursts did not change during auditory stimulation or stroking of the skin and increased during end-expiratory apnea.

MSNA can be quantified by: 1) burst frequency, often recorded as bursts per minute 2) burst per $100 \mathrm{HB}$, since MSNA is linked to the cardiac cycle, and 3) total MSNA, which is a combination of burst frequency and the area under each burst. Microneurography is fast acting and measurements can be taken instantaneously. It is 
safe, can be recorded for an extended period of time, burst pattern and activity is similar among different nerve sites, and it is highly reproducible from day to day (Freeman, 2006). 18 individuals (9 placebo and 9 alcohol) had successful MSNA recordings that were obtained throughout the entire experiment (baseline plus LBNP). 25 subjects (13 alcohol and 12 placebo) had successful MSNA recordings for the baselines of both pretreatment and post-treatment.

\subsubsection{Alcohol Content}

The subject's alcohol level was measured using a portable breath analyzer (AlcoSensor III, Intoximeters) borrowed from Michigan Tech Public Safety. The portable breath analyzer uses the breath alcohol content to estimate the blood alcohol content. The laboratory was given demonstrations and adequate instruction on how to properly use the portable breath analyzer. Upon arrival to the laboratory, the subjects were given a breath test to ensure that they did not have any alcohol already in their system. The subjects were also given a breath test immediately before starting the post-treatment and also at the end of the post-treatment protocol. Blood alcohol readings were obtained for all 30 participants. Following completion of the study, alcohol subjects were given snacks and water and were continuously monitored. When their blood alcohol content measured less than $0.075 \%$ they were allowed to exit the laboratory. All participants had to have their transportation arranged ahead of time and the subjects in the alcohol group were required to sign a voluntary waiver in which they agreed to abstain from operating a motor vehicle for 24 hours upon completion of the study.

\subsubsection{Blood Flows}

Forearm blood flow (FBF) was measured using venous occlusion plethysmography (EC6; D.E. Hokanson, Bellevue, WA) during the baseline and LBNP stages of both protocols. Mercury-in-silastic strain gauges were placed around the maximal circumference of the subject's left forearm. Cuffs were placed on the left wrist and also on the upper left arm of the subject. The wrist cuff was inflated to $220 \mathrm{mmHg}$ to arrest circulation to the hand. The upper arm cuff was continuously inflated (8 seconds) to $60 \mathrm{mmHg}$ and deflated (7 seconds) for a 15 second cycle. When inflated, the upper 
cuff occluded venous blood flow but still allowed arterial blood flow. FBF was measured in milliliters per 100 milliliters per minute and used to calculate vascular resistance and vascular conductance. Forearm vascular resistance (FVR) was calculated as MAP divided by FBF, whereas forearm vascular conductance (FVC) was the reciprocal of this. Baseline measurements were obtained on 15 alcohol subjects and 14 placebo subjects. Blood flows were successfully measured on all 15 of the alcohol subjects for the duration of the experiment, and due to the presyncopal subject, measurements were obtained on 13 placebo participants.

\subsection{Data Analysis}

Data were imported and analyzed in the WinCPRS software program (Absolute Aliens, Turku, Finland). R-waves were identified from the electrocardiogram and marked in the time series. MSNA bursts were automatically detected on the basis of amplitude using a signal-to-noise ratio of $3: 1$ within a 0.5 second search window centered on a 1.3 second expected burst peak latency from the previous R-wave. Potential bursts were displayed and edited by one trained investigator that was blinded to the intervention. The average burst area occurring during baseline was normalized to a mean value of 100 . MSNA was expressed as bursts per minute, bursts per 100 heart beats, and total MSNA (i.e. the sum of normalized burst areas per minute).

\subsection{Statistical Analysis}

All collected data were analyzed using commercial software (SPSS 15.0, SPSS, Chicago, IL). Subject characteristics for alcohol and placebo groups were compared using independent t-tests. Repeated measures ANOVA with time (progressive LBNP stages) and treatment (pre- vs. post-treatment) as the within factor variables and drug (alcohol vs. placebo) as the between-factor variable to analyze values at rest (drug $\times$ treatment interaction) and throughout the LBNP protocol (drug $\times$ time $\times$ treatment interaction). When significant drug $\times$ time $\times$ treatment interactions were observed, each group was analyzed separately as time $\times$ treatment, and a priori post hoc analyses of treatment were performed when a time $\times$ treatment interaction was significant. One-tailed 
analyses were performed on blood pressure, MSNA, and blood flow responses based on our directional hypotheses, which were guided by prior literature. Means were considered significantly different when $\mathrm{P} \leq 0.05$. Results are expressed as means $\pm \mathrm{SE}$. 


\section{Chapter 3 RESULTS $^{3}$}

\subsection{Baseline Responses}

Pre- and post-treatment baseline values for alcohol and placebo are shown in Table 3.1. SAP, DAP, and MAP all increased significantly from pre-treatment to posttreatment in both alcohol and placebo (treatment, $\mathrm{P}<0.05$; drug $\times$ treatment, $\mathrm{P}>0.05$ ). $\mathrm{HR}, \mathrm{MSNA}$ bursts/min, and BAC were elevated in alcohol post-treatment (treatment, $\mathrm{P}<$ 0.05), but not placebo. HR, MSNA bursts/min, and BAC were also significantly different in the alcohol group than compared with the placebo group (drug $\times$ treatment, $\mathrm{P} \leq 0.05$ ). Blood flows remained the same in both treatments and there was no difference between alcohol and placebo.

\footnotetext{
${ }^{3}$ The material in this chapterwas previously published in the American Journal of PhysiologyEndocrinology and Metabolism.

Carter JR, Stream SF, Durocher JJ \& Larson RA. (2011). Influence of acute alcohol ingestion on sympathetic neural responses to orthostatic stress in humans. American journal of physiology Endocrinology and metabolism 300, E771-778.
} 
Table 3.1

Pre- and post-treatment baseline values for alcohol and placebo groups.

\begin{tabular}{lcccc}
\hline & \multicolumn{2}{c}{ Alcohol } & \multicolumn{2}{c}{ Placebo } \\
\cline { 2 - 5 } Variable & Pre-treatment & Post-treatment & Pre-treatment & Post-treatment \\
\hline SAP, mmHg & $120 \pm 3$ & $124 \pm 4^{*}$ & $117 \pm 2$ & $123 \pm 2^{*}$ \\
DAP, mmHg & $64 \pm 2$ & $69 \pm 2^{*}$ & $64 \pm 2$ & $71 \pm 2^{*}$ \\
MAP, mmHg & $83 \pm 2$ & $87 \pm 2^{*}$ & $82 \pm 2$ & $88 \pm 1^{*}$ \\
HR, beats/min & $59 \pm 2$ & $65 \pm 2^{*} \dagger$ & $59 \pm 3$ & $58 \pm 3$ \\
MSNA, burst/min & $13 \pm 3$ & $19 \pm 4^{*} \dagger$ & $15 \pm 2$ & $15 \pm 2$ \\
MSNA, bursts/100 HB & $23 \pm 5$ & $30 \pm 5$ & $25 \pm 3$ & $26 \pm 3$ \\
Total MSNA (a.u.) & $6330 \pm 1312$ & $8535 \pm 1479$ & $6630 \pm 750$ & $6958 \pm 806$ \\
FBF, unit & $2.1 \pm 0.2$ & $2.1 \pm 0.2$ & $2.1 \pm 0.3$ & $2.0 \pm 0.2$ \\
FVR, mmHg/unit & $45 \pm 4$ & $47 \pm 3$ & $46 \pm 5$ & $49 \pm 4$ \\
FVC*100, unit/mmHg & $2.5 \pm 0.2$ & $2.4 \pm 0.2$ & $2.5 \pm 0.3$ & $2.3 \pm 0.2$ \\
BAC, \% & $0.00 \pm 0.00$ & $0.08 \pm 0.01^{*} \dagger$ & $0.00 \pm 0.00$ & $0.00 \pm 0.00$ \\
\hline Valus ar means
\end{tabular}

Values are means \pm SE $(n=15$ for alcohol and $n=15$ for placebo unless otherwise noted). SAP, systolic arterial pressure; DAP, diastolic arterial pressure; MAP, mean arterial pressure; HR, heart rate; MSNA muscle sympathetic nerve activity ( $n=13$ for alcohol and $n=12$ for placebo); HB, heart beats; a.u., arbitrary units; FBF, forearm blood flow; unit $=\mathrm{ml} / 100 \mathrm{ml} / \mathrm{min} ; \mathrm{FVR}$, forearm vascular resistance; FVC forearm vascular conductance ( $n=15$ for alcohol and $n=14$ for placebo, all forearm variables); BAC, blood alcohol content. $* \mathrm{P}<0.05$ pre- vs. post-treatment baseline data in respective groups. $\uparrow \mathrm{P} \leq 0.05$ for alcohol vs. placebo groups. (Carter et al., 2011).

\subsection{Progressive LBNP Responses}

\subsubsection{Hemodynamic Responses}

Figure 3.1 and 3.2 demonstrate the responses showed by SAP, DAP, MAP (Figure 3.1) and HR (Figure 3.2) during progressive LBNP. Arterial pressures were significantly attenuated after alcohol but not placebo (drug $\times$ time $\times$ treatment, $\mathrm{P}<0.05$ ). $\mathrm{HR}$ responses increased during progressive LBNP, but there was no difference between pre- and post-treatment. 

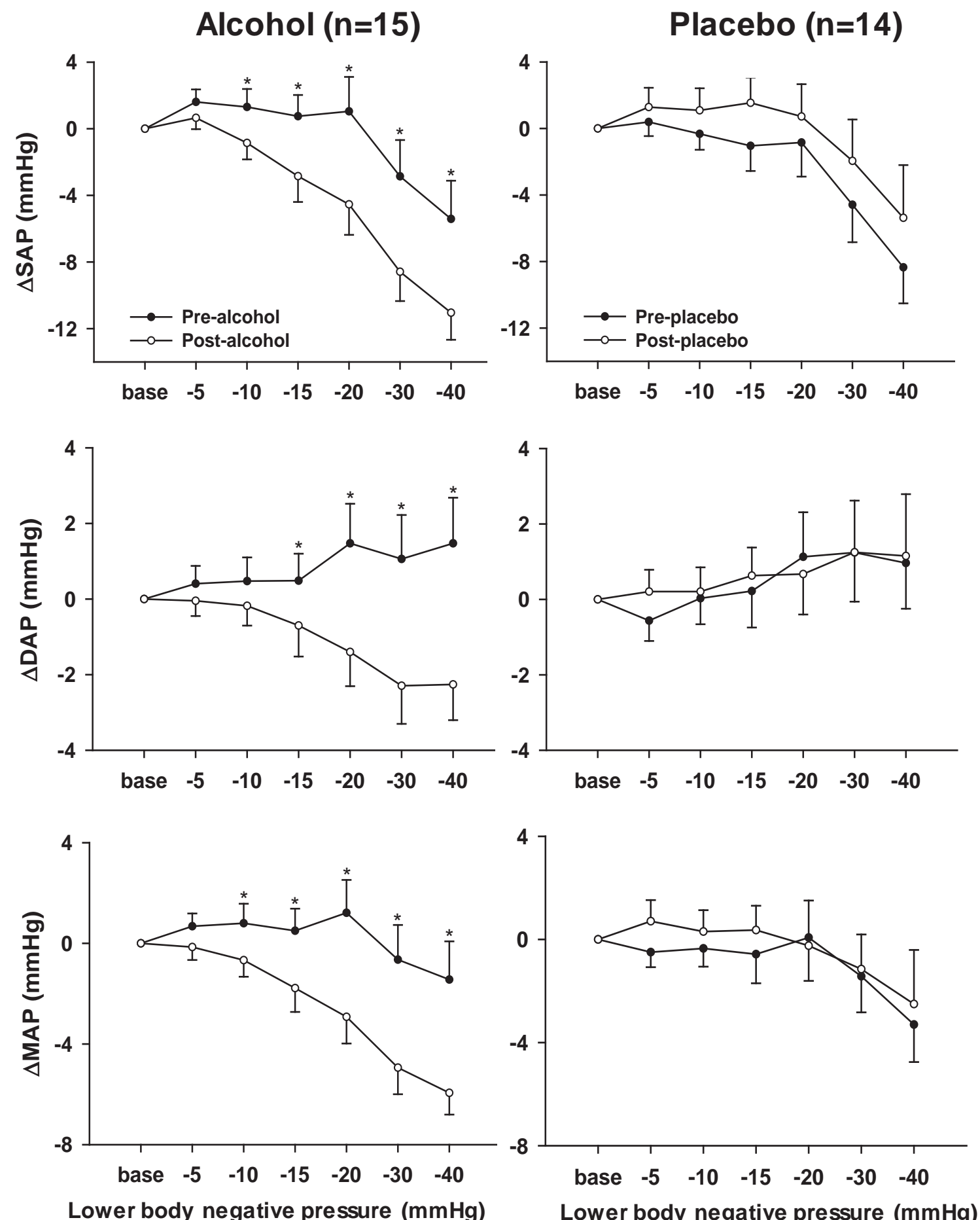

Figure 3.1 Changes $(\Delta)$ in SAP, DAP, and MAP during progressive LBNP. $n=15$ for alcohol and $n=14$ for placebo. Alcohol blunted arterial blood pressure responses. $* \mathrm{P}<$ 0.05 vs. correspond ing post-alcohol value. SAP, systolic arterial pressure; DAP, diastolic arterial pressure; MAP, mean arterial pressure. (Carter et al., 2011). 
Alcohol $(n=15)$

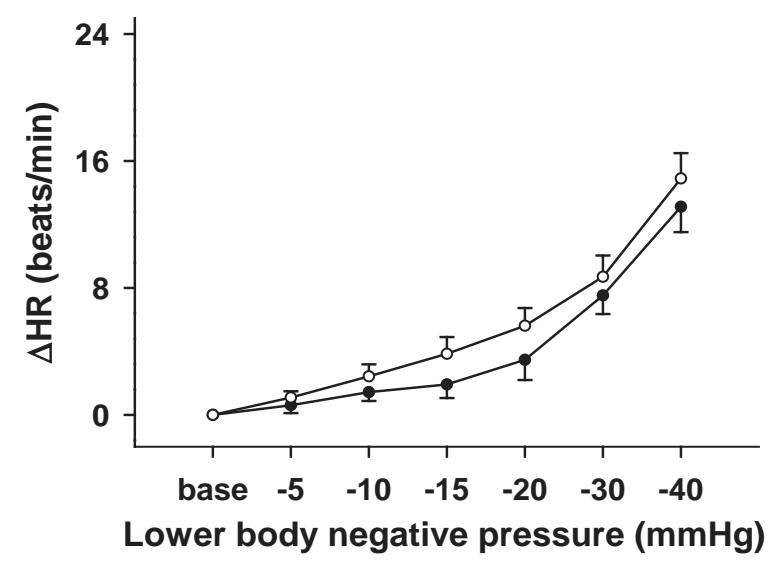

Placebo $(n=14)$

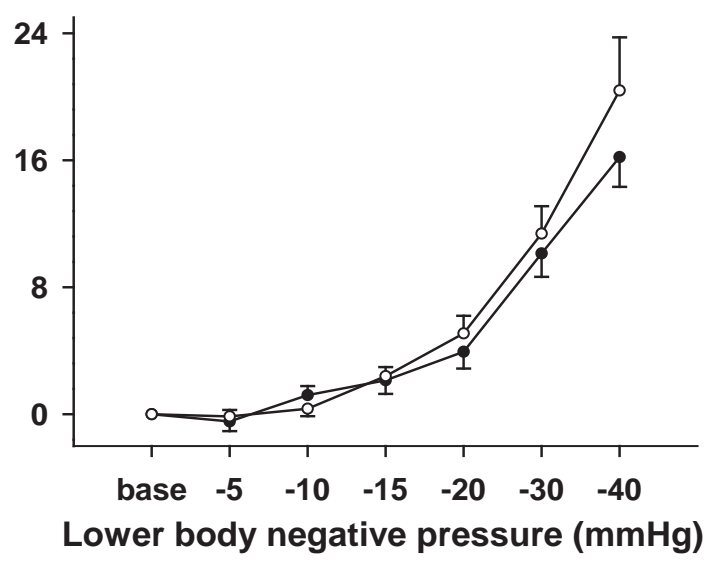

Figure 3.2 Changes $(\Delta)$ in HR during progressive LBNP. $n=15$ for alcohol and $n=14$ for placebo. Progressive LBNP elicited similar increases in HR during both treatments (prevs. post-treatment) and groups (alcohol vs. placebo). Drug $\times$ time $\times$ treatment interactions were $\mathrm{P}>0.05$ for $\mathrm{HR}$, whereas the time effect was $\mathrm{P}<0.001$ for each treatment in both groups. HR, heart rate. (Carter et al., 2011).

\subsubsection{Sympathetic Responses}

Figure 3.3 portrays similar findings to the HR response. MSNA responses all increased during progressive LBNP for both alcohol and placebo, but there was no difference between pre- and post-treatments. 

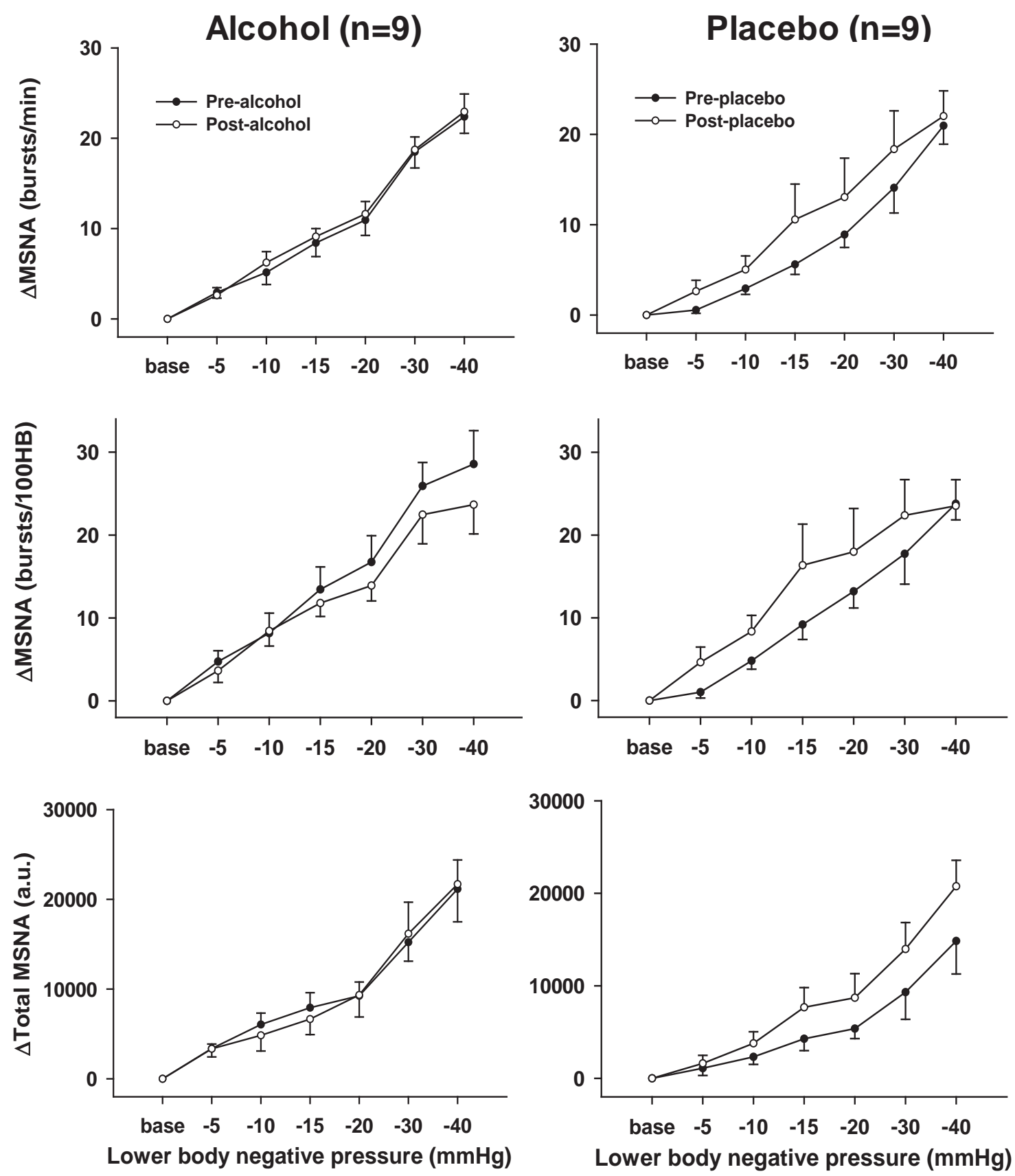

Figure 3.3 Changes $(\Delta)$ in MSNA qualified as bursts/min, bursts/100 HB, and total MSNA during progressive LBNP. Progressive LBNP elicited similar increases in MSNA during both treatments (pre- vs. post-treatment) and groups (alcohol vs. placebo). Drug $\times$ time $\times$ interactions were $\mathrm{P}>0.05$ for all MSNA variables, whereas the time effect was $\mathrm{P}$ $<0.001$ for each treatment in both groups. MSNA, muscle sympathetic nerve activity; $\mathrm{HB}$, heartbeat; a.u., arbitrary units. (Carter et al., 2011). 


\subsubsection{Vasculature Responses}

Lastly, Figure 3.4 demonstrates the responses showed by FBF, FVR, and FVC to progressive LBNP. Increases in FVR were significantly blunted (drug $\times$ time $\times$ treatment, $\mathrm{P}<0.05$ ) during progressive LBNP following the consumption of alcohol, whereas FVR responses were not altered by placebo. Changes in FBF and FVC were not different between pre- and post-treatment in the alcohol or placebo groups during progressive LBNP. 

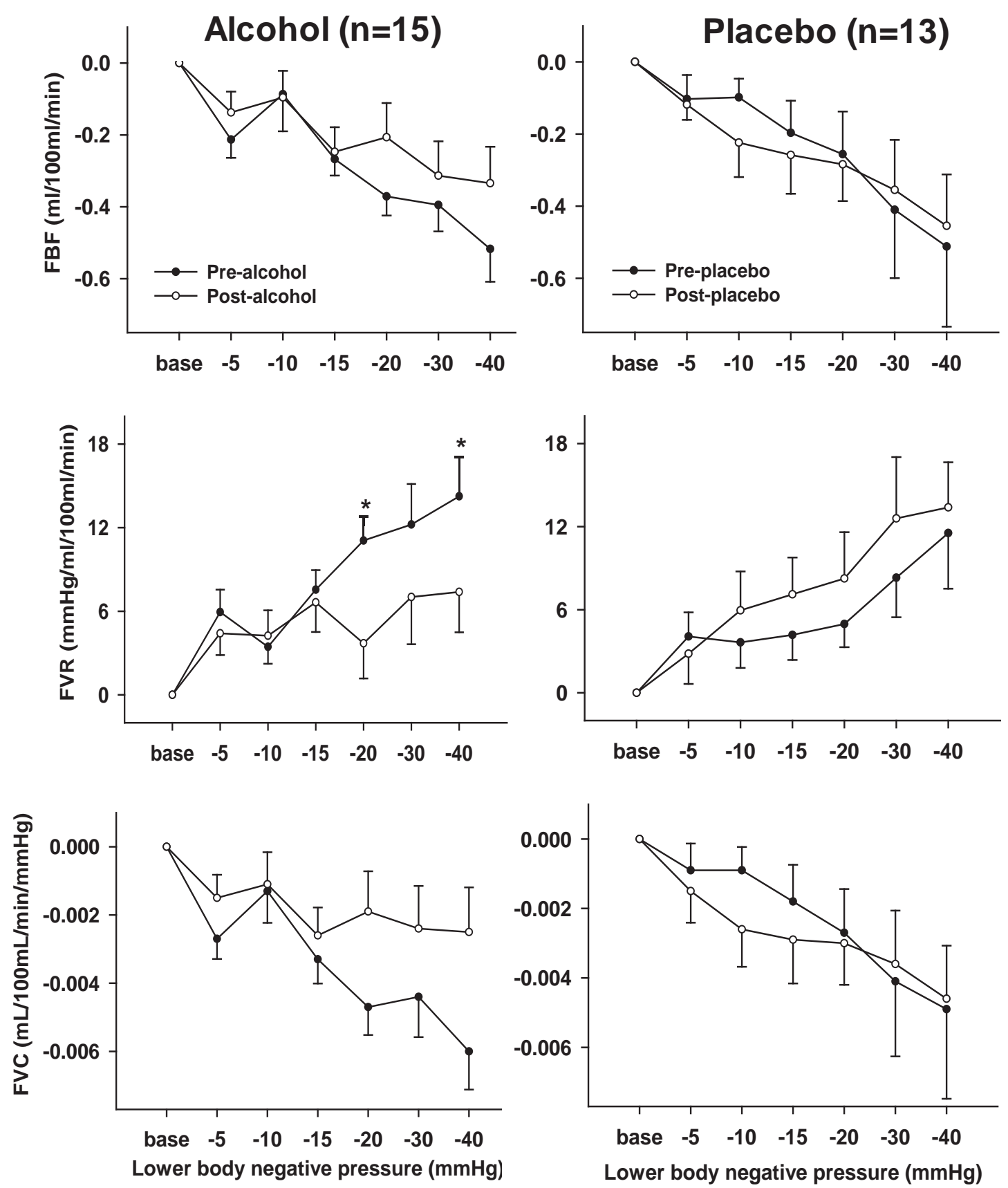

Figure 3.4 Changes $(\Delta) \mathrm{FBF}$, forearm vascular resistance (FVR), and forearm vascular conductance $(\mathrm{FVC})$ during progressive LBNP. Increases in FVR were significantly blunted by alcohol (group $\times$ time $\times$ treatment, $\mathrm{P}<0.05$ ). Drug $\times$ time $\times$ treatment interactions were $\mathrm{P}>0.05$ for both $\mathrm{FBF}$ and $\mathrm{FVC}$, whereas the time effect was $\mathrm{P}<0.01$ for each treatment in both groups. $* \mathrm{P}<0.05$ vs. corresponding post-alcohol value. $\mathrm{FBF}$, forearm blood flow; FVR, forearm vascular resistance; FVC, forearm vascular conductance. (Carter et al., 2011). 


\section{Chapter 4 DISCUSSION}

We investigated sympathetic neural and cardiovascular responses to lower body negative pressure both before and after ingestion of alcohol or placebo. There are three primary findings. First, alcohol consumption increased resting HR and MSNA burst frequency. Second, alcohol blunted the arterial blood pressure responses during progressive LBNP, yet there was no difference in MSNA responses pre-and posttreatment. Third, alcohol compromises increases in FVR during progressive LBNP, but has no effect on FVC.

Previous studies have shown that acute alcohol consumption raises resting HR (Zsoter \& Sellers, 1977; Giles et al., 1982; Kupari, 1983; Stott et al., 1987; Grassi et al., 1989; Iwase et al., 1995; Randin et al., 1995; van de Borne et al., 1997; Narkiewicz et al., 2000; Yoda et al., 2005; Takahashi et al., 2008), resting MAP (Grassi et al., 1989; Iwase et al., 1995; Randin et al., 1995), and MSNA (Grassi et al., 1989; Iwase et al., 1995; Randin et al., 1995; van de Borne et al., 1997; Spaak et al., 2008). This study also demonstrated increases in resting HR and MSNA bursts/min after alcohol, but not placebo consumption. In contrast, both placebo and alcohol demonstrated increases in resting blood pressure after drink ingestion.

Stott et al. (1987) also reported increases in arterial blood pressure in both placebo and alcohol groups after acute ingestion. It would be easy to assume that the increase in arterial pressure is due to an increase in plasma volume, which would increase $\mathrm{CO}$ and thus, MAP. This may or may not be the case in both the present study and others (Stott et al., 1987). Jordan (2000) demonstrated that if a 175 pound $(79 \mathrm{~kg})$ person consumed 500 $\mathrm{mL}$ of water, the total plasma volume would only change by one percent. Almost all of the water would be dispersed into the intra- and extracellular space and would only increase plasma volume by a total of $35 \mathrm{ml}$ (Jordan, 2002). However, our subjects, on average, consumed $1,000 \mathrm{~mL}$ of water. Most studies that look at water drinking and blood pressure responses examined a maximum of $500 \mathrm{~mL}$ consumption (Jordan et al., 2000; Endo et al., 2002; Jordan, 2002; Claydon et al., 2006; Callegaro et al., 2007). 
Jordan et al. (2000) found that in patients with severe autonomic failure, drinking $480 \mathrm{~mL}$ of tap water vs. $240 \mathrm{~mL}$ caused a much greater increase in SAP. The effects of water consumption may be dose dependent, and the effect of more than $500 \mathrm{~mL}$ of water ingestion should be examined further.

Arterial blood pressure reactivity to acute water ingestion appears to be quite variable. Jordan et al. (2000) found that $480 \mathrm{~mL}$ of tap water caused a significant increase in SAP in patients with severe autonomic failure or in the older control group, but not the younger control group. HR did not increase in the younger control group either. Callegaro et al. (2007) displayed that in normotensive subjects who ingested $500 \mathrm{~mL}$ of water, SAP, DAP, and MSNA all increased significantly compared with baseline measurements. Claydon et el. (2006) showed that in patients who consumed $500 \mathrm{~mL}$ of water, MAP significantly increased, but HR remained the same. Endo et al. (2002) found that after $500 \mathrm{~mL}$ of water ingestion significantly increased MAP and HR, and significantly decreased MSNA. It is evident that the research is inconclusive. However, collectively it appears as if drinking a large amount of water in a short amount of time can elicit acute increases in arterial blood pressure. However, how this influences HR or MSNA remains debatable. Many of these studies suggest that the increase in blood pressure may be due to enhanced sympathetic activation (Jordan et al., 2000; Jordan, 2002; Claydon et al., 2006; Callegaro et al., 2007), and this may be stimulated by the osmolality of the liquid being ingested (Brown et al., 2005; Claydon et al., 2006; May \& Jordan, 2011).

Another potential explanation for the increases in arterial blood pressure in both the alcohol and placebo groups could be distension in the lower torso. Many of our subjects stated that they wish they could have voided their urine before the post-treatment protocol began; however this was not an option with the microneurography technique. Hvarness et al. (1999) demonstrated that a "full bladder" and the urge to urinate increased mean blood pressure in 12 healthy females. Fagius et al. (1989) not only demonstrated an increase of blood pressure with bladder distension, but also an increase in MSNA as well. Since alcohol inhibits vasopressin release (Eisenhofer \& Johnson, 1982), it might be 
reasonable to assume that the alcohol group would have a greater gastric distention due to a greater urinary volume. However, Jones (1990) observed that the greatest urinary output after alcohol consumption occurs one to two hours after ingestion, which would have occurred following the completion of the experiment. Although we did not measure gastric or bladder distension in this study, it is reasonable to assume similar distention in both groups (i.e., alcohol vs. placebo) because the total amount of liquid consumption was similar. We believe the physiological data and comparisons are valid given this placebo-based time control approach.

The increase in resting HR in the alcohol group appears to be due to increase in sympathetic activity and does not seem to be caused by withdrawal of the parasympathetic nervous system. Specifically, Eisenhofer et al. (1985) treated a group of subjects with atropine (a parasympathetic blockade) after ingestion of ethanol or placebo. At rest, HR was increased in the alcohol group when compared with placebo. After atropine, both alcohol and placebo elicited similar increases in HR and there was no difference between the two groups. Since the ethanol group did not demonstrate a greater increase in HR after atropine infusion, the increase in HR after ethanol ingestion is unlikely to be vagally mediated (Eisenhofer et al., 1985).

Alcohol appears to elicit a paradoxical vasoconstriction and vasodilation. Specifically, acute alcohol consumption increases sympathetic activity to both the heart and blood vessels, but this sympathoexcitation appears to be opposed by peripheral vasodilation (van de Borne et al., 1997; Wolf et al., 1999). Our subjects demonstrated no change in resting FVR, despite the increase in MSNA. It may be that alcohol consumption results in variable effects depending on where the vascular beds are located throughout the body (Johnson et al., 1986). However, others report that alcohol elicits peripheral vasodilation at rest (Altura et al., 1979; Kupari, 1983; Johnson et al., 1986; Malpas et al., 1990; van de Borne et al., 1997). Although MSNA is increasing, it is possible that the vasoconstriction is being attenuated by the direct vasodilator effect of alcohol on the peripheral blood vessels, and that is why there is no change in resting FVR. 
How exactly alcohol causes peripheral vasodilation remains uncertain, but there are many studies that have looked at alcohol's effect on the peripheral vasculature. It has been reported that alcohol might depress $\alpha$-adrenoceptor-mediated vasoconstriction by reducing the sensitivity of the $\alpha$-adrenoceptors (Takeda \& Momose, 1983; Eisenhofer et al., 1984). Norepinephrine is an $\alpha$-agonist, and is important for increasing vasoconstriction in peripheral blood vessels. Eisenhofer et al. (1984) studied subjects after they were given NE infusions alone or NE plus ethanol. The group who received NE plus ethanol had an increase in DAP, but this response was blunted compared to the group who had only received NE infusions. The ethanol plus NE group demonstrated higher levels of plasma NE. This indicates that ethanol increases plasma NE, perhaps through sympathetic activation. More importantly, this study displays that although blood pressure increases, its response is blunted and this may be due to the direct actions of alcohol on the periphery. Different subjects in this same study were also given methoxamine (which is an $\alpha_{1}$ agonist) or methoxamine plus ethanol. DAP and SAP increases were significantly attenuated in the methoxamine plus ethanol group. Since methoxamine is an $\alpha_{1}$ agonist, these results reveal that alcohol has an inhibitory effect on $\alpha$-adrenoceptor mediated vasoconstriction (Eisenhofer et al., 1984). Similarly, Takeda et al. (1983) looked at the effects of ethanol in the guinea-pig. They noticed that contractile responses to stimulation of adrenergic nerves were reduced as well as the contractile responses to NE infusion (Takeda \& Momose, 1983).

Other studies also support the idea of peripheral vasodilation due to alcohol's effect on the blood vessels. Gillespie et al. (1967) studied six patients who had at least one sympathectomized upper limb. After oral ingestion of whiskey, these subjects had a robust increase in skin blood flow. This demonstrates that the vasodilator properties associated with alcohol consumption are not produced by central inhibition (Gillespie, 1967). Altura et al. (1979) looked at the vasculature effects of ethanol in young male rats. Ethanol inhibited the vasoconstrictor effects of NE, angiotensin, and vasopressin; ethanol also had a direct effect on the smooth muscle itself. They concluded that alcohol caused peripheral vasodilation by direct relaxation of blood vessels, and blunted the 
vasoconstrictor responses of vasoactive substances (Altura et al., 1979). Finally, Randin et al. (1995) provided subjects alcohol plus phentolamine, which is an $\alpha$-adrenergic blockade. After this infusion, blood pressure and calf vascular resistance actually decreased and HR still increased. This finding reinforces the significance of sympathetic activation in response to alcohol ingestion (Randin et al., 1995), as well as the role of $\alpha$ adrenoceptors in blood pressure regulation. In conclusion, the effects of alcohol on the vasculature seem to depend upon both sympathetic activation to the heart and blood vessels, and peripheral vasodilation (van de Borne et al., 1997; Wolf et al., 1999). The peripheral vasodilation that occurs appears to be due to an impairment of the sensitivity of $\alpha$-adrenoceptors. Nevertheless, at rest alcohol still exerts increases HR and MSNA.

The second main finding is that alcohol ingestion blunts arterial blood pressure responses to progressive lower body negative pressure, despite an increase in HR and MSNA. This is consistent with what other studies have reported (Eisenhofer et al., 1984; Narkiewicz et al., 2000). Eisenhofer et al. (1984) demonstrated a greater drop in SAP during four stages of LBNP after ethanol ingestion, despite greater increases in plasma NE. HR increased in both the alcohol and placebo group throughout LBNP, and there was no difference between groups. Due to the increase in NE and the drop in blood pressure, the authors concluded that ethanol exhibits inhibitory effects on vasoconstriction responses, specifically reduced responsiveness to $\alpha$-adrenoceptor agonists (Eisenhofer et al., 1984).

Narkiewicz et al. (2000) reported similar results after alcohol ingestion. At rest, HR increased compared to placebo, but there was no change in arterial blood pressure or FVR. However, they only used $400 \mathrm{~mL}$ of liquid compared to the roughly 1,000 that our study had used, which might explain the differences in resting arterial blood pressure findings between studies. During progressive LBNP, Narkiewicz et al. (2000) reported that MAP significantly decreased throughout the four stages in the alcohol group. FVR responses were also significantly blunted when compared to the placebo and this is similar to what we had demonstrated. Similar to Eisenhofer et al. (1984), HR increased throughout the LBNP protocol, but there was no different between alcohol or placebo. 
Narkiewicz et al. (2000) concluded that this alcohol-induced hypotension was due to an impairment of vasoconstriction. However, they did not measure MSNA or plasma catecholamines, thus they could not conclude with certainty that the vasoconstriction was attenuated due to decreased sympathetic activity (Narkiewicz et al., 2000).

Our study was the first to examine MSNA responses during graded LBNP after acute ethanol ingestion. MSNA typically increases during progressive LBNP through a baroreflex response (Sundlof \& Wallin, 1978), and peripheral vasoconstriction often depends on the degree of MSNA activation (Fu et al., 2002; Mano \& Iwase, 2003; Wallin, 2006). TPR must increase in order to maintain a stable blood pressure. Our study confirms that reductions of blood pressure during LBNP are more dramatic after alcohol, but these responses do not appear to be related to any attenuation in MSNA or HR; we demonstrate similar increases of MSNA and HR during LBNP before and after alcohol consumption. However, the greater decreases in blood pressure after alcohol were associated with greater reductions in FVR. As mentioned previously, alcohol seems to elicit sympathetic activation that is directly opposed by the dilator effects of alcohol. The similar increases in MSNA and HR both pre- and post-treatment in both alcohol and placebo groups demonstrate that the sympathetic reactivity to LBNP after alcohol is intact. This is also supported by the enhanced increase in NE in the alcohol group during LBNP in the study done by Eisenhofer et al. (1984). However, the blunted FVR response that we and Narkiewicz et al. (2000) report exists despite preserved increases in MSNA, a finding we attribute to the impairment on $\alpha$-adrenoceptors discussed previously (Takeda \& Momose, 1983; Eisenhofer et al., 1984). We suggest that a decrease in $\alpha$-adrenergic receptor sensitivity attenuates vasoconstrictor effect of increased sympathetic activity (Wallin, 2006), and that this resulted in the more dramatic reductions in arterial blood pressure during LBNP after ethanol ingestion.

While blunted $\alpha$-adrenergic receptor sensitivity remains a viable explanation for our findings, another interpretation could be that alcohol alters sympathetic baroreflex function. MSNA is mediated by the arterial baroreflex. Since there was a greater drop in blood pressure during LBNP after alcohol consumption, it is reasonable to speculate that 
there should have been an augmentation in MSNA during graded LBNP (i.e., classic negative feedback control). Others suggest an impairment of the baroreflex function after alcohol (Zsoter \& Sellers, 1977; Abdel-Rahman et al., 1987; Narkiewicz et al., 2000). A decrease in baroreflex sensitivity could have contributed to the lack of MSNA adjustment in our subjects, despite the larger drop in blood pressure. Theoretically, this could lead to attenuated vasoconstriction during progressive LBNP, eventually leading to a greater decrease in blood pressure. However, with this being said, we found alcohol to cause an increase in resting MSNA burst frequency between pre- and post-treatment and this is consistent with the literature. Therefore, we do not believe alcohol would cause an augmentation in sympathetic outflow at rest and attenuation in sympathetic outflow during progressive LBNP. No matter the mechanism, it is evident acute alcohol ingestion can lead to hypotension upon an orthostatic challenge, which might precede syncope.

The last important finding in our study was that alcohol blunts FVR responses to LBNP after ethanol ingestion. This is similar to what Narkiewicz et al. (2000) demonstrated. However, Narkiewicz et al. (2000) did not report FVC. We did examine FVC, but found no changes at rest or during progressive LBNP between alcohol and placebo. Thus, caution should be taken when interpreting the blunted FVR results reported in the present study and others (Narkiewicz et al., 2000). Changes in conductance appear to be a better indicator of regional vascular responses in maintaining blood pressure than changes in resistance (O'Leary, 1991). More specifically, when CO is not in a steady state (i.e. progressive LBNP), changes in resistance may not be as reliable as changes in conductance (O'Leary, 1991).

\subsection{Summary}

In summary, acute alcohol ingestion increased resting HR and MSNA burst frequency. During progressive LBNP, alcohol elicits more of a dramatic decrease in arterial blood pressure, despite similar increases in MSNA both pre- and post-alcohol. This can be interpreted two ways: 1) Alcohol reduces the sensitivity of $\alpha$-adrenoceptors, causing a peripheral vasodilation despite the increase in MSNA. During progressive LBNP, when TPR must increase to maintain a stable blood pressure, the vasodilator 
effects of alcohol attenuates the sympathetic-mediated vasoconstriction, which eventually results in a significant drop in arterial blood pressure. 2) Since arterial blood pressure and MSNA are inversely related, the more dramatic drop in arterial pressure in the alcohol group during LBNP should have been accompanied by an increase in MSNA. Thus, it remains plausible that alcohol decreases baroreflex sensitivity. Finally, although FVR responses were blunted during LBNP after alcohol ingestion, these responses should be interpreted with caution because FVC is more of a reliable measurement when $\mathrm{CO}$ is not in a steady state.

\subsection{Clinical Relevance}

This study is important in advancing our mechanistic understanding of how acute alcohol ingestion can lead to orthostatic hypotension, and eventually syncope. After consuming even one or two drinks, one should be cautious when moving from a supine or seated position to standing and postural changes should be done in a slow, careful manner. This is particularly significant if one has a history of neurally-mediated syncope, or is currently taking any medications that may cause low blood pressure, or is suffering from hypovolemia. Alcohol ingestion can potentially exacerbate any pre-existing conditions that may lead to $\mathrm{OH}$.

\subsection{Limitations and Future Work}

Limitations of this study include the fact that our subjects had to consume a very large amount of liquid in a short amount of time. Many of them complained about having the urge to urinate before the post-treatment protocol even started. If the subjects did undergo gastric/bladder distension, we did not have the equipment available to monitor. However, the experimental approach (i.e., double-blinded, placebo-based) still allows for appropriate comparisons to test the stated hypotheses. Another limitation is that we did

not measure any hormone levels throughout the experimental protocol. Measurements of $\mathrm{NE}$ and $\mathrm{E}$ would have given us valuable insight in to understanding what might have been happening at the peripheral level. Also, we did not attempt to elicit presyncope for the safety of our subjects. Therefore, we don't know what would have happened to 
MSNA responses had the LBNP protocol been extended, but we can assume that responses would have followed the trend that we had observed.

Future investigations of acute alcohol ingestion and orthostatic stress might include ethanol infusions instead of oral ingestion. This would take out the possibility of gastric/bladder distension and also be more time efficient. However, this eliminates the role of gastric absorption, which may be important. Additionally, future work might also examine the responses of alcohol or placebo in combination with infusion of an $\alpha$-agonist prior to progressive LBNP. If alcohol does decrease $\alpha$-adrenoceptor sensitivity, then looking at the responses of $\alpha$-agonists versus $\alpha$-agonists plus ethanol would provide a better understanding of what occurs at the periphery. Lastly, having our subjects fill out a questionnaire about their alcohol consumption, similar to the one used by the National Institute on Alcohol Abuse and Alcoholism (Alcoholism, 2003), would provide a quantification of the drinking patterns of our subjects. We could then use their alcohol habits to see if there is a correlation with how they respond to orthostatic stress after acute alcohol consumption. 


\section{References}

(NIAAA) NIoAAaA. (2012). FAQs for the General Public Bethesda, MD. http://www.niaaa.nih.gov/publications/brochures-and-fact-sheets

Abdel-Rahman AR, Merrill RH \& Wooles WR. (1987). Effect of acute ethanol administration on the baroreceptor reflex control of heart rate in normotensive human volunteers. Clinical science 72, 113-122.

Alcoholism NIoAAa. (2003). Recommended Alcohol Questions. Bethesda, MD. http://www.niaaa.nih.gov/research/guidelines-and-resources/recommended-alcoholquestions

Altura BM, Ogunkoya A, Gebrewold A \& Altura BT. (1979). Effects of ethanol on terminal arterioles and muscular venules: direct observations on the microcirculation. $J$ Cardiovasc Pharmacol 1, 97-113.

Aydin MA, Salukhe TV, Wilke I \& Willems S. (2010). Management and therapy of vasovagal syncope: A review. World J Cardiol 2, 308-315.

Blanc JJ, L'Her C, Touiza A, Garo B, L'Her E \& Mansourati J. (2002). Prospective evaluation and outcome of patients admitted for syncope over a 1 year period. European heart journal 23, 815-820.

Bradley JG \& Davis KA. (2003). Orthostatic hypotension. Am Fam Physician 68, 2393-2398.

Brown CM, Barberini L, Dulloo AG \& Montani JP. (2005). Cardiovascular responses to water drinking: does osmolality play a role? American journal of physiology Regulatory, integrative and comparative physiology 289, R1687-1692.

Burke D, Sundlof G \& Wallin G. (1977). Postural effects on muscle nerve sympathetic activity in man. J Physiol 272, 399-414.

Bylund DB. (2007). Alpha- and beta-adrenergic receptors: Ahlquist's landmark hypothesis of a single mediator with two receptors. American journal of physiology Endocrinology and metabolism 293, E1479-1481.

Callegaro CC, Moraes RS, Negrao CE, Trombetta IC, Rondon MU, Teixeira MS, Silva SC, Ferlin EL, Krieger EM \& Ribeiro JP. (2007). Acute water ingestion increases arterial blood pressure in hypertensive and normotensive subjects. J Hum Hypertens 21, 564-570.

Cannon WB. (1915). Bodily Changes in Pain, Hunger, Fear and Rage. D. Appleton and Company, New York and London.

Cannon WB. (1929). Organization for Physiological Homeostasis. Physiological Reviews 9, 399431.

Carmichael FJ, Saldivia V, Varghese GA, Israel Y \& Orrego H. (1988). Ethanol-induced increase in portal blood flow: role of acetate and A1- and A2-adenosine receptors. Am J Physiol 255, G417-423. 
Carter JR, Lawrence JE \& Klein JC. (2009). Menstrual cycle alters sympathetic neural responses to orthostatic stress in young, eumenorrheic women. Am J Physiol Endocrinol Metab 297, E85-91.

Carter JR, Stream SF, Durocher JJ \& Larson RA. (2011). Influence of acute alcohol ingestion on sympathetic neural responses to orthostatic stress in humans. American journal of physiology Endocrinology and metabolism 300, E771-778.

Charkoudian N \& Rabbitts JA. (2009). Sympathetic neural mechanisms in human cardiovascular health and disease. Mayo Clin Proc 84, 822-830.

Chaudhuri KR, Maule S, Thomaides T, Pavitt D \& Mathias CJ. (1994). Alcohol ingestion lowers supine blood pressure, causes splanchnic vasodilatation and worsens postural hypotension in primary autonomic failure. J Neurol 241, 145-152.

Chen LY, Benditt DG \& Shen WK. (2008). Management of syncope in adults: an update. Mayo Clin Proc 83, 1280-1293.

Claydon VE, Schroeder C, Norcliffe LJ, Jordan J \& Hainsworth R. (2006). Water drinking improves orthostatic tolerance in patients with posturally related syncope. Clinical science 110, 343-352.

Cooke WH, Rickards CA, Ryan KL, Kuusela TA \& Convertino VA. (2009). Muscle sympathetic nerve activity during intense lower body negative pressure to presyncope in humans. $J$ Physiol 587, 4987-4999.

Costantino G, Perego F, Dipaola F, Borella M, Galli A, Cantoni G, Dell'Orto S, Dassi S, Filardo N, Duca PG, Montano N \& Furlan R. (2008). Short- and long-term prognosis of syncope, risk factors, and role of hospital admission: results from the STePS (Short-Term Prognosis of Syncope) study. J Am Coll Cardiol 51, 276-283.

Di Castelnuovo A, Rotondo S, Iacoviello L, Donati MB \& De Gaetano G. (2002). Meta-analysis of wine and beer consumption in relation to vascular risk. Circulation 105, 2836-2844.

Diamond I \& Messing RO. (1994). Neurologic effects of alcoholism. West J Med 161, 279-287.

Eisenhofer G \& Johnson RH. (1982). Effect of ethanol ingestion on plasma vasopressin and water balance in humans. Am J Physiol 242, R522-527.

Eisenhofer G, Lambie DG \& Johnson RH. (1984). Effects of ethanol ingestion on alphaadrenoceptor-mediated circulatory responses in man. Br J Clin Pharmacol 18, 581-586.

Eisenhofer G, Lambie DG \& Johnson RH. (1985). No effect of ethanol ingestion on betaadrenoceptor-mediated circulatory responses to isoprenaline in man. British journal of clinical pharmacology 20,684-687.

Endo Y, Yamauchi K, Tsutsui Y, Ishihara Z, Yamazaki F, Sagawa S \& Shiraki K. (2002). Changes in blood pressure and muscle sympathetic nerve activity during water drinking in humans. Jpn J Physiol 52, 421-427. 
Fagius J \& Karhuvaara S. (1989). Sympathetic activity and blood pressure increases with bladder distension in humans. Hypertension 14,511-517.

Fewings JD, Hanna MJ, Walsh JA \& Whelan RF. (1966). The effects of ethyl alcohol on the blood vessels of the hand and forearm in man. Br J Pharmacol Chemother 27,93-106.

Fisher CM. (1979). Syncope of obscure nature. Can J Neurol Sci 6, 7-20.

Freeman R. (2006). Assessment of cardiovascular autonomic function. Clin Neurophysiol 117, 716-730.

Freeman R, Wieling W, Axelrod FB, Benditt DG, Benarroch E, Biaggioni I, Cheshire WP, Chelimsky T, Cortelli P, Gibbons CH, Goldstein DS, Hainsworth R, Hilz MJ, Jacob G, Kaufmann H, Jordan J, Lipsitz LA, Levine BD, Low PA, Mathias C, Raj SR, Robertson D, Sandroni P, Schatz I, Schondorff R, Stewart JM \& van Dijk JG. (2011). Consensus statement on the definition of orthostatic hypotension, neurally mediated syncope and the postural tachycardia syndrome. Clinical autonomic research: official journal of the Clinical Autonomic Research Society 21, 69-72.

Fu Q, Iwase S, Niimi Y, Kamiya A, Michikami D, Mano T \& Suzumura A. (2002). Age-related influences of leg vein filling and emptying on blood volume redistribution and sympathetic reflex during lower body negative pressure in humans. Jpn J Physiol 52, 7784.

Fu Q, Okazaki K, Shibata S, Shook RP, VanGunday TB, Galbreath MM, Reelick MF \& Levine BD. (2009). Menstrual cycle effects on sympathetic neural responses to upright tilt. $J$ Physiol 587, 2019-2031.

Furchgott RF. (1959). The receptors for epinephrine and norepinephrine (adrenergic receptors). Pharmacol Rev 11, 429-441; discussion 441-422.

Ganzeboom KS, Mairuhu G, Reitsma JB, Linzer M, Wieling W \& van Dijk N. (2006). Lifetime cumulative incidence of syncope in the general population: a study of 549 Dutch subjects aged 35-60 years. J Cardiovasc Electrophysiol 17, 1172-1176.

Giles TD, Cook JR, Sachitano RA \& Iteld BJ. (1982). Influence of alcohol on the cardiovascular response to isometric exercise in normal subjects. Angiology 33, 332-338.

Gillespie JA. (1967). Vasodilator properties of alcohol. Br Med J 2, 274-277.

Grassi G \& Esler M. (1999). How to assess sympathetic activity in humans. Journal of hypertension 17, 719-734.

Grassi GM, Somers VK, Renk WS, Abboud FM \& Mark AL. (1989). Effects of alcohol intake on blood pressure and sympathetic nerve activity in normotensive humans: a preliminary report. J Hypertens Suppl 7, S20-21.

Hill L. (1894). The influence of the force of gravity on the circulation of the blood. Proc R S 57, 17-53. 
Hollister AS. (1992). Orthostatic hypotension. Causes, evaluation, and management. The Western journal of medicine 157,652-657.

Hvarness H, Jakobsen H, Hermansen F, Marving J \& Meyhoff HH. (1999). Effect of a full bladder on urine production in humans. Scand J Urol Nephrol 33, 386-391.

Ichinose M, Saito M, Fujii N, Kondo N \& Nishiyasu T. (2006). Modulation of the control of muscle sympathetic nerve activity during severe orthostatic stress. J Physiol 576, 947 958.

Ireland MA, Vandongen R, Davidson L, Beilin LJ \& Rouse IL. (1984). Acute effects of moderate alcohol consumption on blood pressure and plasma catecholamines. Clin Sci (Lond) 66, 643-648.

Israel Y, Orrego H \& Carmichael FJ. (1994). Acetate-mediated effects of ethanol. Alcohol Clin Exp Res 18, 144-148.

Iwase S, Matsukawa T, Ishihara S, Tanaka A, Tanabe K, Danbara A, Matsuo M, Sugiyama Y \& Mano T. (1995). Effect of oral ethanol intake on muscle sympathetic nerve activity and cardiovascular functions in humans. J Auton Nerv Syst 54, 206-214.

Jenkins JS \& Connolly J. (1968). Adrenocortical response to ethanol in man. Br Med J 2, 804805.

Johnson RH, Eisenhofer G \& Lambie DG. (1986). The effects of acute and chronic ingestion of ethanol on the autonomic nervous system. Drug Alcohol Depend 18, 319-328.

Jones AW. (1990). Excretion of alcohol in urine and diuresis in healthy men in relation to their age, the dose administered and the time after drinking. Forensic Sci Int 45, 217-224.

Jordan J. (2002). Acute effect of water on blood pressure. What do we know? Clinical autonomic research: official journal of the Clinical Autonomic Research Society 12, 250-255.

Jordan J, Shannon JR, Black BK, Ali Y, Farley M, Costa F, Diedrich A, Robertson RM, Biaggioni I \& Robertson D. (2000). The pressor response to water drinking in humans : a sympathetic reflex? Circulation 101, 504-509.

Kirchheim HR. (1976). Systemic arterial baroreceptor reflexes. Physiological Reviews 56, 100177.

Klatsky AL. (2009). Alcohol and cardiovascular diseases. Expert Rev Cardiovasc Ther 7, 499506.

Kloner RA \& Rezkalla SH. (2007). To drink or not to drink? That is the question. Circulation 116, 1306-1317.

Kupari M. (1983). Acute cardiovascular effects of ethanol A controlled non-invasive study. $\mathrm{Br}$ Heart J 49, 174-182.

Lanier JB, Mote MB \& Clay EC. (2011). Evaluation and management of orthostatic hypotension. American family physician 84, 527-536. 
Lewis T. (1920). The soldier's heart and the effort syndrome. London.

Lichtenstein AH, Appel LJ, Brands M, Carnethon M, Daniels S, Franch HA, Franklin B, KrisEtherton P, Harris WS, Howard B, Karanja N, Lefevre M, Rudel L, Sacks F, Van Horn L, Winston M \& Wylie-Rosett J. (2006). Diet and lifestyle recommendations revision 2006: a scientific statement from the American Heart Association Nutrition Committee. Circulation 114, 82-96.

Linkola J, Fyhrquist F \& Ylikahri R. (1979). Renin, aldosterone and cortisol during ethanol intoxication and hangover. Acta physiologica Scandinavica 106, 75-82.

Malpas SC, Robinson BJ \& Maling TJ. (1990). Mechanism of ethanol-induced vasodilation. $J$ Appl Physiol 68, 731-734.

Mano T \& Iwase S. (2003). Sympathetic nerve activity in hypotension and orthostatic intolerance. Acta Physiol Scand 177, 359-365.

Marieb EN \& Hoehn K. (2008). Anatomy \& physiology. Pearson/Benjamin Cummings, San Francisco, Calif.

May M \& Jordan J. (2011). The osmopressor response to water drinking. American journal of physiology Regulatory, integrative and comparative physiology 300, R40-46.

Medow MS, Stewart JM, Sanyal S, Mumtaz A, Sica D \& Frishman WH. (2008). Pathophysiology, diagnosis, and treatment of orthostatic hypotension and vasovagal syncope. Cardiol Rev 16, 4-20.

Morichetti A \& Astorino G. (1998). [Epidemiological and clinical findings in 697 syncope events]. Minerva Med 89,211-220.

Morlin C, Wallin BG \& Eriksson BM. (1983). Muscle sympathetic activity and plasma noradrenaline in normotensive and hypertensive man. Acta physiologica Scandinavica 119, $117-121$.

Mosqueda-Garcia R, Furlan R, Tank J \& Fernandez-Violante R. (2000). The elusive pathophysiology of neurally mediated syncope. Circulation 102, 2898-2906.

Moya A, Sutton R, Ammirati F, Blanc JJ, Brignole M, Dahm JB, Deharo JC, Gajek J, Gjesdal K, Krahn A, Massin M, Pepi M, Pezawas T, Ruiz Granell R, Sarasin F, Ungar A, van Dijk JG, Walma EP \& Wieling W. (2009). Guidelines for the diagnosis and management of syncope (version 2009). European heart journal 30, 2631-2671.

Narkiewicz K, Cooley RL \& Somers VK. (2000). Alcohol potentiates orthostatic hypotension : implications for alcohol-related syncope. Circulation 101, 398-402.

Naschitz JE \& Rosner I. (2007). Orthostatic hypotension: framework of the syndrome. Postgrad Med J 83, 568-574. 
Nixon JV, Klein K, Smucker MW \& Raven PB. (1989). Effects of acute alcohol ingestion on the left ventricular performance of normal subjects before and after incomplete autonomic blockade. Am J Med Sci 298, 161-166.

Norsk P. (1992). Gravitational stress and volume regulation. Clin Physiol 12, 505-526.

Nutt DJ, King LA \& Phillips LD. (2010). Drug harms in the UK: a multicriteria decision analysis. Lancet 376, 1558-1565.

O'Leary DS. (1991). Regional vascular resistance vs. conductance: which index for baroreflex responses? Am J Physiol 260, H632-637.

Orrego H, Carmichael FJ \& Israel Y. (1988). New insights on the mechanism of the alcoholinduced increase in portal blood flow. Can J Physiol Pharmacol 66, 1-9.

Randin D, Vollenweider P, Tappy L, Jequier E, Nicod P \& Scherrer U. (1995). Suppression of alcohol-induced hypertension by dexamethasone. N Engl J Med 332, 1733-1737.

Raven PB \& Pawelczyk JA. (1993). Chronic endurance exercise training: a condition of inadequate blood pressure regulation and reduced tolerance to LBNP. Medicine and science in sports and exercise 25, 713-721.

Rosenblueth W, \& Bigelow. (1943). Behavior, purpose and teleology. Philosophy of Science 10, 18-24.

Rowell LB. (1993). Human Cardiovascular Control. New York.

Rushmer RF \& Smith OA, Jr. (1959). Cardiac control. Physiological Reviews 39, 41-68.

Saremi A \& Arora R. (2008). The cardiovascular implications of alcohol and red wine. Am J Ther 15, 265-277.

Savage DD, Corwin L, McGee DL, Kannel WB \& Wolf PA. (1985). Epidemiologic features of isolated syncope: the Framingham Study. Stroke 16, 626-629.

Sharpey-Schafer EP. (1956). Syncope. Br Med J 1, 506-509.

Shepherd JT. (1987). Circulatory response to exercise in health. Circulation 76, VI3-10.

Spaak J, Merlocco AC, Soleas GJ, Tomlinson G, Morris BL, Picton P, Notarius CF, Chan CT \& Floras JS. (2008). Dose-related effects of red wine and alcohol on hemodynamics, sympathetic nerve activity, and arterial diameter. Am J Physiol Heart Circ Physiol 294, H605-612.

Stott DJ, Ball SG, Inglis GC, Davies DL, Fraser R, Murray GD \& McInnes GT. (1987). Effects of a single moderate dose of alcohol on blood pressure, heart rate and associated metabolic and endocrine changes. Clin Sci (Lond) 73, 411-416.

Streeten DH. (1999). Orthostatic intolerance. A historical introduction to the pathophysiological mechanisms. The American journal of the medical sciences 317, 78-87. 
Sun BC, Emond JA \& Camargo CA, Jr. (2005). Direct medical costs of syncope-related hospitalizations in the United States. Am J Cardiol 95, 668-671.

Sun MK \& Reis DJ. (1996). Ethanol inhibits chemoreflex excitation of reticulospinal vasomotor neurons. Brain Res 730, 182-192.

Sundlof G \& Wallin BG. (1978). Effect of lower body negative pressure on human muscle nerve sympathetic activity. J Physiol 278,525-532.

Sundlof GaBGW. (1978). Human Muscle Nerve Sympathetic Activity at Rest. Relationship to Blood Pressure and Age. J Physiol 274, 621-637.

Takahashi N, Imai S, Saito F, Suzuki K, Tanaka H, Kushiro T, Yagi H \& Hirayama A. (2008). Alcohol produces imbalance of adrenal and neuronal sympathetic activity in patients with alcohol-induced neurocardiogenic syncope. Circ J 72, 979-985.

Takeda R \& Momose Y. (1983). An inhibitory effect of ethanol on adrenergic neuromuscular transmission in the guinea-pig vas deferens. Jpn J Pharmacol 33, 757-764.

Taneja I, Moran C, Medow MS, Glover JL, Montgomery LD \& Stewart JM. (2007). Differential effects of lower body negative pressure and upright tilt on splanchnic blood volume. Am J Physiol Heart Circ Physiol 292, H1420-1426.

Tateoka K, Iwasaki YK, Ono T, Kobayashi Y, Katoh T \& Takano T. (2007). A new alcohol provocation head up tilt protocol in the patients with alcohol-related syncope. Europace 9, 220-224.

Tidgren B, Hjemdahl P, Theodorsson E \& Nussberger J. (1990). Renal responses to lower body negative pressure in humans. Am J Physiol 259, F573-579.

Tomaszewski C, Cline DM, Whitley TW \& Grant T. (1995). Effect of acute ethanol ingestion on orthostatic vital signs. Ann Emerg Med 25, 636-641.

United States. Dept. of Health and Human Services. Office of the Secretary. \& National Institute on Alcohol Abuse and Alcoholism (U.S.). (2000). 10th special report to the U.S. Congress on alcohol and health: highlights from current research from the Secretary of Health and Human Services. U.S. Dept. of Health and Human Services, Public Health Service, National Institutes of Health, National Institute on Alcohol Abuse and Alcoholism, [Rockville, Md.].

Vaddadi G, Lambert E, Corcoran SJ \& Esler MD. (2007). Postural syncope: mechanisms and management. Med J Aust 187, 299-304.

Vallbo AB, Hagbarth KE \& Wallin BG. (2004). Microneurography: how the technique developed and its role in the investigation of the sympathetic nervous system. J Appl Physiol 96, 1262-1269.

van de Borne P, Mark AL, Montano N, Mion D \& Somers VK. (1997). Effects of alcohol on sympathetic activity, hemodynamics, and chemoreflex sensitivity. Hypertension 29, 1278-1283. 
van de Wiel A \& de Lange DW. (2008). Cardiovascular risk is more related to drinking pattern than to the type of alcoholic drinks. Neth J Med 66, 467-473.

Wakabayashi I. (2009). Impact of body weight on the relationship between alcohol intake and blood pressure. Alcohol Alcohol 44, 204-210.

Wallin BG. (2006). Regulation of sympathetic nerve traffic to skeletal muscle in resting humans. Clinical autonomic research: official journal of the Clinical Autonomic Research Society 16, 262-269.

Wallin BG, Esler M, Dorward P, Eisenhofer G, Ferrier C, Westerman R \& Jennings G. (1992). Simultaneous measurements of cardiac noradrenaline spillover and sympathetic outflow to skeletal muscle in humans. J Physiol 453,45-58.

Wallin BG \& Sundlof G. (1982). Sympathetic outflow to muscles during vasovagal syncope. Journal of the autonomic nervous system 6, 287-291.

Wallin BG, Thompson JM, Jennings GL \& Esler MD. (1996). Renal noradrenaline spillover correlates with muscle sympathetic activity in humans. The Journal of physiology 491 ( Pt 3), 881-887.

Wieling W, Krediet CT, van Dijk N, Linzer M \& Tschakovsky ME. (2007). Initial orthostatic hypotension: review of a forgotten condition. Clinical science 112, 157-165.

Wolf R, Tuzun B \& Tuzun Y. (1999). Alcohol ingestion and the cutaneous vasculature. Clin Dermatol 17, 395-403.

Yoda T, Crawshaw LI, Nakamura M, Saito K, Konishi A, Nagashima K, Uchida S \& Kanosue K. (2005). Effects of alcohol on thermoregulation during mild heat exposure in humans. Alcohol 36, 195-200.

Zaidi AM \& Fitzpatrick AP. (2000). Investigation of syncope: increasing the yield and reducing the cost. Eur Heart J 21, 877-880.

Zilkens RR, Burke V, Hodgson JM, Barden A, Beilin LJ \& Puddey IB. (2005). Red wine and beer elevate blood pressure in normotensive men. Hypertension 45, 874-879.

Zsoter TT \& Sellers EM. (1977). Effect of alcohol on cardiovascular reflexes. J Stud Alcohol 38, $1-10$. 
Appendix A-1: Raw data for subject characteristics

Placebo

\begin{tabular}{c|ccccc} 
Subject & Sex & Age (years) & Height $(\mathbf{c m})$ & Weight $(\mathbf{k g})$ & BMI $\left(\mathbf{k g} / \mathbf{m}^{2}\right)$ \\
\hline 1 & F & 21 & 177.5 & 48.2 & 15.3 \\
2 & M & 23 & 169.5 & 71.0 & 24.7 \\
3 & M & 23 & 176.0 & 77.2 & 24.9 \\
4 & M & 33 & 183.0 & 94.1 & 28.1 \\
5 & M & 23 & 183.0 & 79.3 & 23.7 \\
6 & F & 28 & 162.0 & 61.8 & 23.5 \\
7 & M & 30 & 169.5 & 74.0 & 25.8 \\
8 & M & 26 & 187.0 & 95.4 & 27.3 \\
9 & M & 28 & 172.0 & 78.0 & 26.4 \\
10 & M & 23 & 180.5 & 73.0 & 22.4 \\
11 & F & 21 & 165.0 & 62.8 & 23.1 \\
12 & M & 21 & 175.0 & 80.5 & 26.3 \\
13 & F & 24 & 178.0 & 78.7 & 24.8 \\
14 & M & 26 & 170.0 & 71.5 & 24.7 \\
15 & M & 23 & 183.0 & 94.0 & 28.1
\end{tabular}

\begin{tabular}{|c|c|c|c|c|c|}
\hline \multicolumn{6}{|l|}{ Alcohol } \\
\hline Subject & Sex & Age (years) & Height $(\mathrm{cm})$ & Weight (kg) & BMI $\left(\mathrm{kg} / \mathrm{m}^{2}\right)$ \\
\hline 16 & $\mathrm{~F}$ & 21 & 164.5 & 75.7 & 28.0 \\
\hline 17 & M & 24 & 182.0 & 83.5 & 25.2 \\
\hline 18 & $\mathrm{~F}$ & 22 & 166.0 & 78.0 & 28.3 \\
\hline 19 & M & 22 & 172.0 & 73.6 & 24.9 \\
\hline 20 & M & 21 & 196.0 & 105.6 & 27.5 \\
\hline 21 & $\mathrm{~F}$ & 30 & 165.5 & 64.3 & 23.5 \\
\hline 22 & M & 22 & 186.0 & 78.3 & 22.6 \\
\hline 23 & M & 23 & 182.0 & 77.6 & 23.4 \\
\hline 24 & M & 24 & 182.5 & 92.0 & 27.6 \\
\hline 25 & M & 22 & 179.0 & 91.0 & 28.4 \\
\hline 26 & M & 34 & 170.0 & 75.5 & 26.1 \\
\hline 27 & M & 21 & 186.0 & 107.5 & 31.1 \\
\hline 28 & M & 22 & 186.0 & 107.3 & 31.0 \\
\hline 29 & M & 21 & 186.0 & 97.0 & 28.0 \\
\hline 30 & M & 21 & 191.0 & 81.5 & 22.3 \\
\hline
\end{tabular}


Appendix A-2: Raw data for resting seated blood pressures taken with an automated sphy gmomanometer upon subject arrival.

\section{Placebo}

\begin{tabular}{c|ccc} 
Subject & S AP $(\mathbf{m m H g})$ & DAP $(\mathbf{m m H g})$ & MAP $(\mathbf{m m H g})$ \\
\hline 1 & 112.5 & 81.3 & 91.7 \\
2 & 128.0 & 65.7 & 86.5 \\
3 & 121.0 & 73.5 & 89.3 \\
4 & 132.8 & 79.5 & 97.3 \\
5 & 119.7 & 71.7 & 87.7 \\
6 & 119.8 & 75.0 & 89.9 \\
7 & 128.5 & 79.5 & 95.8 \\
8 & 125.7 & 67.0 & 86.6 \\
9 & 134.3 & 71.0 & 92.1 \\
10 & 141.0 & 82.8 & 102.2 \\
11 & 111.0 & 71.5 & 84.7 \\
12 & 112.0 & 77.3 & 88.9 \\
13 & 94.3 & 65.0 & 74.8 \\
14 & 106.3 & 56.0 & 72.8 \\
15 & 135.0 & 64.5 & 88.0 \\
& & &
\end{tabular}

\section{Alcohol}

\begin{tabular}{c|ccc} 
Subject & S AP $(\mathbf{m m H g})$ & DAP $(\mathbf{m m H g})$ & MAP $(\mathbf{m m H g})$ \\
\hline 16 & 101.0 & 70.3 & 80.5 \\
17 & 139.8 & 85.0 & 103.3 \\
18 & 109.3 & 66.5 & 80.8 \\
19 & 138.7 & 83.3 & 101.8 \\
20 & 131.7 & 80.3 & 97.4 \\
21 & 97.5 & 65.3 & 76.0 \\
22 & 119.3 & 65.0 & 83.1 \\
23 & 113.5 & 55.3 & 74.7 \\
24 & 115.5 & 68.8 & 84.4 \\
25 & 149.8 & 96.5 & 114.3 \\
26 & 132.3 & 81.0 & 98.1 \\
27 & 137.8 & 85.3 & 102.8 \\
28 & 124.5 & 81.3 & 95.7 \\
29 & 126.8 & 66.5 & 86.6 \\
30 & 118.0 & 68.0 & 84.7
\end{tabular}


Appendix A-3: Raw data for baseline blood pressures taken with an automated sphy gmomanometer in the supine position

\section{Placebo}

\begin{tabular}{|c|c|c|c|c|c|c|}
\hline \multirow[b]{2}{*}{ Subject } & \multicolumn{3}{|c|}{ Pre-treatment } & \multicolumn{3}{|c|}{ Post-treatment } \\
\hline & $\begin{array}{c}\mathbf{S A P} \\
(\mathbf{m m H g})\end{array}$ & DAP (mmHg) & MAP (mmHg) & $\underset{(\mathbf{m m H g})}{\mathbf{S A P}}$ & DAP (mmHg) & MAP (mmHg) \\
\hline 1 & 107.7 & 71.0 & 83.2 & 111.0 & 73.3 & 85.9 \\
\hline 2 & 116.7 & 49.3 & 71.8 & 122.0 & 56.0 & 78.0 \\
\hline 3 & 115.7 & 64.7 & 81.7 & 114.3 & 66.0 & 82.1 \\
\hline 4 & 114.7 & 60.3 & 78.4 & 114.0 & 73.0 & 86.7 \\
\hline 5 & 106.7 & 57.0 & 73.6 & 120.8 & 70.0 & 86.9 \\
\hline 6 & 111.7 & 66.3 & 81.4 & 127.0 & 76.7 & 93.5 \\
\hline 7 & 122.3 & 84.3 & 97.0 & 126.7 & 86.7 & 100.0 \\
\hline 8 & 128.7 & 63.7 & 85.4 & 134.0 & 66.0 & 88.7 \\
\hline 9 & 122.7 & 63.7 & 83.4 & 127.3 & 68.0 & 87.8 \\
\hline 10 & 126.7 & 68.3 & 87.8 & 133.0 & 70.7 & 91.5 \\
\hline 11 & 117.0 & 76.7 & 90.1 & 111.3 & 75.0 & 87.1 \\
\hline 12 & 115.0 & 63.7 & 80.8 & 121.3 & 75.0 & 90.4 \\
\hline 13 & 104.7 & 59.7 & 74.7 & 125.7 & 81.7 & 96.4 \\
\hline 14 & 119.3 & 56.7 & 77.6 & 122.0 & 66.7 & 85.1 \\
\hline 15 & 117.3 & 55.3 & 76.0 & 128.0 & 63.7 & 85.1 \\
\hline
\end{tabular}

Alcohol

\begin{tabular}{|c|c|c|c|c|c|c|}
\hline \multirow[b]{2}{*}{ Subject } & \multicolumn{3}{|c|}{ Pre-treatment } & \multicolumn{3}{|c|}{ Post-treatment } \\
\hline & (mmHg) & DAP (mmHg) & MAP (mmHg) & $\mathrm{SAP}(\mathrm{mmHg})$ & DAP (mmHg) & MAP (mmHg) \\
\hline 16 & 105.3 & 68.3 & 80.6 & 101.7 & 69.0 & 79.9 \\
\hline 17 & 125.0 & 64.7 & 84.8 & 139.0 & 64.3 & 89.2 \\
\hline 18 & 107.0 & 63.7 & 78.1 & 104.3 & 63.0 & 76.8 \\
\hline 19 & 118.3 & 60.7 & 79.9 & 138.3 & 80.3 & 99.6 \\
\hline 20 & 129.7 & 65.0 & 86.6 & 123.3 & 78.3 & 93.3 \\
\hline 21 & 92.3 & 64.3 & 73.6 & 93.3 & 68.3 & 76.6 \\
\hline 22 & 128.3 & 58.7 & 81.9 & 125.3 & 61.3 & 82.6 \\
\hline 23 & 113.7 & 54.7 & 74.4 & 117.7 & 61.0 & 79.9 \\
\hline 24 & 117.3 & 62.0 & 80.4 & 124.3 & 72.3 & 89.6 \\
\hline 25 & 135.0 & 78.7 & 97.5 & 146.7 & 77.7 & 100.7 \\
\hline 26 & 114.7 & 66.3 & 82.4 & 117.0 & 68.0 & 84.3 \\
\hline 27 & 135.0 & 68.3 & 90.5 & 130.0 & 79.3 & 96.2 \\
\hline 28 & 122.0 & 61.0 & 81.3 & 139.7 & 65.7 & 90.4 \\
\hline 29 & 138.7 & 71.0 & 93.6 & 144.3 & 58.7 & 87.2 \\
\hline 30 & 112.0 & 57.0 & 75.3 & 121.3 & 67.0 & 85.1 \\
\hline
\end{tabular}


Appendix A-4: Raw data for blood alcohol content. Measured in \%, which is equal to g/100 mL.

\section{Placebo}

\begin{tabular}{c|cc} 
Subject & Pre-treatment & Post-treatment \\
\hline 1 & 0.000 & 0.000 \\
2 & 0.000 & 0.000 \\
3 & 0.000 & 0.000 \\
4 & 0.000 & 0.000 \\
5 & 0.000 & 0.000 \\
6 & 0.000 & 0.000 \\
7 & 0.000 & 0.000 \\
8 & 0.000 & 0.000 \\
9 & 0.000 & 0.000 \\
10 & 0.000 & 0.000 \\
11 & 0.000 & 0.000 \\
12 & 0.000 & 0.000 \\
13 & 0.000 & 0.000 \\
14 & 0.000 & 0.000 \\
15 & 0.000 & 0.000
\end{tabular}

\section{Alcohol}

\begin{tabular}{c|cc} 
Subject & Pre-treatment & Post-treatment \\
\hline 16 & 0.000 & 0.122 \\
17 & 0.000 & 0.086 \\
18 & 0.000 & 0.111 \\
19 & 0.000 & 0.100 \\
20 & 0.000 & 0.078 \\
21 & 0.000 & 0.078 \\
22 & 0.000 & 0.078 \\
23 & 0.000 & 0.076 \\
24 & 0.000 & 0.062 \\
25 & 0.000 & 0.088 \\
26 & 0.000 & 0.077 \\
27 & 0.000 & 0.061 \\
28 & 0.000 & 0.036 \\
29 & 0.000 & 0.076 \\
30 & 0.000 & 0.119
\end{tabular}


Appendix A-5: Raw data for SAP (mmHg) during LBNP

\section{Placebo}

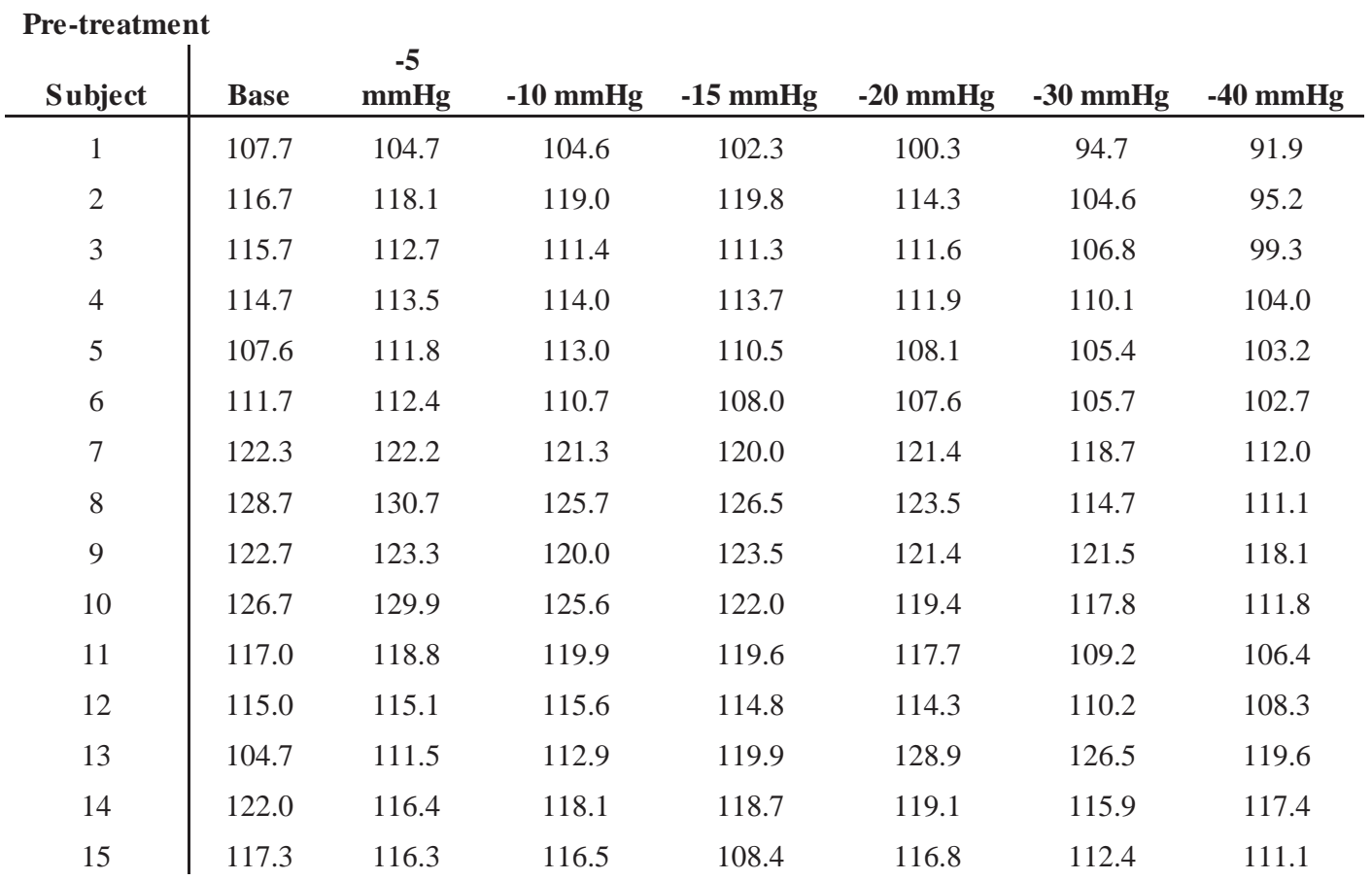

\begin{tabular}{|c|c|c|c|c|c|c|c|}
\hline \multicolumn{8}{|c|}{ Post-treatment } \\
\hline Subject & Base & $\begin{array}{c}-5 \\
\mathrm{mmHg}\end{array}$ & $-10 \mathrm{mmHg}$ & $-15 \mathrm{mmHg}$ & $-20 \mathrm{mmHg}$ & $-30 \mathrm{mmHg}$ & $-40 \mathrm{mmHg}$ \\
\hline 1 & 111.0 & 109.5 & 108.1 & 106.3 & 103.3 & 98.8 & 95.6 \\
\hline 2 & 122.0 & 122.0 & 120.6 & 117.6 & 111.9 & . & . \\
\hline 3 & 114.3 & 113.9 & 116.9 & 116.3 & 115.0 & 114.5 & 109.6 \\
\hline 4 & 114.0 & 115.8 & 115.6 & 114.3 & 114.3 & 110.4 & 107.3 \\
\hline 5 & 120.8 & 119.7 & 118.8 & 121.3 & 120.6 & 109.4 & 102.9 \\
\hline 6 & 127.0 & 124.8 & 123.7 & 121.5 & 116.4 & 112.8 & 109.4 \\
\hline 7 & 126.7 & 126.9 & 126.2 & 123.6 & 125.0 & 119.8 & 109.0 \\
\hline 8 & 134.0 & 139.8 & 143.1 & 137.4 & 131.9 & 128.2 & 120.4 \\
\hline 9 & 127.3 & 129.2 & 128.4 & 131.2 & 129.7 & 128.6 & 123.6 \\
\hline 10 & 133.0 & 133.4 & 134.1 & 132.3 & 132.9 & 128.4 & 126.6 \\
\hline 11 & 111.3 & 117.4 & 118.0 & 119.8 & 122.3 & 127.9 & 133.5 \\
\hline 12 & 121.3 & 115.2 & 117.7 & 117.4 & 115.5 & 113.7 & 109.9 \\
\hline 13 & 125.7 & 131.3 & 124.6 & 136.7 & 142.1 & 138.8 & 134.4 \\
\hline 14 & 122.0 & 132.3 & 133.6 & 134.2 & 131.2 & 131.0 & 128.9 \\
\hline 15 & 128.0 & 125.2 & 122.9 & 125.7 & 126.3 & 126.8 & 130.1 \\
\hline
\end{tabular}




\section{Alcohol}

\begin{tabular}{|c|c|c|c|c|c|c|c|}
\hline \multicolumn{8}{|c|}{ Pre-treatment } \\
\hline Subject & Base & $\begin{array}{c}-5 \\
\mathrm{mmHg}\end{array}$ & $-10 \mathrm{mmHg}$ & $-15 \mathrm{mmHg}$ & $-20 \mathrm{mmHg}$ & $-30 \mathrm{mmHg}$ & $-40 \mathrm{mmHg}$ \\
\hline 16 & 105.3 & 101.4 & 109.4 & 106.7 & 103.1 & 99.5 & 100.1 \\
\hline 17 & 125.0 & 129.0 & 120.3 & 127.1 & 129.3 & 129.7 & 127.2 \\
\hline 18 & 107.0 & 112.4 & 113.5 & 114.4 & 111.8 & 110.2 & 107.3 \\
\hline 19 & 118.3 & 121.7 & 124.8 & 127.2 & 133.8 & 134.5 & 134.1 \\
\hline 20 & 129.7 & 131.6 & 128.0 & 123.0 & 114.1 & 111.5 & 105.9 \\
\hline 21 & 92.3 & 95.9 & 99.3 & 99.7 & 101.2 & 96.3 & 90.5 \\
\hline 22 & 128.3 & 133.4 & 131.2 & 130.4 & 134.1 & 126.8 & 121.9 \\
\hline 23 & 113.7 & 111.9 & 111.2 & 108.5 & 108.9 & 101.5 & 98.2 \\
\hline 24 & 117.3 & 115.3 & 115.6 & 116.9 & 115.4 & 110.2 & 111.7 \\
\hline 25 & 135.0 & 139.5 & 135.3 & 137.3 & 143.8 & 138.2 & 132.9 \\
\hline 26 & 114.7 & 115.5 & 118.9 & 115.2 & 123.3 & 115.2 & 110.6 \\
\hline 27 & 135.0 & 135.3 & 139.2 & 134.2 & 130.5 & 126.0 & 128.9 \\
\hline 28 & 122.0 & 121.5 & 116.9 & 116.2 & 118.8 & 116.8 & 112.2 \\
\hline 29 & 138.7 & 138.5 & 135.6 & 133.5 & 130.8 & 129.3 & 124.5 \\
\hline 30 & 112.0 & 115.6 & 114.7 & 115.3 & 111.1 & 105.7 & 107.1 \\
\hline
\end{tabular}

\begin{tabular}{c|ccccccc}
\multicolumn{1}{c}{ Post-treatment } \\
Subject & Base & $\begin{array}{c}\mathbf{- 5} \\
\mathbf{m m H g}\end{array}$ & $\mathbf{- 1 0} \mathbf{~ m m H g}$ & $\mathbf{- 1 5} \mathbf{~ m m H g}$ & $\mathbf{- 2 0} \mathbf{~ m m H g}$ & $\mathbf{- 3 0} \mathbf{~ m m H g}$ & $\mathbf{- 4 0 ~} \mathbf{~ m H g}$ \\
\hline 16 & 101.7 & 100.5 & 100.8 & 94.5 & 91.6 & 91.8 & 91.9 \\
17 & 139.0 & 137.6 & 137.8 & 138.4 & 136.2 & 133.3 & 133.4 \\
18 & 104.3 & 106.6 & 104.2 & 102.1 & 100.4 & 95.8 & 95.5 \\
19 & 138.3 & 139.3 & 133.5 & 140.4 & 139.9 & 138.7 & 133.6 \\
20 & 123.3 & 122.9 & 117.1 & 111.5 & 107.6 & 106.5 & 101.7 \\
21 & 93.3 & 99.4 & 99.2 & 99.4 & 99.5 & 94.2 & 89.7 \\
22 & 125.3 & 131.1 & 126.6 & 119.3 & 118.4 & 116.6 & 112.3 \\
23 & 117.7 & 118.0 & 114.0 & 105.4 & 106.0 & 99.8 & 107.1 \\
24 & 124.3 & 124.0 & 123.1 & 122.2 & 122.5 & 123.0 & 116.8 \\
25 & 146.7 & 148.8 & 148.3 & 149.8 & 145.4 & 140.4 & 140.2 \\
26 & 117.0 & 116.7 & 115.5 & 112.8 & 111.0 & 106.8 & 99.8 \\
27 & 130.0 & 128.9 & 125.7 & 124.9 & 123.9 & 120.6 & 119.0 \\
28 & 139.7 & 135.7 & 134.0 & 129.3 & 122.2 & 116.9 & 113.8 \\
29 & 144.3 & 145.0 & 145.9 & 147.3 & 148.4 & 133.5 & 132.0 \\
30 & 121.3 & 121.5 & 127.7 & 126.2 & 125.1 & 119.5 & 113.7 \\
& & & & & & &
\end{tabular}


Appendix A-6: Raw data for DAP (mmHg) during LBNP

\section{Placebo}

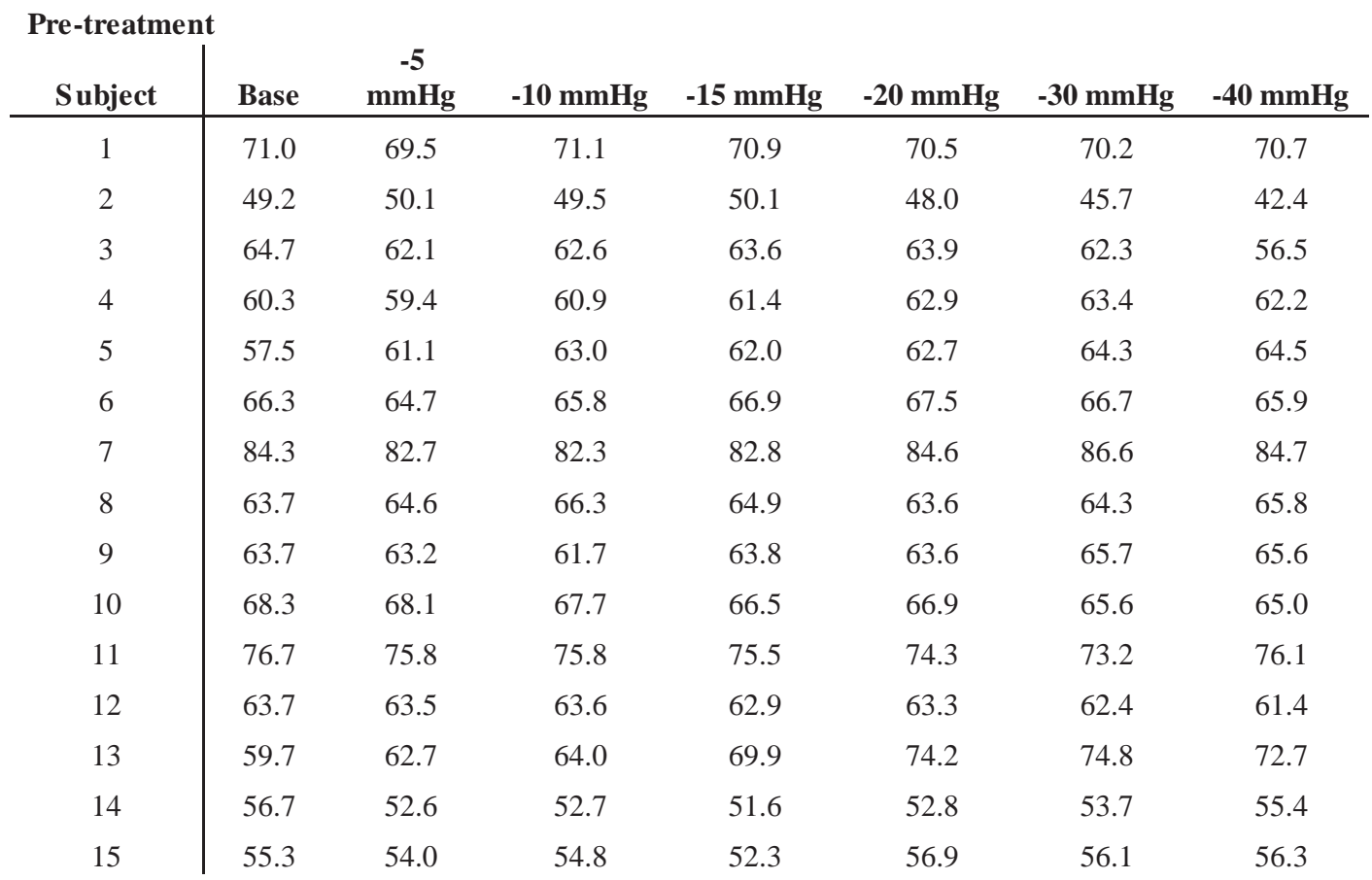

\begin{tabular}{|c|c|c|c|c|c|c|c|}
\hline \multicolumn{8}{|c|}{ Post-treatment } \\
\hline Subject & Base & $\begin{array}{c}-5 \\
\mathrm{mmHg}\end{array}$ & $-10 \mathrm{mmHg}$ & $-15 \mathrm{mmHg}$ & $-20 \mathrm{mmHg}$ & $-30 \mathrm{mmHg}$ & $-40 \mathrm{mmHg}$ \\
\hline 1 & 73.3 & 71.4 & 70.7 & 70.0 & 69.8 & 70.3 & 70.6 \\
\hline 2 & 56.0 & 55.5 & 54.9 & 53.6 & 51.2 & . & . \\
\hline 3 & 66.0 & 66.0 & 67.1 & 67.8 & 66.4 & 66.8 & 64.3 \\
\hline 4 & 73.0 & 74.2 & 74.0 & 72.7 & 73.6 & 72.5 & 72.6 \\
\hline 5 & 70.0 & 68.2 & 68.8 & 70.2 & 68.9 & 66.1 & 66.6 \\
\hline 6 & 76.7 & 75.9 & 75.2 & 74.4 & 73.3 & 73.3 & 72.7 \\
\hline 7 & 86.7 & 86.7 & 86.6 & 86.3 & 86.9 & 86.1 & 82.9 \\
\hline 8 & 66.0 & 69.4 & 71.9 & 70.3 & 69.2 & 70.1 & 67.1 \\
\hline 9 & 68.0 & 68.2 & 67.5 & 70.0 & 69.6 & 71.2 & 70.7 \\
\hline 10 & 70.7 & 71.5 & 71.8 & 72.0 & 73.1 & 72.0 & 74.0 \\
\hline 11 & 75.0 & 77.3 & 77.4 & 78.9 & 81.8 & 87.7 & 91.4 \\
\hline 12 & 75.0 & 71.5 & 72.3 & 71.5 & 68.1 & 69.2 & 68.0 \\
\hline 13 & 81.7 & 84.3 & 82.8 & 87.6 & 90.5 & 91.6 & 91.7 \\
\hline 14 & 66.7 & 69.7 & 68.6 & 66.8 & 67.2 & 67.7 & 68.4 \\
\hline 15 & 63.7 & 61.1 & 60.7 & 62.8 & 63.5 & 65.4 & 67.6 \\
\hline
\end{tabular}




\section{Alcohol}

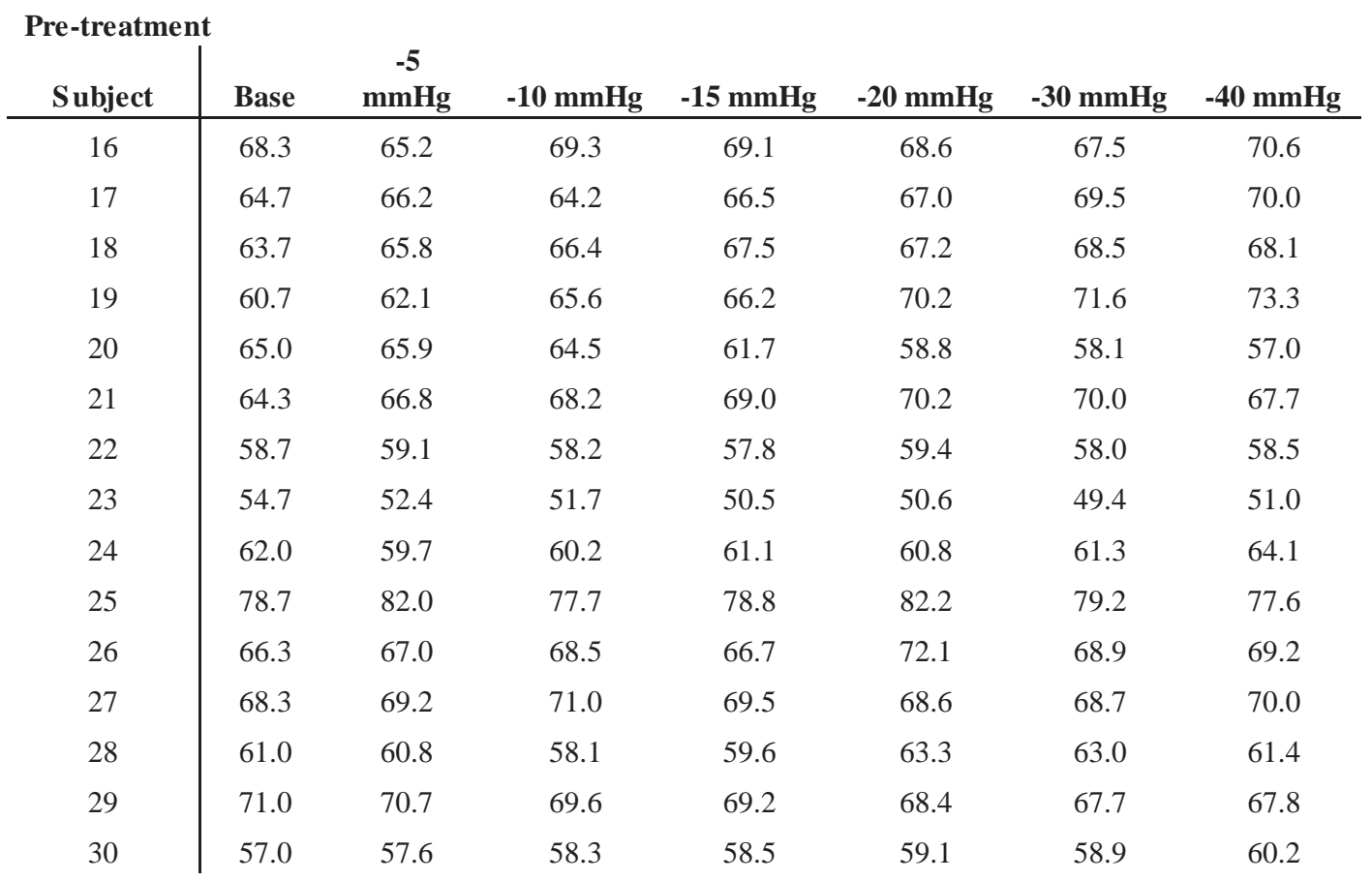

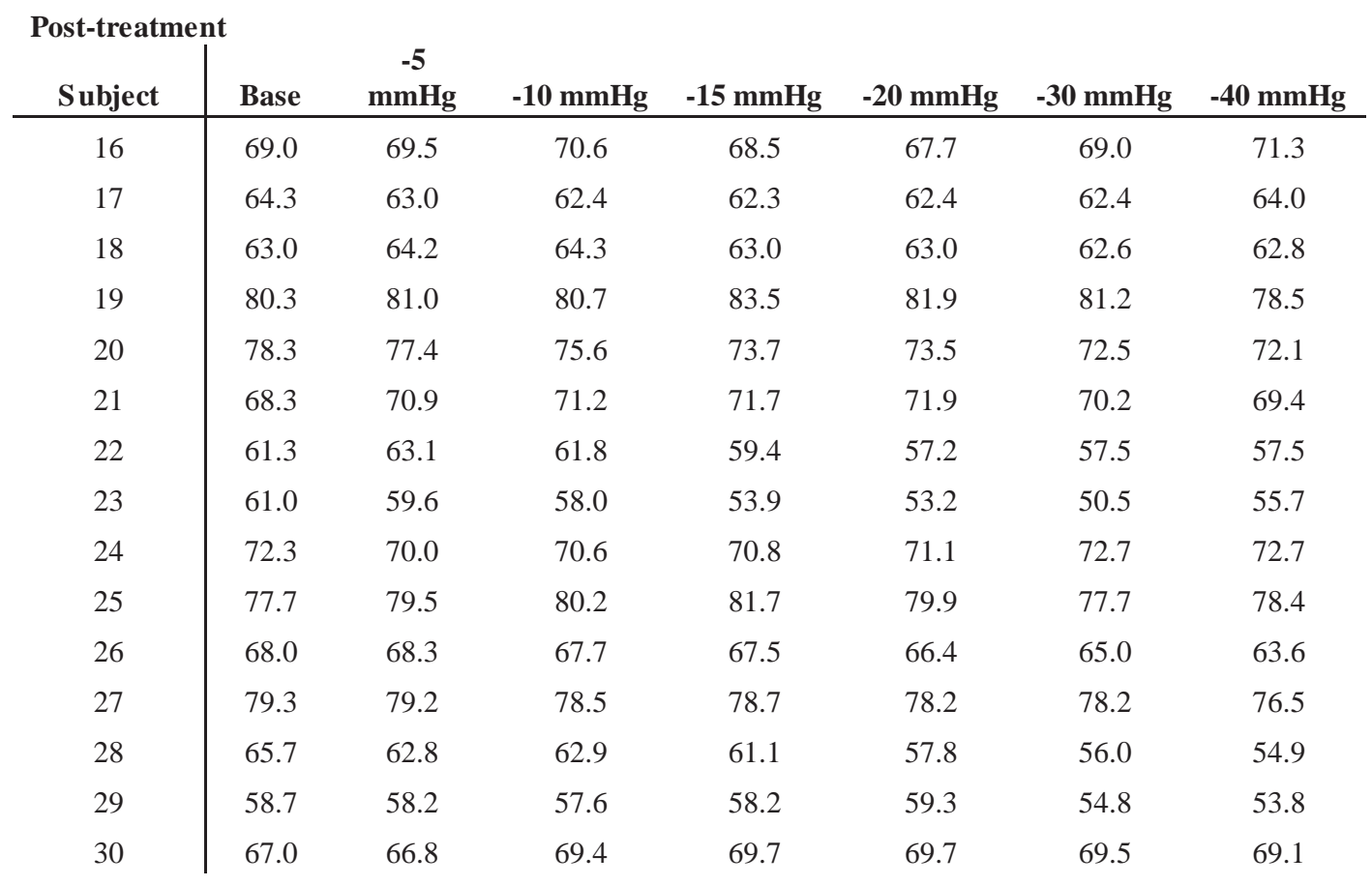


Appendix A-7: Raw data for MAP (mmHg) during LBNP

\section{Placebo}

\begin{tabular}{|c|c|c|c|c|c|c|c|}
\hline $\begin{array}{l}\text { Pre-treatm } \\
\text { Subject }\end{array}$ & Base & $\begin{array}{c}-5 \\
\mathrm{mmHg}\end{array}$ & $-10 \mathrm{mmHg}$ & $-15 \mathrm{mmHg}$ & $-20 \mathrm{mmHg}$ & $-30 \mathrm{mmHg}$ & $-40 \mathrm{mmHg}$ \\
\hline 1 & 83.2 & 80.8 & 81.7 & 79.8 & 78.3 & 75.2 & 74.2 \\
\hline 2 & 71.8 & 73.0 & 72.5 & 72.5 & 69.5 & 64.4 & 59.8 \\
\hline 3 & 81.7 & 78.3 & 78.5 & 78.8 & 79.0 & 76.6 & 70.2 \\
\hline 4 & 78.4 & 77.6 & 79.1 & 79.1 & 79.6 & 79.3 & 76.2 \\
\hline 5 & 74.3 & 78.5 & 80.4 & 78.6 & 78.1 & 78.5 & 77.6 \\
\hline 6 & 81.4 & 79.7 & 81.3 & 82.6 & 83.7 & 81.5 & 79.1 \\
\hline 7 & 97.0 & 96.1 & 94.9 & 94.6 & 96.2 & 96.6 & 92.7 \\
\hline 8 & 85.4 & 86.3 & 85.7 & 84.5 & 83.2 & 79.9 & 79.1 \\
\hline 9 & 83.4 & 82.8 & 80.3 & 82.2 & 81.5 & 83.0 & 81.5 \\
\hline 10 & 87.8 & 88.1 & 87.0 & 84.9 & 84.2 & 82.4 & 80.1 \\
\hline 11 & 90.1 & 90.1 & 90.6 & 90.1 & 88.6 & 83.4 & 84.3 \\
\hline 12 & 80.8 & 81.0 & 80.7 & 79.7 & 79.4 & 77.6 & 76.6 \\
\hline 13 & 74.7 & 77.5 & 78.2 & 85.8 & 91.5 & 90.8 & 85.5 \\
\hline 14 & 77.6 & 74.0 & 74.0 & 72.7 & 73.7 & 73.3 & 74.5 \\
\hline 15 & 76.0 & 74.1 & 74.5 & 70.4 & 75.8 & 73.7 & 74.0 \\
\hline
\end{tabular}

\begin{tabular}{|c|c|c|c|c|c|c|c|}
\hline \multicolumn{8}{|c|}{ Post-treatment } \\
\hline Subject & Base & $\begin{array}{c}-5 \\
\mathrm{mmHg}\end{array}$ & $-10 \mathrm{mmHg}$ & $-15 \mathrm{mmHg}$ & $-20 \mathrm{mmHg}$ & $-30 \mathrm{mmHg}$ & $-40 \mathrm{mmHg}$ \\
\hline 1 & 85.9 & 83.4 & 82.3 & 80.6 & 78.8 & 76.4 & 75.1 \\
\hline 2 & 78.0 & 77.7 & 76.9 & 74.6 & 71.1 & . & . \\
\hline 3 & 82.1 & 81.9 & 83.4 & 83.9 & 82.6 & 82.3 & 79.3 \\
\hline 4 & 86.7 & 87.6 & 87.0 & 85.2 & 85.5 & 83.0 & 81.7 \\
\hline 5 & 86.9 & 85.7 & 86.5 & 87.3 & 85.4 & 79.9 & 78.5 \\
\hline 6 & 93.5 & 92.9 & 92.0 & 91.0 & 89.0 & 87.7 & 84.5 \\
\hline 7 & 100.0 & 100.2 & 99.8 & 98.6 & 99.2 & 96.1 & 88.9 \\
\hline 8 & 88.7 & 92.9 & 95.2 & 91.3 & 88.0 & 86.9 & 84.0 \\
\hline 9 & 87.8 & 88.5 & 87.3 & 90.0 & 88.7 & 89.4 & 87.5 \\
\hline 10 & 91.5 & 91.9 & 91.8 & 91.2 & 92.0 & 89.7 & 91.0 \\
\hline 11 & 87.1 & 90.8 & 90.9 & 92.0 & 94.6 & 99.8 & 103.7 \\
\hline 12 & 90.4 & 86.7 & 87.4 & 86.7 & 82.7 & 83.5 & 81.0 \\
\hline 13 & 96.4 & 102.0 & 97.3 & 104.1 & 108.3 & 106.9 & 105.2 \\
\hline 14 & 85.1 & 90.8 & 89.9 & 87.7 & 86.0 & 85.2 & 85.1 \\
\hline 15 & 85.1 & 81.8 & 80.7 & 82.7 & 83.0 & 84.3 & 86.6 \\
\hline
\end{tabular}




\section{Alcohol}

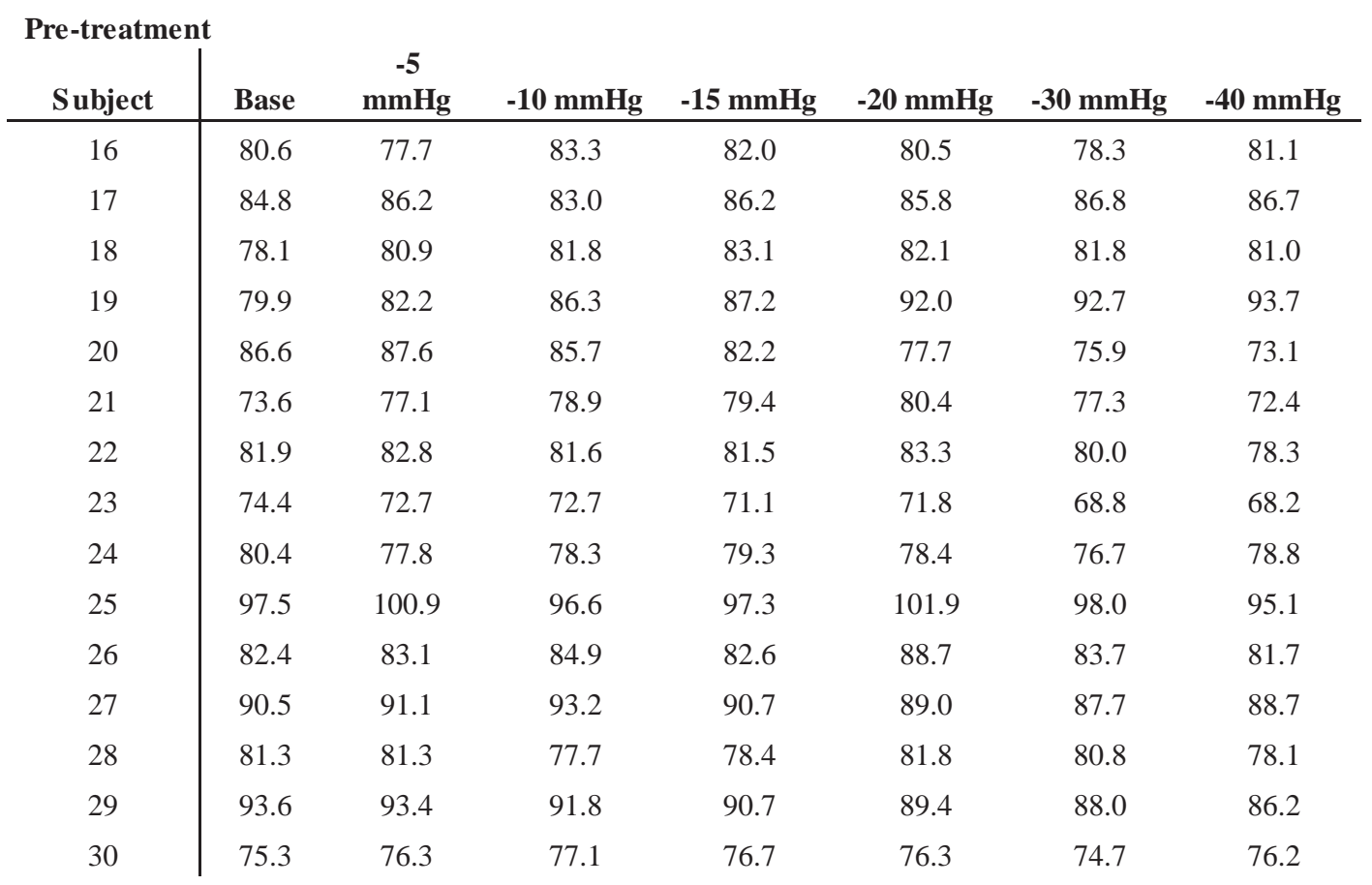

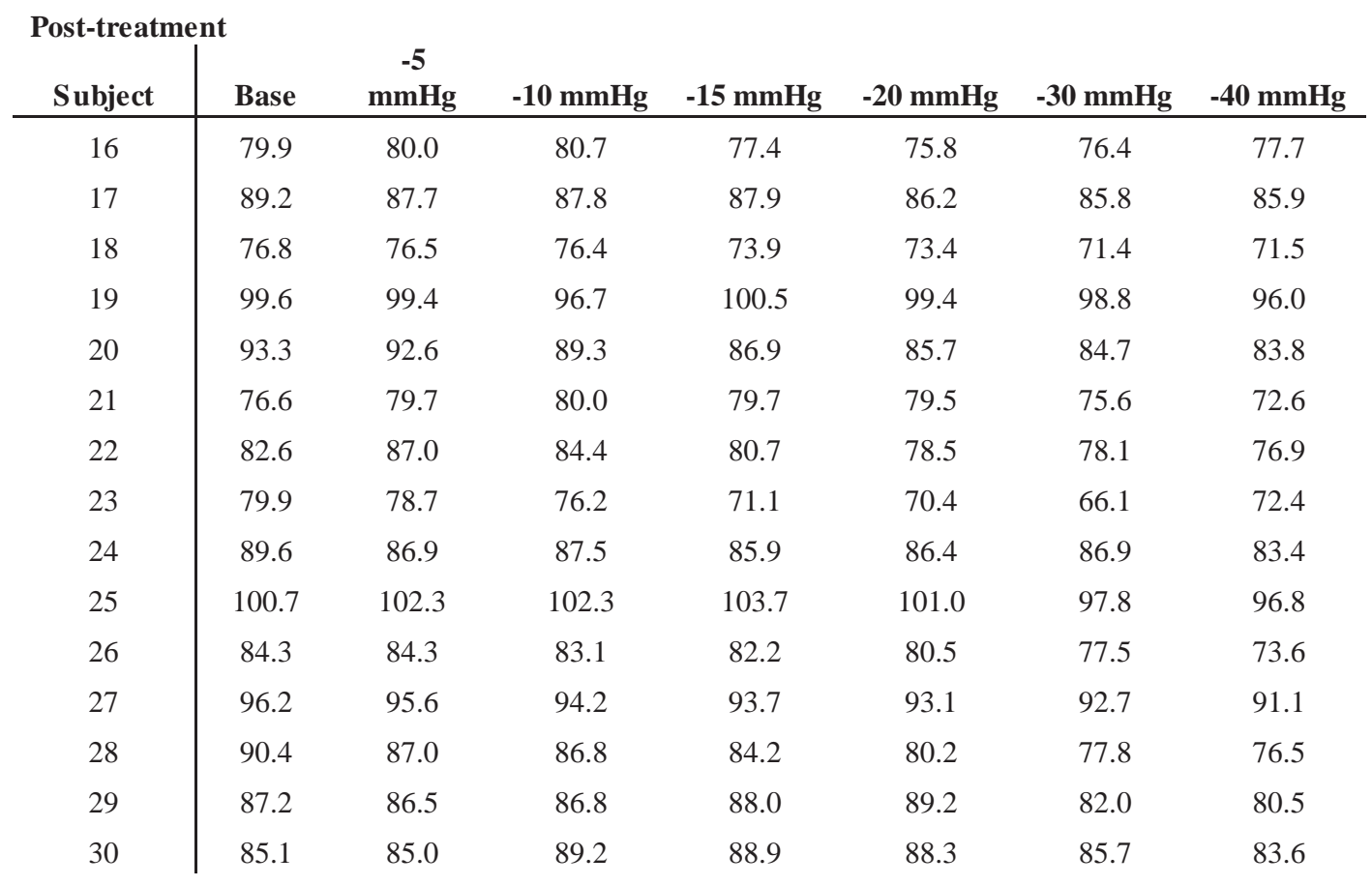


Appendix A-8: Raw data for HR (bpm) during LBNP

\section{Placebo}

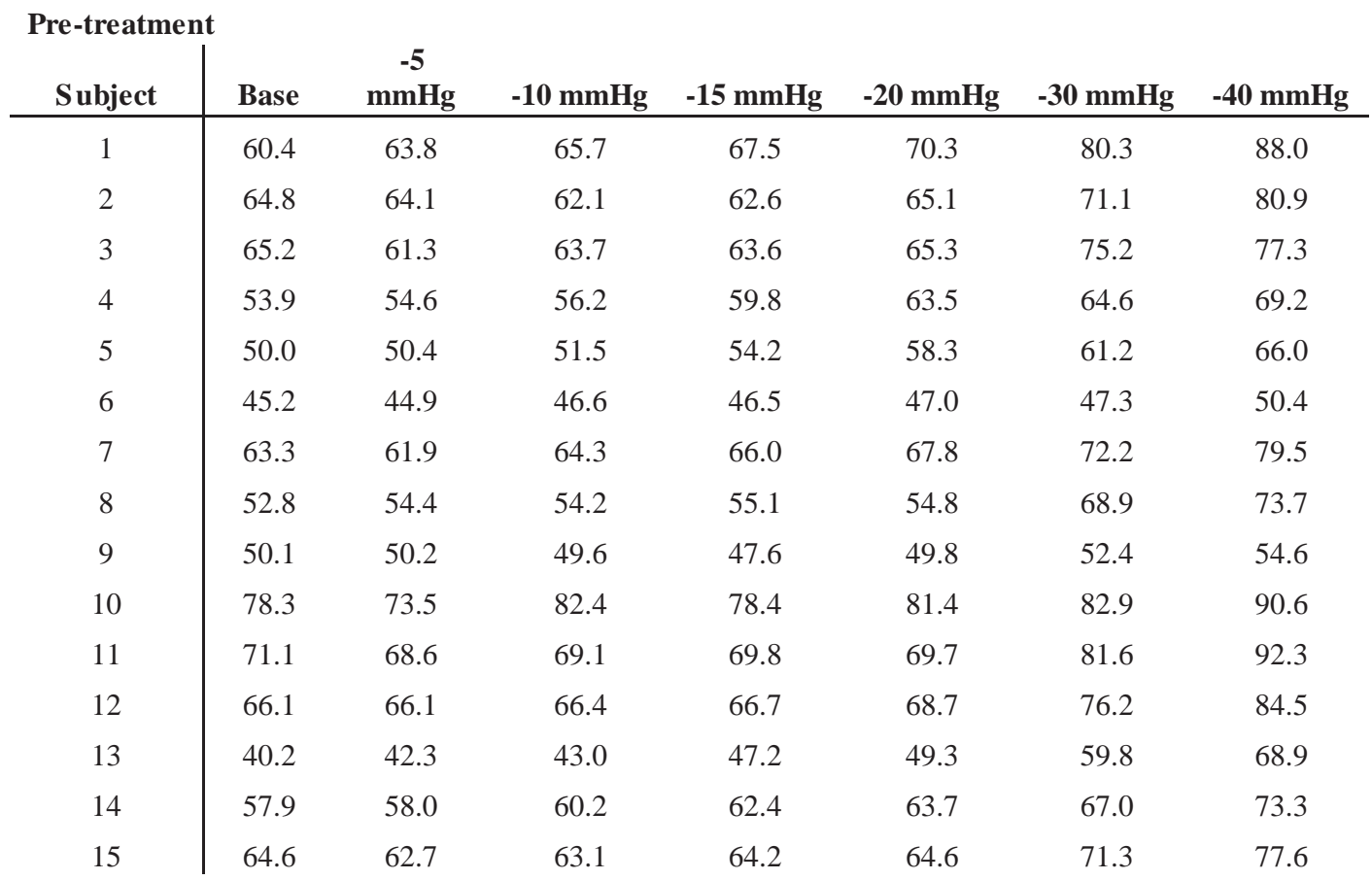

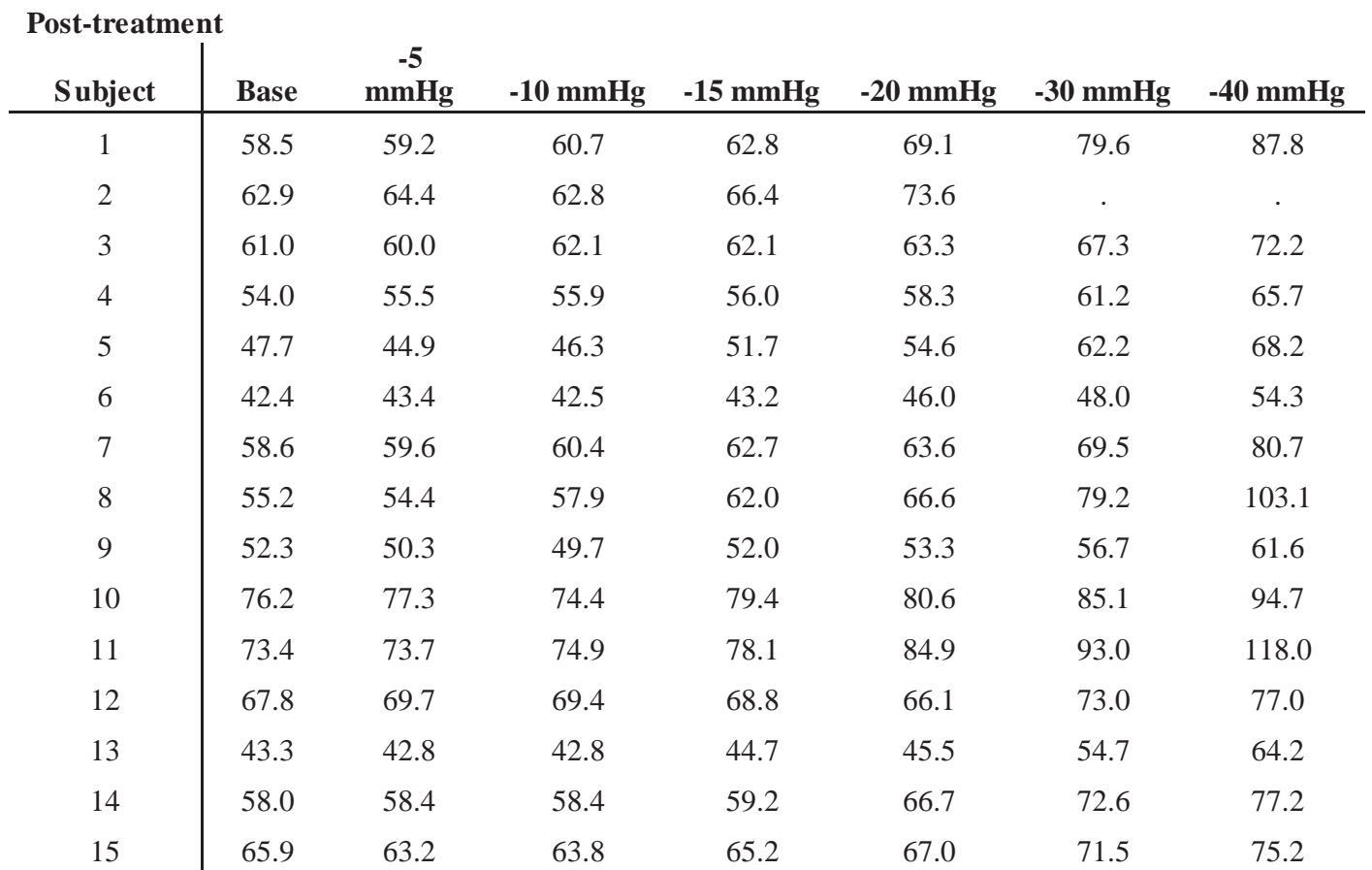




\section{Alcohol}

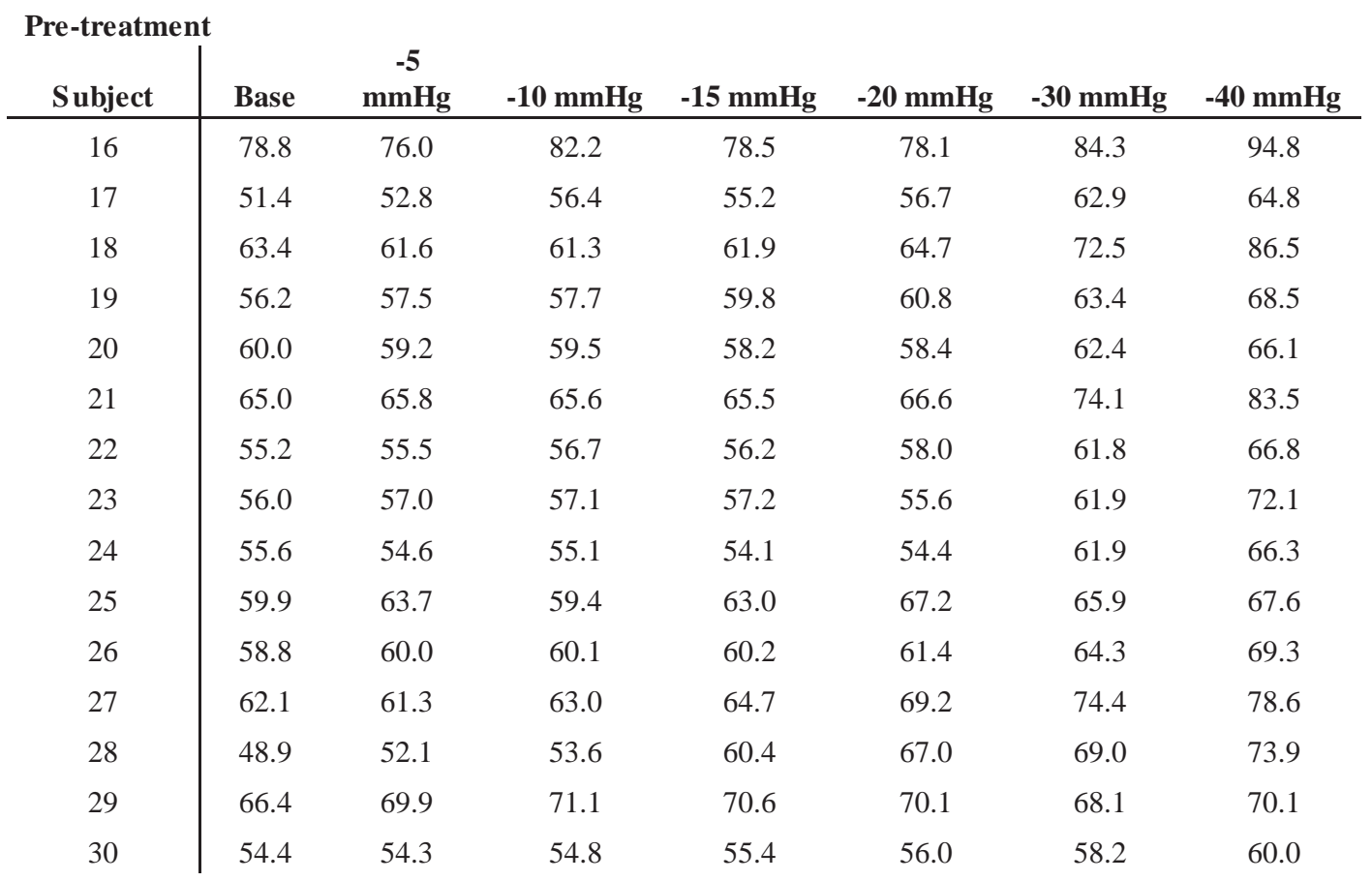

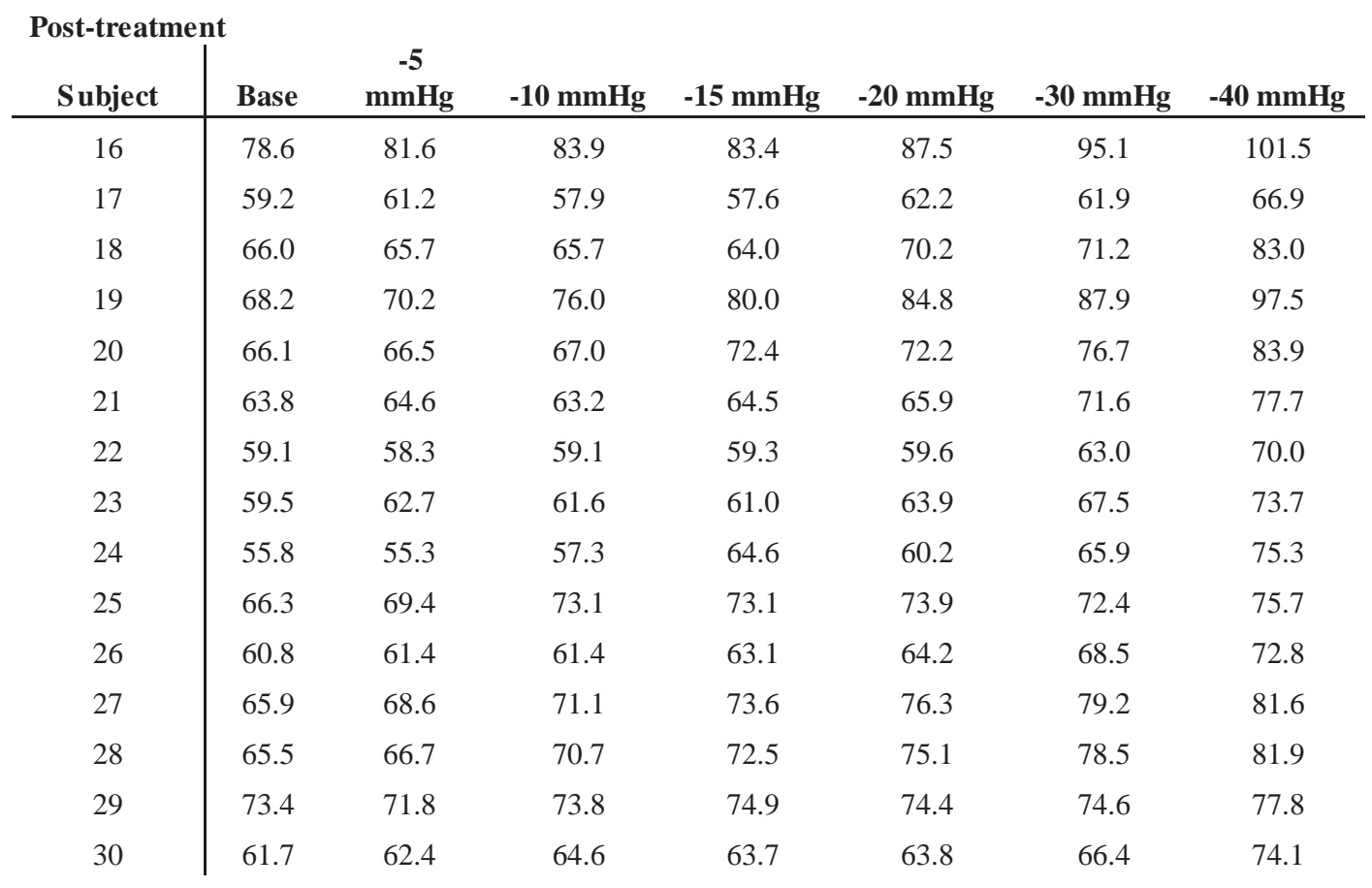


Appendix A-9: Raw data for MSNA burst frequency (bursts/min) during LBNP

\section{Placebo}

\section{Pre-treatment}

\begin{tabular}{|c|c|c|c|c|c|c|c|}
\hline Subject & Base & $-5 \mathrm{mmHg}$ & $-10 \mathrm{mmHg}$ & $-15 \mathrm{mmHg}$ & $-20 \mathrm{mmHg}$ & $-30 \mathrm{mmHg}$ & $-40 \mathrm{mmHg}$ \\
\hline 1 & 13.0 & 12.7 & 18.7 & 22.7 & 25.3 & 29.3 & 36.0 \\
\hline 2 & 24.2 & 21.3 & 26.7 & 27.0 & 29.3 & 31.0 & 35.3 \\
\hline 3 & . & . & . & . & . & . & . \\
\hline 4 & 12.6 & 12.3 & 15.3 & 18.3 & 26.0 & 28.7 & 32.7 \\
\hline 5 & . & . & . & . & . & . & . \\
\hline 6 & 15.4 & 16.7 & 17.0 & 21.3 & 19.7 & 21.7 & 31.3 \\
\hline 7 & 11.8 & 12.3 & 16.0 & 18.0 & 20.0 & 13.7 & 27.3 \\
\hline 8 & . & . & . & . & . & . & . \\
\hline 9 & 18.2 & 19.3 & 19.7 & 22.3 & 21.3 & 24.0 & 30.0 \\
\hline 10 & 7.2 & . & . & . & . & . & . \\
\hline 11 & 15.0 & 17.0 & 17.3 & 18.7 & 21.7 & 39.7 & 45.7 \\
\hline 12 & 17.0 & . & . & . & . & . & . \\
\hline 13 & 9.0 & 9.0 & 14.0 & 18.7 & 21.3 & 35.0 & 37.7 \\
\hline 14 & 6.4 & 8.3 & 10.3 & 13.0 & 20.7 & 24.3 & 29.3 \\
\hline 15 & 25.2 & 24.0 & 24.7 & 24.0 & 30.7 & 37.0 & 45.3 \\
\hline
\end{tabular}

\begin{tabular}{|c|c|c|c|c|c|c|c|}
\hline $\begin{array}{l}\text { Post-treatn } \\
\text { Subject }\end{array}$ & Base & $\begin{array}{c}-5 \\
\mathrm{mmHg}\end{array}$ & $-10 \mathrm{mmHg}$ & $-15 \mathrm{mmHg}$ & $-20 \mathrm{mmHg}$ & $-30 \mathrm{mmHg}$ & $-40 \mathrm{mmHg}$ \\
\hline 1 & 15.8 & 15.7 & 17.3 & 21.3 & 24.7 & 36.3 & 44.7 \\
\hline 2 & 23.6 & 26.7 & 31.7 & 29.0 & 31.3 & . & . \\
\hline 3 & . & . & . & . & . & . & . \\
\hline 4 & 9.4 & 11.0 & 14.0 & 9.7 & 6.7 & 16.0 & 26.3 \\
\hline 5 & . & . & . & . & . & . & . \\
\hline 6 & 16.6 & 19.0 & 19.0 & 24.7 & 25.7 & 30.3 & 38.0 \\
\hline 7 & 18.0 & 16.0 & 20.3 & 22.7 & 23.7 & 26.0 & 24.3 \\
\hline 8 & . & . & . & . & . & . & . \\
\hline 9 & 13.4 & 16.3 & 16.7 & 21.3 & 22.7 & 28.7 & 32.0 \\
\hline 10 & 11.6 & 2.0 & 4.3 & 6.0 & 8.7 & 7.7 & 9.0 \\
\hline 11 & 9.8 & 21.0 & 26.3 & 50.0 & 52.3 & 58.3 & 46.3 \\
\hline 12 & 23.0 & . & . & . & . & . & . \\
\hline 13 & 9.0 & 12.7 & 12.7 & 16.7 & 19.0 & 21.7 & 30.3 \\
\hline 14 & 9.2 & 11.0 & 14.7 & 24.1 & 32.7 & 35.0 & 35.8 \\
\hline 15 & 20.8 & 23.0 & 26.3 & 26.7 & 32.0 & 35.0 & 42.5 \\
\hline
\end{tabular}




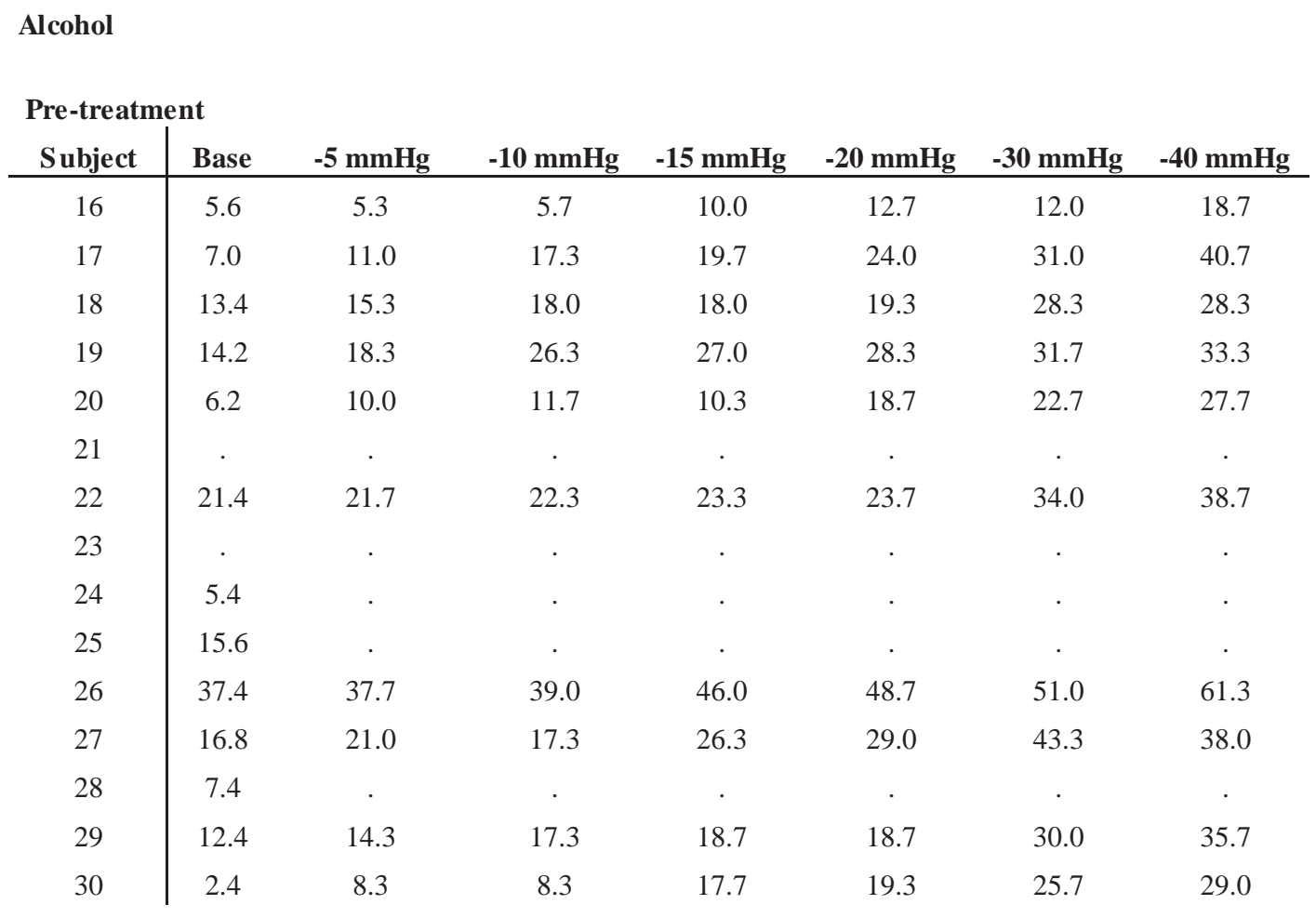

\begin{tabular}{|c|c|c|c|c|c|c|c|}
\hline \multicolumn{8}{|c|}{ Post-treatment } \\
\hline Subject & Base & $-5 \mathrm{mmHg}$ & $-10 \mathrm{mmHg}$ & $-15 \mathrm{mmHg}$ & $-20 \mathrm{mmHg}$ & $-30 \mathrm{mmHg}$ & $-40 \mathrm{mmHg}$ \\
\hline 16 & 11.0 & . & . & . & . & . & . \\
\hline 17 & 20.8 & 22.7 & 27.0 & 29.3 & 32.7 & 43.7 & 41.7 \\
\hline 18 & 9.0 & 13.0 & 17.0 & 21.0 & 21.0 & 27.3 & 34.0 \\
\hline 19 & 45.2 & 46.3 & 55.0 & 55.7 & 61.7 & 66.3 & 69.7 \\
\hline 20 & 13.6 & 20.0 & 25.0 & 25.0 & 29.3 & 37.3 & 35.5 \\
\hline 21 & . & . & . & . & . & . & . \\
\hline 22 & 17.8 & 22.0 & 17.7 & 22.0 & 20.3 & 23.7 & 26.3 \\
\hline 23 & . & . & . & . & . & . & . \\
\hline 24 & 19.4 & . & . & . & . & . & . \\
\hline 25 & 34.4 & . & . & . & . & . & . \\
\hline 26 & 32.8 & 30.3 & 41.7 & 39.7 & 43.0 & 44.3 & 59.0 \\
\hline 27 & 12.4 & 16.0 & 17.0 & 24.7 & 26.3 & 35.3 & 40.7 \\
\hline 28 & 10.2 & . & . & . & . & . & . \\
\hline 29 & 13.8 & 17.3 & 17.7 & 22.3 & 23.3 & 34.0 & 38.3 \\
\hline 30 & 2.6 & 4.0 & 6.0 & 10.3 & 15.0 & 24.7 & 29.3 \\
\hline
\end{tabular}


Appendix A-10: Raw data for MSNA burst incidence (bursts/100 HB) during LBNP

\section{Placebo}

\begin{tabular}{|c|c|c|c|c|c|c|c|}
\hline \multicolumn{8}{|c|}{ Pre-treatment } \\
\hline Subject & Base & $-5 \mathrm{mmHg}$ & $-10 \mathrm{mmHg}$ & $-15 \mathrm{mmHg}$ & $-20 \mathrm{mmHg}$ & $-30 \mathrm{mmHg}$ & $-40 \mathrm{mmHg}$ \\
\hline 1 & 21.7 & 20.0 & 28.6 & 33.7 & 36.2 & 36.5 & 40.9 \\
\hline 2 & 37.6 & 33.3 & 43.0 & 43.3 & 45.4 & 43.7 & 43.8 \\
\hline 3 & . & . & . & . & . & . & . \\
\hline 4 & 23.5 & 22.7 & 27.4 & 30.9 & 41.1 & 44.3 & 47.3 \\
\hline 5 & . & . & . & . & . & . & . \\
\hline 6 & 34.4 & 37.3 & 36.7 & 46.0 & 41.8 & 46.1 & 62.3 \\
\hline 7 & 18.8 & 20.0 & 25.1 & 27.6 & 29.7 & 19.1 & 34.5 \\
\hline 8 & . & . & . & . & . & . & . \\
\hline 9 & 36.7 & 38.9 & 40.1 & 47.2 & 43.2 & 46.2 & 55.2 \\
\hline 10 & 9.4 & . & . & . & . & . & . \\
\hline 11 & 21.2 & 25.0 & 25.2 & 27.2 & 31.3 & 48.8 & 49.6 \\
\hline 12 & 25.9 & . & . & & & & \\
\hline 13 & 22.6 & 21.8 & 33.1 & 40.9 & 44.8 & 59.3 & 54.9 \\
\hline 14 & 11.1 & 14.5 & 17.2 & 21.0 & 32.6 & 36.5 & 40.0 \\
\hline 15 & 39.3 & 38.3 & 39.2 & 37.5 & 47.4 & 52.1 & 58.6 \\
\hline
\end{tabular}

\begin{tabular}{|c|c|c|c|c|c|c|c|}
\hline $\begin{array}{r}\text { Post-treatr } \\
\text { Subject }\end{array}$ & Base & $\begin{array}{c}-5 \\
\mathrm{mmHg}\end{array}$ & $-10 \mathrm{mmHg}$ & $-15 \mathrm{mmHg}$ & $-20 \mathrm{mmHg}$ & $-30 \mathrm{mmHg}$ & $-40 \mathrm{mmHg}$ \\
\hline 1 & 27.2 & 26.7 & 28.7 & 34.2 & 35.9 & 45.8 & 51.0 \\
\hline 2 & 37.7 & 41.7 & 50.5 & 43.9 & 42.7 & . & . \\
\hline 3 & . & . & . & . & . & . & . \\
\hline 4 & 17.4 & 19.9 & 25.1 & 17.4 & 11.4 & 26.2 & 40.1 \\
\hline 5 & . & . & . & . & . & . & . \\
\hline 6 & 39.3 & 43.8 & 44.9 & 56.9 & 55.8 & 63.2 & 69.9 \\
\hline 7 & 30.9 & 27.0 & 33.9 & 36.4 & 37.2 & 37.5 & 30.3 \\
\hline 8 & . & . & . & . & . & . & . \\
\hline 9 & 25.9 & 32.9 & 33.8 & 41.0 & 42.8 & 50.9 & 52.2 \\
\hline 10 & 15.4 & 2.6 & 5.9 & 7.6 & 10.9 & 9.1 & 9.6 \\
\hline 11 & 13.4 & 28.6 & 35.3 & 64.1 & 61.8 & 63.2 & 39.4 \\
\hline 12 & 34.0 & . & . & . & . & . & . \\
\hline 13 & 21.5 & 30.6 & 30.2 & 38.5 & 42.9 & 40.1 & 47.6 \\
\hline 14 & 16.0 & 18.9 & 25.1 & 40.9 & 49.2 & 48.4 & 47.4 \\
\hline 15 & 31.6 & 36.5 & 41.4 & 41.0 & 48.0 & 49.3 & 57.1 \\
\hline
\end{tabular}




\begin{tabular}{|c|c|c|c|c|c|c|c|}
\hline Pre-treat & nent & & & & & & \\
\hline Subject & Base & $-5 \mathrm{mmHg}$ & $-10 \mathrm{mmHg}$ & $-15 \mathrm{mmHg}$ & $-20 \mathrm{mmHg}$ & $-30 \mathrm{mmHg}$ & $-40 \mathrm{mmHg}$ \\
\hline 16 & 7.1 & 7.1 & 6.9 & 12.8 & 16.3 & 14.2 & 19.7 \\
\hline 17 & 13.7 & 20.9 & 31.0 & 35.8 & 42.4 & 49.5 & 62.9 \\
\hline 18 & 21.3 & 24.9 & 29.5 & 29.2 & 30.1 & 39.2 & 32.9 \\
\hline 19 & 25.4 & 32.0 & 45.9 & 45.3 & 46.7 & 50.3 & 48.8 \\
\hline 20 & 10.5 & 16.9 & 19.7 & 17.9 & 32.2 & 36.6 & 41.9 \\
\hline 21 & . & . & . & . & . & . & . \\
\hline 22 & 38.9 & 39.2 & 39.4 & 41.7 & 41.0 & 55.4 & 58.0 \\
\hline 23 & . & . & . & . & . & . & . \\
\hline 24 & 9.8 & . & . & . & . & . & . \\
\hline 25 & 26.2 & . & . & . & . & . & . \\
\hline 26 & 64.0 & 62.8 & 65.0 & 76.2 & 79.3 & 79.7 & 88.5 \\
\hline 27 & 27.4 & 34.4 & 27.8 & 40.9 & 42.2 & 58.6 & 48.7 \\
\hline 28 & 15.3 & . & . & . & . & . & . \\
\hline 29 & 18.8 & 20.6 & 24.4 & 26.5 & 26.7 & 44.1 & 51.2 \\
\hline 30 & 4.4 & 15.4 & 15.2 & 31.9 & 34.5 & 44.3 & 48.6 \\
\hline
\end{tabular}

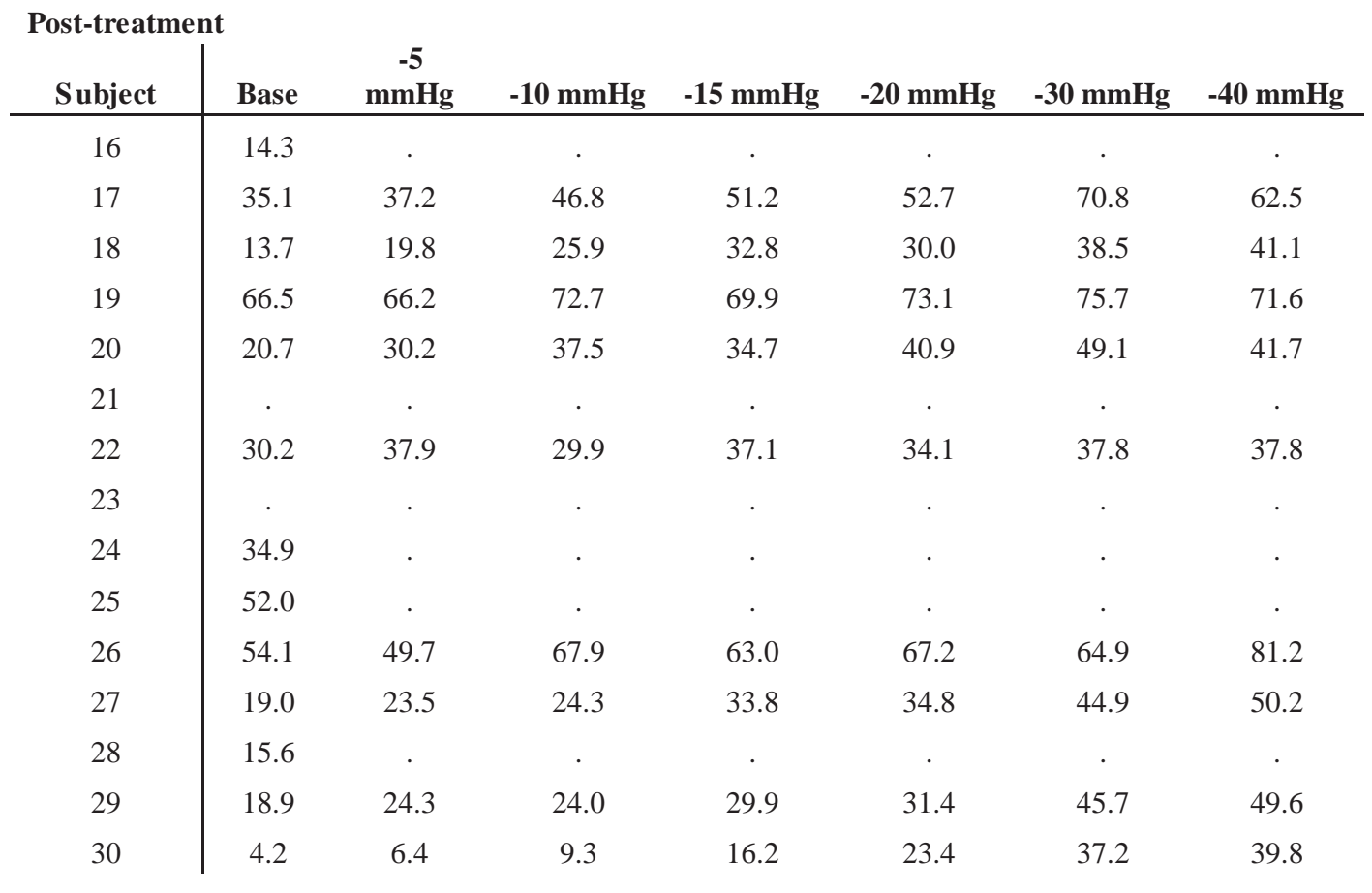


Appendix A-11: Raw data for total MSNA (arbitrary units) during LBNP

\section{Placebo}

\begin{tabular}{|c|c|c|c|c|c|c|c|}
\hline \multicolumn{8}{|c|}{ Pre-treatment } \\
\hline Subject & Base & $-5 \mathrm{mmHg}$ & $-10 \mathrm{mmHg}$ & $-15 \mathrm{mmHg}$ & $-20 \mathrm{mmHg}$ & $-30 \mathrm{mmHg}$ & $-40 \mathrm{mmHg}$ \\
\hline 1 & 4609 & 5354 & 7779 & 8912 & 8274 & 12598 & 15826 \\
\hline 2 & 10573 & 9006 & 11640 & 11261 & 12168 & 15278 & 17325 \\
\hline 3 & . & . & . & . & . & . & . \\
\hline 4 & 5687 & 6042 & 6502 & 8353 & 13203 & 16495 & 21440 \\
\hline 5 & . & . & . & . & . & . & . \\
\hline 6 & 5487 & 5959 & 7103 & 8878 & 7615 & 8695 & 13855 \\
\hline 7 & 6360 & 6977 & 9385 & 10928 & 11074 & 4578 & 10736 \\
\hline 8 & . & . & . & . & . & . & . \\
\hline 9 & 8273 & 13476 & 12975 & 17148 & 16477 & 18335 & 22880 \\
\hline 10 & 4152 & . & . & . & . & . & . \\
\hline 11 & 6846 & 11308 & 12606 & 14710 & 15229 & 36415 & 47145 \\
\hline 12 & 7563 & . & . & & & & \\
\hline 13 & 4886 & 4851 & 7266 & 12641 & 13441 & 17510 & 25745 \\
\hline 14 & 3213 & 3842 & 5401 & 6291 & 9144 & 10436 & 13153 \\
\hline 15 & 11909 & 9297 & 9129 & 7930 & 11168 & 16020 & 20148 \\
\hline
\end{tabular}

\begin{tabular}{|c|c|c|c|c|c|c|c|}
\hline \multicolumn{8}{|c|}{ Post-treatment } \\
\hline Subject & Base & $-5 \mathrm{mmHg}$ & $-10 \mathrm{mmHg}$ & $-15 \mathrm{mmHg}$ & $-20 \mathrm{mmHg}$ & $-30 \mathrm{mmHg}$ & $-40 \mathrm{mmHg}$ \\
\hline 1 & 6621 & 7145 & 8314 & 10411 & 12512 & 19687 & 25596 \\
\hline 2 & 11589 & 15417 & 19663 & 19400 & 22309 & . & . \\
\hline 3 & . & . & . & . & . & . & . \\
\hline 4 & 5181 & 7001 & 9932 & 9790 & 4993 & 11408 & 23153 \\
\hline 5 & . & . & . & . & . & . & . \\
\hline 6 & 8238 & 11740 & 12786 & 17832 & 19654 & 27377 & 37019 \\
\hline 7 & 9481 & 8183 & 10674 & 12310 & 11241 & 11186 & 11993 \\
\hline 8 & . & . & . & . & . & . & . \\
\hline 9 & 4964 & 5613 & 6807 & 8947 & 11968 & 17447 & 22266 \\
\hline 10 & 6889 & 600 & 1307 & 1683 & 3361 & 2740 & 3384 \\
\hline 11 & 4292 & 11439 & 16912 & 24271 & 27004 & 32647 & 32984 \\
\hline 12 & 11292 & . & . & . & . & . & . \\
\hline 13 & 2501 & 4842 & 5780 & 8303 & 10097 & 12129 & 22366 \\
\hline 14 & 5185 & 6379 & 9652 & 21558 & 24413 & 29710 & 34710 \\
\hline 15 & 7264 & 5967 & 6941 & 9440 & 10283 & 17971 & 30495 \\
\hline
\end{tabular}


Alcohol

\begin{tabular}{|c|c|c|c|c|c|c|c|}
\hline \multicolumn{8}{|c|}{ Pre-treatment } \\
\hline Subject & Base & $-5 \mathrm{mmHg}$ & $-10 \mathrm{mmHg}$ & $-15 \mathrm{mmHg}$ & $-20 \mathrm{mmHg}$ & $-30 \mathrm{mmHg}$ & $-40 \mathrm{mmHg}$ \\
\hline 16 & 3079 & 3477 & 3307 & 6815 & 7658 & 6359 & 11534 \\
\hline 17 & 3634 & 9159 & 12808 & 16770 & 19524 & 25519 & 33452 \\
\hline 18 & 6606 & 7456 & 8613 & 8625 & 7231 & 8367 & 10866 \\
\hline 19 & 5669 & 9174 & 14275 & 16480 & 16307 & 20127 & 25614 \\
\hline 20 & 3189 & 6280 & 7395 & 5623 & 11579 & 14100 & 18213 \\
\hline 21 & . & . & . & . & . & . & . \\
\hline 22 & 11814 & 15188 & 24073 & 17029 & 19966 & 32140 & 40229 \\
\hline 23 & . & . & . & . & . & . & . \\
\hline 24 & 2688 & . & . & . & . & . & . \\
\hline 25 & 8201 & . & . & . & . & . & . \\
\hline 26 & 17536 & 22691 & 26836 & 33397 & 30548 & 37507 & 54065 \\
\hline 27 & 7135 & 10364 & 10013 & 14418 & 16176 & 23810 & 21987 \\
\hline 28 & 4553 & . & . & . & . & . & . \\
\hline 29 & 3823 & 5261 & 5863 & 7267 & 8488 & 15707 & 20878 \\
\hline 30 & 1114 & 5253 & 5130 & 12235 & 13918 & 20250 & 25578 \\
\hline
\end{tabular}

\begin{tabular}{|c|c|c|c|c|c|c|c|}
\hline \multicolumn{8}{|c|}{ Post-treatment } \\
\hline Subject & Base & $-5 \mathrm{mmHg}$ & $-10 \mathrm{mmHg}$ & $-15 \mathrm{mmHg}$ & $-20 \mathrm{mmHg}$ & $-30 \mathrm{mmHg}$ & $-40 \mathrm{mmHg}$ \\
\hline 16 & 12009 & . & . & . & . & . & . \\
\hline 17 & 6695 & 12347 & 16770 & 18687 & 20967 & 29334 & 31806 \\
\hline 18 & 4495 & 8252 & 10724 & 13996 & 16537 & 23867 & 31742 \\
\hline 19 & 19648 & 25210 & 31862 & 32259 & 36694 & 44524 & 54592 \\
\hline 20 & 7761 & 13831 & 18189 & 16468 & 19905 & 29585 & 30339 \\
\hline 21 & . & . & . & . & . & . & . \\
\hline 22 & 10165 & 16305 & 8892 & 10348 & 8281 & 11423 & 18275 \\
\hline 23 & . & . & . & . & . & . & . \\
\hline 24 & 6911 & . & . & . & . & . & . \\
\hline 25 & 17147 & . & . & . & . & . & . \\
\hline 26 & 9560 & 8749 & 9930 & 9693 & 10328 & 10384 & 13294 \\
\hline 27 & 6517 & 9223 & 11539 & 17726 & 25467 & 37435 & 49485 \\
\hline 28 & 5948 & . & . & . & . & . & . \\
\hline 29 & 5881 & 6548 & 4605 & 7412 & 9074 & 14939 & 19209 \\
\hline 30 & 1696 & 2055 & 3471 & 5706 & 9201 & 16484 & 18937 \\
\hline
\end{tabular}


Appendix A-12: Raw data for FBF (ml/100ml/min) during LBNP

\section{Placebo}

\begin{tabular}{|c|c|c|c|c|c|c|c|}
\hline \multicolumn{8}{|c|}{ Pre-treatment } \\
\hline Subject & Base & $-5 \mathrm{mmHg}$ & $-10 \mathrm{mmHg}$ & $-15 \mathrm{mmHg}$ & $-20 \mathrm{mmHg}$ & $-30 \mathrm{mmHg}$ & $-40 \mathrm{mmHg}$ \\
\hline 1 & 1.6 & 1.5 & 1.5 & 1.5 & 1.4 & 1.4 & 1.6 \\
\hline 2 & 2.0 & 2.0 & 1.9 & 1.7 & 1.6 & 1.6 & 1.5 \\
\hline 3 & 3.0 & 2.8 & 2.7 & 3.0 & 2.8 & 2.6 & 2.6 \\
\hline 4 & 1.2 & 1.0 & 1.1 & 1.1 & 1.1 & 1.0 & 1.0 \\
\hline 5 & 1.7 & 1.8 & 1.7 & 1.5 & 1.6 & 1.4 & 1.1 \\
\hline 6 & 1.8 & 1.5 & 1.7 & 1.7 & 1.8 & 1.7 & 1.7 \\
\hline 7 & 1.7 & 1.5 & 1.9 & 1.7 & 1.7 & 1.6 & 1.6 \\
\hline 8 & 1.8 & 1.7 & 1.8 & 2.0 & 1.8 & 2.0 & 1.9 \\
\hline 9 & 2.1 & 2.0 & 1.9 & 1.6 & 1.5 & 1.3 & 1.1 \\
\hline 10 & 5.2 & 5.0 & 5.1 & 4.1 & 3.7 & 2.8 & 2.3 \\
\hline 11 & 1.0 & 0.8 & 0.8 & 0.8 & 0.8 & 0.8 & 0.7 \\
\hline 12 & 1.7 & 1.4 & 1.3 & 1.4 & 1.5 & 1.4 & 1.1 \\
\hline 13 & . & . & . & . & . & . & . \\
\hline 14 & 2.3 & 2.0 & 1.9 & 1.8 & 1.6 & 1.3 & 1.4 \\
\hline 15 & 2.0 & 2.6 & 2.4 & 2.2 & 2.3 & 2.5 & 2.4 \\
\hline
\end{tabular}

\begin{tabular}{|c|c|c|c|c|c|c|c|}
\hline \multicolumn{8}{|c|}{ Post-treatment } \\
\hline Subject & Base & $-5 \mathrm{mmHg}$ & $-10 \mathrm{mmHg}$ & $-15 \mathrm{mmHg}$ & $-20 \mathrm{mmHg}$ & $-30 \mathrm{mmHg}$ & $-40 \mathrm{mmHg}$ \\
\hline 1 & 1.5 & 1.5 & 1.6 & 1.5 & 1.6 & 1.3 & 1.3 \\
\hline 2 & 2.5 & 2.6 & 2.6 & 2.5 & 2.7 & . & . \\
\hline 3 & 3.2 & 2.6 & 3.1 & 2.8 & 3.0 & 2.9 & 2.7 \\
\hline 4 & 1.1 & 1.1 & 1.1 & 1.1 & 1.1 & 1.1 & 1.1 \\
\hline 5 & 2.0 & 1.4 & 1.3 & 1.5 & 1.1 & 1.2 & 1.2 \\
\hline 6 & 1.6 & 1.5 & 1.6 & 1.4 & 1.4 & 1.1 & 1.0 \\
\hline 7 & 1.7 & 2.3 & 1.8 & 1.7 & 1.8 & 2.0 & 1.5 \\
\hline 8 & 1.7 & 1.5 & 1.6 & 1.6 & 1.5 & 1.3 & 1.1 \\
\hline 9 & 1.3 & 1.6 & 1.6 & 1.5 & 1.5 & 1.3 & 1.2 \\
\hline 10 & 3.7 & 3.4 & 2.6 & 2.4 & 2.6 & 2.2 & 1.8 \\
\hline 11 & 1.6 & 1.5 & 1.4 & 1.3 & 1.2 & 1.2 & 1.7 \\
\hline 12 & 1.5 & 1.3 & 1.0 & 1.0 & 1.0 & 0.8 & 0.9 \\
\hline 13 & . & . & . & . & . & . & . \\
\hline 14 & 1.8 & 1.6 & 1.5 & 1.3 & 1.3 & 1.3 & 1.2 \\
\hline 15 & 2.8 & 2.6 & 2.5 & 3.1 & 2.8 & 3.2 & 3.1 \\
\hline
\end{tabular}


Alcohol

\begin{tabular}{|c|c|c|c|c|c|c|c|}
\hline \multicolumn{8}{|c|}{ Pre-treatment } \\
\hline Subject & Base & $-5 \mathrm{mmHg}$ & $-10 \mathrm{mmHg}$ & $-15 \mathrm{mmHg}$ & $-20 \mathrm{mmHg}$ & $-30 \mathrm{mmHg}$ & $-40 \mathrm{mmHg}$ \\
\hline 16 & 1.8 & 1.6 & 1.8 & 1.6 & 1.3 & 1.2 & 1.2 \\
\hline 17 & 1.6 & 1.3 & 1.5 & 1.4 & 1.4 & 1.2 & 1.3 \\
\hline 18 & 1.4 & 1.2 & 1.2 & 1.1 & 1.0 & 0.9 & 0.9 \\
\hline 19 & 3.0 & 2.6 & 2.3 & 2.5 & 2.3 & 2.3 & 2.5 \\
\hline 20 & 1.7 & 1.5 & 1.6 & 1.4 & 1.4 & 1.5 & 1.3 \\
\hline 21 & 1.1 & 0.9 & 1.0 & 1.0 & 1.0 & 0.9 & 0.9 \\
\hline 22 & 1.3 & 1.5 & 1.2 & 1.1 & 1.0 & 0.9 & 1.0 \\
\hline 23 & 2.8 & 2.3 & 2.9 & 2.8 & 2.1 & 3.0 & 2.2 \\
\hline 24 & 2.0 & 1.6 & 1.7 & 1.5 & 1.4 & 1.5 & 1.2 \\
\hline 25 & 2.2 & 1.6 & 2.1 & 2.1 & 1.9 & 1.8 & 2.2 \\
\hline 26 & 1.3 & 1.2 & 1.5 & 1.3 & 1.3 & 1.5 & 1.3 \\
\hline 27 & 3.2 & 3.0 & 3.2 & 2.7 & 2.8 & 2.6 & 2.6 \\
\hline 28 & 1.8 & 1.7 & 1.6 & 1.6 & 1.4 & 1.4 & 1.2 \\
\hline 29 & 4.2 & 4.1 & 4.7 & 3.8 & 4.0 & 3.6 & 3.0 \\
\hline 30 & 2.3 & 2.2 & 1.9 & 1.6 & 1.7 & 1.4 & 1.1 \\
\hline
\end{tabular}

\begin{tabular}{|c|c|c|c|c|c|c|c|}
\hline \multicolumn{8}{|c|}{ Post-treatment } \\
\hline Subject & Base & $-5 \mathrm{mmHg}$ & $-10 \mathrm{mmHg}$ & $-15 \mathrm{mmHg}$ & $-20 \mathrm{mmHg}$ & $-30 \mathrm{mmHg}$ & $-40 \mathrm{mmHg}$ \\
\hline 16 & 1.6 & 1.5 & 1.4 & 1.3 & 1.2 & 1.9 & 1.4 \\
\hline 17 & 1.6 & 1.6 & 1.6 & 1.6 & 2.3 & 1.2 & 1.5 \\
\hline 18 & 1.6 & 1.4 & 1.4 & 1.2 & 1.3 & 1.2 & 1.1 \\
\hline 19 & 2.5 & 2.4 & 2.2 & 2.1 & 2.2 & 2.0 & 2.3 \\
\hline 20 & 1.6 & 1.5 & 1.3 & 1.1 & 1.2 & 1.1 & 1.0 \\
\hline 21 & 1.3 & 1.2 & 1.1 & 1.0 & 1.1 & 0.9 & 1.0 \\
\hline 22 & 1.3 & 1.2 & 1.2 & 1.2 & 1.4 & 1.2 & 1.1 \\
\hline 23 & 2.2 & 2.4 & 2.1 & 2.1 & 2.0 & 2.0 & 2.2 \\
\hline 24 & 1.7 & 1.3 & 1.4 & 1.3 & 1.4 & 1.1 & 1.3 \\
\hline 25 & 2.6 & 2.7 & 3.5 & 2.9 & 2.8 & 2.6 & 2.5 \\
\hline 26 & 2.3 & 1.7 & 1.5 & 1.5 & 1.3 & 1.2 & 1.5 \\
\hline 27 & 2.2 & 1.8 & 2.0 & 2.1 & 2.0 & 2.3 & 2.0 \\
\hline 28 & 1.3 & 1.3 & 1.3 & 1.3 & 1.3 & 1.5 & 1.3 \\
\hline 29 & 4.2 & 4.2 & 4.0 & 3.8 & 3.5 & 3.7 & 4.2 \\
\hline 30 & 3.0 & 2.8 & 3.4 & 2.7 & 2.7 & 2.3 & 1.5 \\
\hline
\end{tabular}


Appendix A-13: Raw data for FVR ( $\mathrm{mmHg} / \mathrm{ml} / 100 \mathrm{ml} / \mathrm{min})$ during LBNP

\section{Placebo}

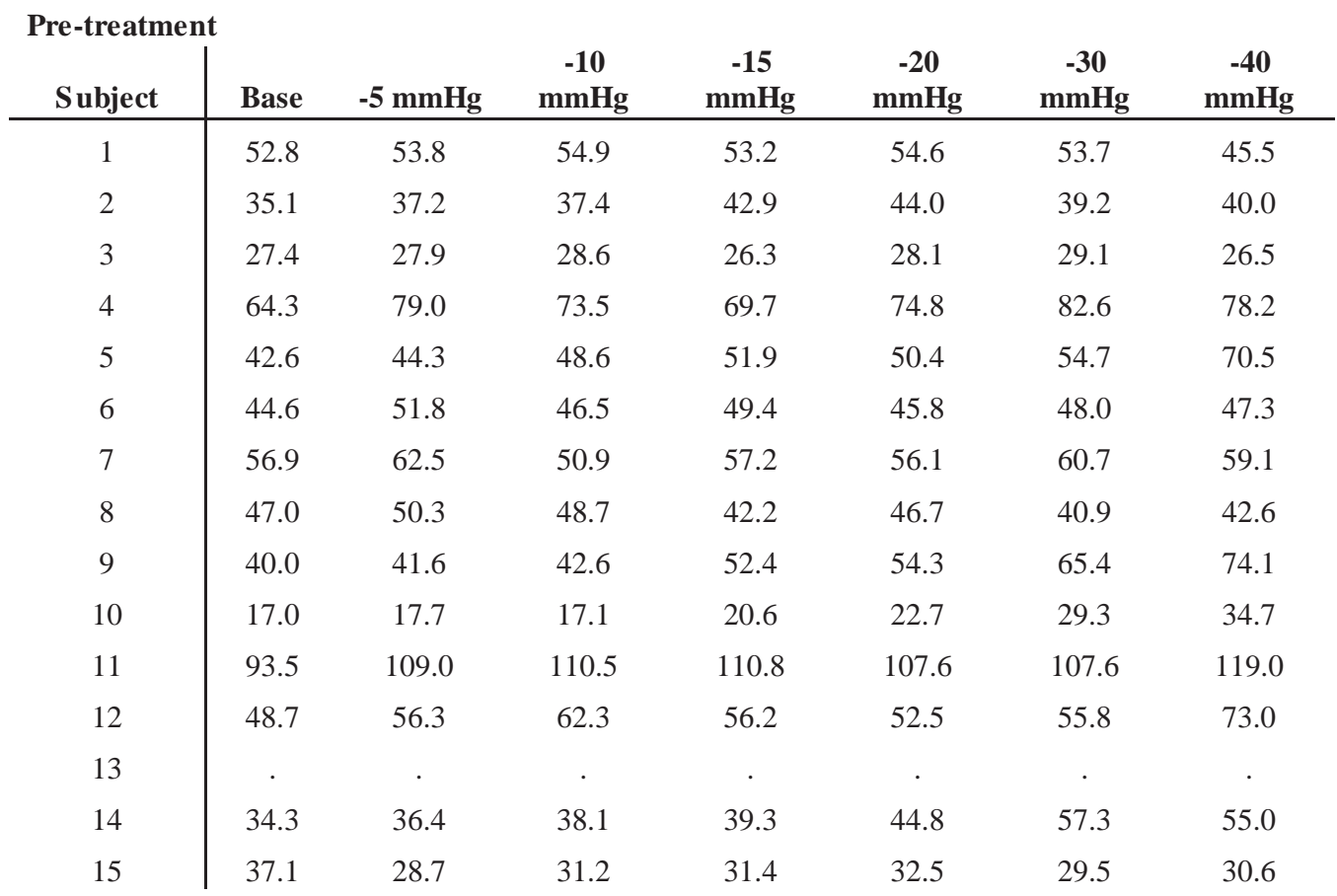

\begin{tabular}{|c|c|c|c|c|c|c|c|}
\hline \multicolumn{8}{|c|}{ Post-treatment } \\
\hline Subject & Base & $-5 \mathrm{mmHg}$ & $\begin{array}{c}-10 \\
\mathrm{mmHg}\end{array}$ & $\begin{array}{c}-15 \\
\mathrm{mmHg}\end{array}$ & $\begin{array}{c}-20 \\
\mathrm{mmHg}\end{array}$ & $\begin{array}{c}-30 \\
\mathrm{mmHg}\end{array}$ & $\begin{array}{c}-40 \\
\mathrm{mmHg}\end{array}$ \\
\hline 1 & 55.8 & 55.1 & 53.0 & 55.6 & 50.8 & 57.8 & 58.1 \\
\hline 2 & 30.9 & 29.5 & 29.4 & 29.7 & 26.7 & . & . \\
\hline 3 & 25.7 & 30.9 & 27.3 & 30.4 & 27.4 & 27.9 & 29.5 \\
\hline 4 & 75.7 & 79.3 & 79.0 & 76.9 & 79.9 & 77.0 & 77.0 \\
\hline 5 & 42.9 & 60.3 & 64.4 & 59.1 & 75.1 & 68.2 & 66.6 \\
\hline 6 & 59.7 & 62.1 & 58.6 & 63.3 & 62.8 & 82.7 & 81.7 \\
\hline 7 & 57.5 & 43.7 & 56.4 & 56.9 & 54.8 & 48.4 & 60.6 \\
\hline 8 & 52.8 & 60.2 & 60.9 & 57.6 & 60.3 & 65.5 & 74.7 \\
\hline 9 & 65.2 & 56.1 & 54.1 & 58.8 & 59.3 & 66.7 & 73.3 \\
\hline 10 & 25.0 & 27.4 & 35.1 & 37.4 & 35.5 & 41.4 & 49.6 \\
\hline 11 & 53.2 & 58.7 & 63.2 & 71.5 & 77.7 & 83.5 & 62.5 \\
\hline 12 & 60.5 & 69.3 & 86.7 & 83.2 & 81.7 & 108.0 & 95.0 \\
\hline 13 & . & . & . & . & . & . & . \\
\hline 14 & 48.3 & 55.9 & 59.7 & 67.9 & 65.3 & 63.7 & 70.2 \\
\hline 15 & 30.6 & 31.0 & 32.1 & 27.0 & 30.0 & 26.0 & 28.3 \\
\hline
\end{tabular}




\section{Alcohol}

\begin{tabular}{c|ccccccc}
\multicolumn{1}{c}{$\begin{array}{c}\text { Pre-treatment } \\
\text { Subject }\end{array}$} & Base & $\mathbf{- 5} \mathbf{~ m m H g}$ & $\begin{array}{c}\mathbf{- 1 0} \\
\mathbf{m m H g}\end{array}$ & $\begin{array}{c}\mathbf{- 1 5} \\
\mathbf{m m H g}\end{array}$ & $\begin{array}{c}\mathbf{- 2 0} \\
\mathbf{m m H g}\end{array}$ & $\begin{array}{c}\mathbf{- 3 0} \\
\mathbf{m m H g}\end{array}$ & $\begin{array}{c}\mathbf{- 4 0} \\
\mathbf{m m} \mathbf{H g}\end{array}$ \\
\hline 16 & 45.8 & 49.6 & 46.4 & 52.9 & 62.0 & 63.0 & 69.1 \\
17 & 52.1 & 63.9 & 55.3 & 62.5 & 61.0 & 74.3 & 66.6 \\
18 & 57.6 & 66.3 & 70.6 & 76.6 & 83.6 & 93.2 & 86.8 \\
19 & 27.0 & 31.0 & 37.0 & 34.3 & 39.8 & 41.0 & 37.0 \\
20 & 51.5 & 59.6 & 54.1 & 57.2 & 55.6 & 51.2 & 58.5 \\
21 & 68.1 & 81.3 & 76.8 & 81.1 & 79.0 & 84.2 & 78.6 \\
22 & 62.9 & 56.3 & 66.4 & 74.3 & 83.7 & 87.6 & 79.1 \\
23 & 26.6 & 32.3 & 24.8 & 25.2 & 34.8 & 23.2 & 30.9 \\
24 & 41.2 & 47.7 & 46.7 & 51.9 & 55.6 & 49.8 & 66.3 \\
25 & 44.0 & 64.2 & 46.3 & 46.3 & 54.7 & 55.1 & 43.1 \\
26 & 61.2 & 67.9 & 57.9 & 64.4 & 66.6 & 57.3 & 64.9 \\
27 & 28.5 & 30.8 & 29.5 & 33.4 & 32.4 & 33.2 & 34.5 \\
28 & 45.5 & 47.6 & 47.7 & 49.7 & 57.7 & 57.8 & 66.0 \\
29 & 22.3 & 22.5 & 19.5 & 24.1 & 22.3 & 24.4 & 29.1 \\
30 & 32.9 & 35.1 & 39.8 & 46.6 & 44.7 & 55.1 & 70.7
\end{tabular}

\begin{tabular}{|c|c|c|c|c|c|c|c|}
\hline \multicolumn{8}{|c|}{ Post-treatment } \\
\hline Subject & Base & $-5 \mathrm{mmHg}$ & $\begin{array}{c}-10 \\
\mathrm{mmHg}\end{array}$ & $\begin{array}{c}-15 \\
\mathrm{mmHg} \\
\end{array}$ & $\begin{array}{c}-20 \\
\mathrm{mmHg} \\
\end{array}$ & $\begin{array}{c}-30 \\
\mathrm{mmHg} \\
\end{array}$ & $\begin{array}{c}-40 \\
\mathrm{mmHg} \\
\end{array}$ \\
\hline 16 & 50.2 & 55.0 & 56.5 & 60.1 & 61.3 & 40.3 & 54.2 \\
\hline 17 & 54.4 & 53.6 & 56.2 & 56.0 & 37.9 & 73.9 & 55.5 \\
\hline 18 & 48.4 & 56.0 & 53.7 & 63.3 & 58.0 & 60.5 & 67.3 \\
\hline 19 & 39.9 & 41.5 & 43.3 & 47.5 & 44.8 & 48.9 & 41.2 \\
\hline 20 & 58.5 & 60.9 & 67.5 & 78.3 & 69.2 & 75.4 & 86.2 \\
\hline 21 & 60.9 & 68.2 & 74.4 & 77.7 & 73.7 & 81.5 & 75.9 \\
\hline 22 & 62.2 & 71.5 & 70.6 & 67.1 & 57.3 & 62.9 & 72.1 \\
\hline 23 & 36.7 & 32.4 & 35.8 & 34.2 & 35.6 & 32.6 & 33.6 \\
\hline 24 & 53.7 & 69.4 & 63.6 & 64.5 & 59.7 & 76.0 & 63.7 \\
\hline 25 & 39.2 & 37.7 & 29.5 & 35.3 & 35.6 & 38.1 & 38.0 \\
\hline 26 & 37.2 & 50.4 & 54.9 & 54.9 & 60.8 & 65.5 & 50.1 \\
\hline 27 & 43.0 & 53.8 & 47.5 & 44.6 & 45.4 & 40.1 & 45.4 \\
\hline 28 & 69.6 & 67.3 & 65.5 & 62.7 & 60.9 & 52.3 & 57.0 \\
\hline 29 & 20.6 & 20.4 & 21.5 & 23.4 & 25.3 & 22.0 & 19.2 \\
\hline 30 & 28.3 & 30.8 & 25.9 & 32.6 & 32.9 & 37.9 & 54.0 \\
\hline
\end{tabular}


Appendix A-14: Raw data for FVC (ml/100ml/min/mmHg)*100 during LBNP

Placebo

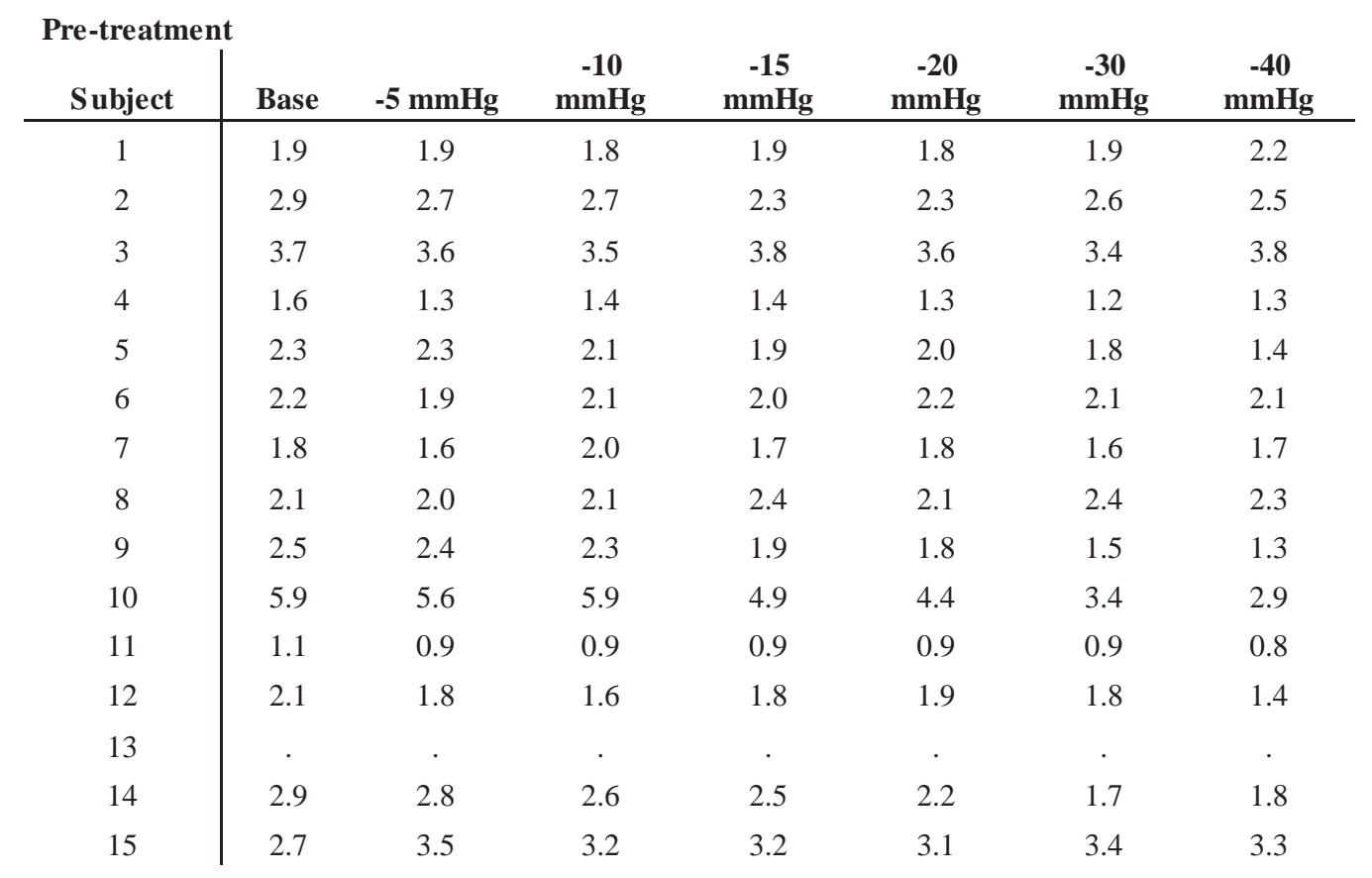

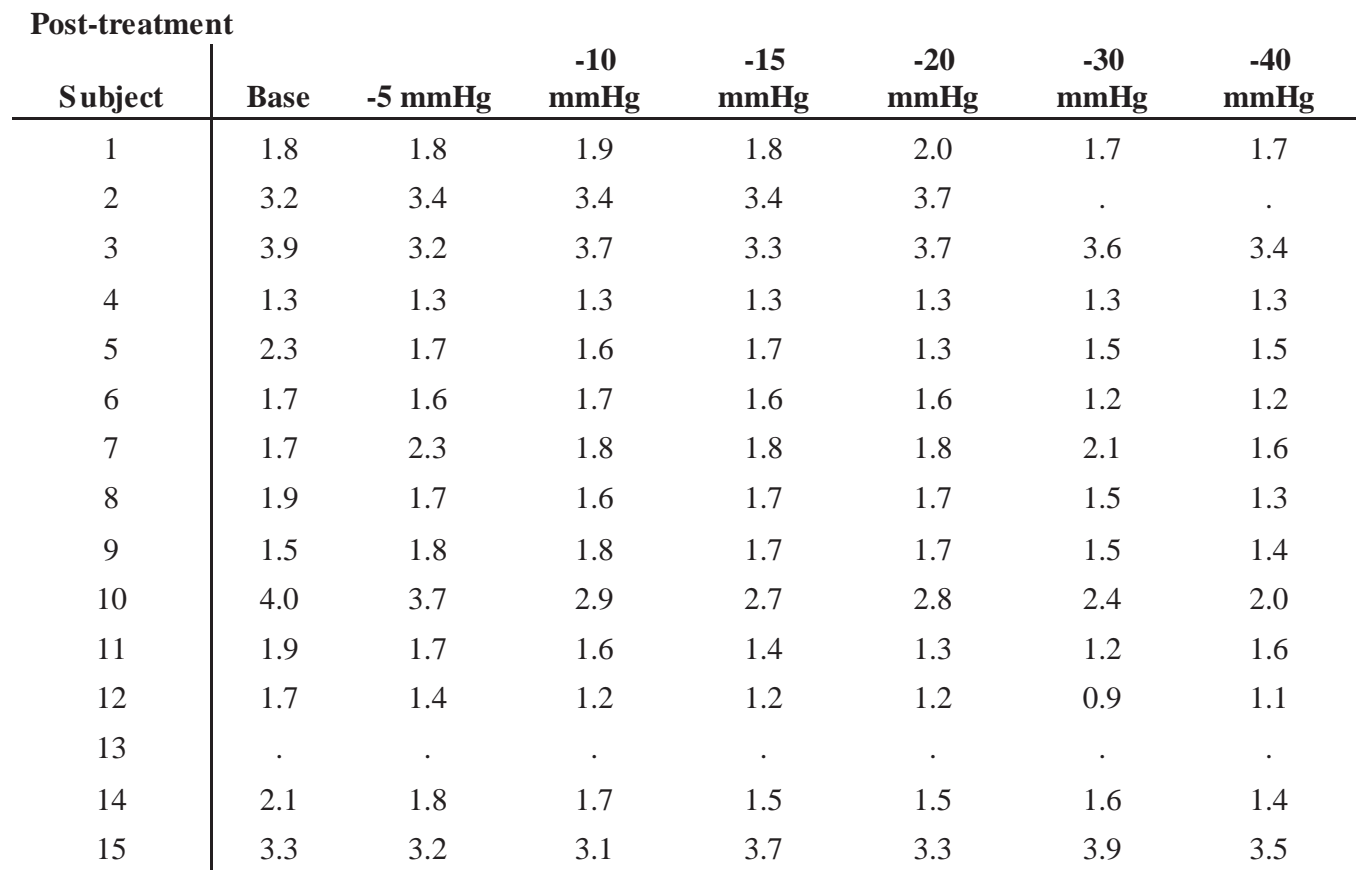




\section{Alcohol}

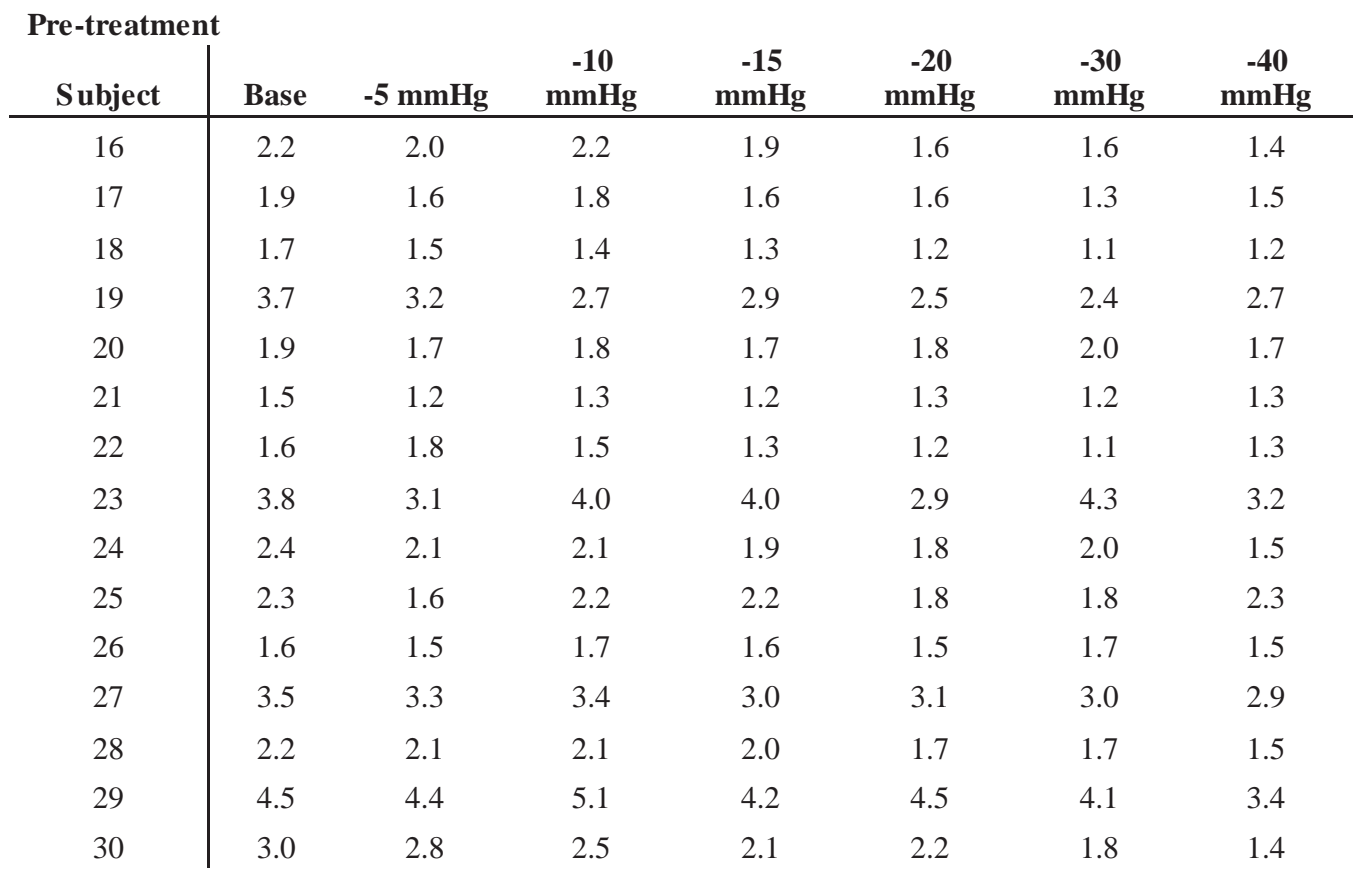

\begin{tabular}{|c|c|c|c|c|c|c|c|}
\hline \multicolumn{8}{|c|}{ Post-treatment } \\
\hline Subject & Base & $-5 \mathrm{mmHg}$ & $\begin{array}{c}-10 \\
\mathrm{mmHg}\end{array}$ & $\begin{array}{c}-15 \\
\mathrm{mmHg}\end{array}$ & $\begin{array}{c}-20 \\
\mathrm{mmHg}\end{array}$ & $\begin{array}{c}-30 \\
\mathrm{mmHg}\end{array}$ & $\begin{array}{c}-40 \\
\mathrm{mmHg} \\
\end{array}$ \\
\hline 16 & 2.0 & 1.8 & 1.8 & 1.7 & 1.6 & 2.5 & 1.8 \\
\hline 17 & 1.8 & 1.9 & 1.8 & 1.8 & 2.6 & 1.4 & 1.8 \\
\hline 18 & 2.1 & 1.8 & 1.9 & 1.6 & 1.7 & 1.7 & 1.5 \\
\hline 19 & 2.5 & 2.4 & 2.3 & 2.1 & 2.2 & 2.0 & 2.4 \\
\hline 20 & 1.7 & 1.6 & 1.5 & 1.3 & 1.4 & 1.3 & 1.2 \\
\hline 21 & 1.6 & 1.5 & 1.3 & 1.3 & 1.4 & 1.2 & 1.3 \\
\hline 22 & 1.6 & 1.4 & 1.4 & 1.5 & 1.7 & 1.6 & 1.4 \\
\hline 23 & 2.7 & 3.1 & 2.8 & 2.9 & 2.8 & 3.1 & 3.0 \\
\hline 24 & 1.9 & 1.4 & 1.6 & 1.5 & 1.7 & 1.3 & 1.6 \\
\hline 25 & 2.6 & 2.6 & 3.4 & 2.8 & 2.8 & 2.6 & 2.6 \\
\hline 26 & 2.7 & 2.0 & 1.8 & 1.8 & 1.6 & 1.5 & 2.0 \\
\hline 27 & 2.3 & 1.9 & 2.1 & 2.2 & 2.2 & 2.5 & 2.2 \\
\hline 28 & 1.4 & 1.5 & 1.5 & 1.6 & 1.6 & 1.9 & 1.8 \\
\hline 29 & 4.8 & 4.9 & 4.7 & 4.3 & 4.0 & 4.5 & 5.2 \\
\hline 30 & 3.5 & 3.2 & 3.9 & 3.1 & 3.0 & 2.6 & 1.9 \\
\hline
\end{tabular}


Appendix B-1: Mean values plus/minus SE for pre-treatment

\begin{tabular}{|c|c|c|c|c|c|c|}
\hline Variable & Group & $\mathbf{N}$ & Baseline & $-5 \mathrm{mmHg}$ & $-10 \mathrm{mmHg}$ & $-15 \mathrm{mmHg}$ \\
\hline $\mathbf{S A P}$ & Placebo & 14 & $117 \pm 2$ & $117 \pm 2$ & $116 \pm 2$ & $116 \pm 2$ \\
\hline $\mathrm{mmHg}$ & Alcohol & 15 & $120 \pm 3$ & $121 \pm 3$ & $121 \pm 3$ & $120 \pm 3$ \\
\hline DAP & Placebo & 14 & $65 \pm 2$ & $65 \pm 2$ & $65 \pm 2$ & $65 \pm 2$ \\
\hline $\mathrm{mmHg}$ & Alcohol & 15 & $64 \pm 2$ & $65 \pm 2$ & $65 \pm 2$ & $65 \pm 2$ \\
\hline MAP & Placebo & 14 & $82 \pm 2$ & $82 \pm 2$ & $82 \pm 2$ & $82 \pm 2$ \\
\hline $\mathrm{mmHg}$ & Alcohol & 15 & $82 \pm 2$ & $83 \pm 2$ & $84 \pm 2$ & $83 \pm 2$ \\
\hline HR & Placebo & 14 & $59 \pm 3$ & $58 \pm 2$ & $60 \pm 3$ & $61 \pm 3$ \\
\hline bpm & Alcohol & 15 & $60 \pm 2$ & $60 \pm 2$ & $61 \pm 2$ & $61 \pm 2$ \\
\hline MSNA & Placebo & 9 & $14 \pm 2$ & $15 \pm 2$ & $17 \pm 1$ & $20 \pm 1$ \\
\hline bursts/min & Alcohol & 9 & $15 \pm 3$ & $18 \pm 3$ & $20 \pm 3$ & $23 \pm 3$ \\
\hline MSNA & Placebo & 9 & $26 \pm 3$ & $27 \pm 3$ & $30 \pm 3$ & $35 \pm 3$ \\
\hline bursts/100 HB & Alcohol & 9 & $25 \pm 6$ & $30 \pm 5$ & $33 \pm 5$ & $39 \pm 6$ \\
\hline Total MSNA & Placebo & 9 & $6363 \pm 842$ & $7456 \pm 1075$ & $8683 \pm 877$ & $10643 \pm 1182$ \\
\hline a.u. & Alcohol & 9 & $6724 \pm 1692$ & $10092 \pm 1881$ & $12778 \pm 2603$ & $14649 \pm 2747$ \\
\hline FBF & Placebo & 13 & $2.1 \pm 0.3$ & $2.0 \pm 0.3$ & $2.0 \pm 0.3$ & $1.9 \pm 0.2$ \\
\hline unit & Alcohol & 15 & $2.1 \pm 0.2$ & $1.9 \pm 0.2$ & $2.0 \pm 0.2$ & $1.8 \pm 0.2$ \\
\hline FVR & Placebo & 13 & $47 \pm 5$ & $51 \pm 7$ & $50 \pm 7$ & $51 \pm 6$ \\
\hline mmHg/unit & Alcohol & 15 & $45 \pm 4$ & $50 \pm 4$ & $48 \pm 4$ & $52 \pm 5$ \\
\hline FVC*100 & Placebo & 13 & $2.5 \pm 0.3$ & $2.4 \pm 0.3$ & $2.4 \pm 0.4$ & $2.3 \pm 0.3$ \\
\hline unit/mmHg & Alcohol & 15 & $2.5 \pm 0.2$ & $2.3 \pm 0.2$ & $2.5 \pm 0.2$ & $2.2 \pm 0.2$ \\
\hline
\end{tabular}

unit $=\mathrm{ml} / 100 \mathrm{ml} / \mathrm{min}$ 


\begin{tabular}{|c|c|c|c|c|c|}
\hline Variable & Group & $\mathbf{N}$ & $-20 \mathrm{mmHg}$ & $-30 \mathrm{mmHg}$ & $-40 \mathrm{mmHg}$ \\
\hline SAP & Placebo & 14 & $116 \pm 2$ & $112 \pm 2$ & $108 \pm 2$ \\
\hline $\mathrm{mmHg}$ & Alcohol & 15 & $121 \pm 3$ & $117 \pm 3$ & $114 \pm 4$ \\
\hline DAP & Placebo & 14 & $66 \pm 2$ & $66 \pm 2$ & $66 \pm 2$ \\
\hline $\mathrm{mmHg}$ & Alcohol & 15 & $66 \pm 2$ & $65 \pm 2$ & $66 \pm 2$ \\
\hline MAP & Placebo & 14 & $82 \pm 2$ & $81 \pm 2$ & $79 \pm 2$ \\
\hline $\mathrm{mmHg}$ & Alcohol & 15 & $84 \pm 2$ & $82 \pm 2$ & $81 \pm 2$ \\
\hline HR & Placebo & 14 & $62 \pm 3$ & $69 \pm 3$ & $75 \pm 3$ \\
\hline Bpm & Alcohol & 15 & $63 \pm 2$ & $67 \pm 2$ & $73 \pm 2$ \\
\hline MSNA & Placebo & 9 & $23 \pm 1$ & $28 \pm 3$ & $35 \pm 2$ \\
\hline bursts/min & Alcohol & 9 & $26 \pm 3$ & $33 \pm 3$ & $37 \pm 3$ \\
\hline MSNA & Placebo & 9 & $39 \pm 2$ & $43 \pm 4$ & $49 \pm 3$ \\
\hline bursts/100 HB & Alcohol & 9 & $42 \pm 5$ & $51 \pm 4$ & $54 \pm 5$ \\
\hline Total MSNA & Placebo & 9 & $11736 \pm 1029$ & $15676 \pm 2001$ & $21214 \pm 3642$ \\
\hline a.u. & Alcohol & 9 & $15971 \pm 2349$ & $21947 \pm 3012$ & $27876 \pm 4324$ \\
\hline FBF & Placebo & 13 & $1.8 \pm 0.2$ & $1.7 \pm 0.2$ & $1.6 \pm 0.2$ \\
\hline unit & Alcohol & 15 & $1.7 \pm 0.2$ & $1.7 \pm 0.2$ & $1.6 \pm 0.2$ \\
\hline FVR & Placebo & 13 & $52 \pm 6$ & $55 \pm 6$ & $58 \pm 7$ \\
\hline mmHg/unit & Alcohol & 15 & $56 \pm 5$ & $57 \pm 5$ & $59 \pm 5$ \\
\hline FVC $* 100$ & Placebo & 13 & $2.3 \pm 0.3$ & $2.1 \pm 0.2$ & $2.0 \pm 0.2$ \\
\hline unit/mmHg & Alcohol & 15 & $2.1 \pm 0.2$ & $2.1 \pm 0.3$ & $1.9 \pm 0.2$ \\
\hline
\end{tabular}

unit $=\mathrm{ml} / 100 \mathrm{ml} / \mathrm{min}$ 
Appendix B-2: Mean values plus/minus SE for post-treatment

\begin{tabular}{c|cccccc} 
Variable & Group & $\mathbf{N}$ & Baseline & $\mathbf{- 5} \mathbf{~ m m H g}$ & $\mathbf{- 1 0 ~} \mathbf{~ m H g}$ & $\mathbf{- 1 5} \mathbf{~ m m H g}$ \\
\hline SAP & Placebo & 14 & $123 \pm 2$ & $124 \pm 2$ & $124 \pm 2$ & $124 \pm 3$ \\
mmHg & Alcohol & 15 & $124 \pm 4$ & $125 \pm 4$ & $124 \pm 4$ & $122 \pm 5$ \\
\hline DAP & Placebo & 14 & $72 \pm 2$ & $73 \pm 2$ & $73 \pm 2$ & $73 \pm 2$ \\
mmHg & Alcohol & 15 & $69 \pm 2$ & $69 \pm 2$ & $69 \pm 2$ & $68 \pm 2$ \\
\hline MAP & Placebo & 14 & $89 \pm 1$ & $90 \pm 2$ & $89 \pm 2$ & $90 \pm 2$ \\
mmHg & Alcohol & 15 & $87 \pm 2$ & $87 \pm 2$ & $87 \pm 2$ & $86 \pm 2$ \\
\hline HR & Placebo & 14 & $58 \pm 3$ & $58 \pm 3$ & $59 \pm 3$ & $61 \pm 3$ \\
Bpm & Alcohol & 15 & $65 \pm 2$ & $66 \pm 2$ & $67 \pm 2$ & $69 \pm 2$ \\
\hline MSNA & Placebo & 9 & $14 \pm 2$ & $16 \pm 1$ & $25 \pm 5$ & $24 \pm 4$ \\
bursts/min & Alcohol & 9 & $19 \pm 4$ & $21 \pm 4$ & $33 \pm 2$ & $41 \pm 4$ \\
\hline MSNA & Placebo & 9 & $25 \pm 3$ & $29 \pm 3$ & $38 \pm 7$ & $41 \pm 6$ \\
bursts/100 HB & Alcohol & 9 & $29 \pm 7$ & $33 \pm 6$ & $9755 \pm 1153$ & $13651 \pm 2002$ \\
\hline Total MSNA & Placebo & 9 & $5970 \pm 714$ & $7590 \pm 821$ & $12887 \pm 2867$ & $14699 \pm 2675$ \\
\hline a.u. & Alcohol & 9 & $8046 \pm 1680$ & $11391 \pm 2218$ & $1.7 \pm 0.2$ & $1.7 \pm 0.2$ \\
\hline FBF & Placebo & 13 & $2.0 \pm 0.2$ & $1.8 \pm 0.2$ & $2.0 \pm 0.2$ & $1.8 \pm 0.2$ \\
\hline unit & Alcohol & 15 & $2.1 \pm 0.2$ & $1.9 \pm 0.2$ & $56 \pm 5$ & $57 \pm 5$ \\
\hline FVR & Placebo & 13 & $50 \pm 4$ & $53 \pm 4$ & $51 \pm 4$ & $54 \pm 4$ \\
\hline IVI* $* 100$ & Placebo & 13 & $2.2 \pm 2.5$ & $2.1 \pm 0.2$ & $2.2 \pm 0.3$ & $2.1 \pm 0.2$ \\
\hline
\end{tabular}

unit $=\mathrm{ml} / 100 \mathrm{ml} / \mathrm{min}$ 


\begin{tabular}{|c|c|c|c|c|c|}
\hline Variable & Group & $\mathbf{N}$ & $-20 \mathrm{mmHg}$ & $-30 \mathrm{mmHg}$ & $-40 \mathrm{mmHg}$ \\
\hline $\mathbf{S A P}$ & Placebo & 14 & $123 \pm 3$ & $121 \pm 3$ & $117 \pm 4$ \\
\hline mmHg & Alcohol & 15 & $120 \pm 5$ & $116 \pm 4$ & $113 \pm 4$ \\
\hline DAP & Placebo & 14 & $73 \pm 2$ & $74 \pm 2$ & $74 \pm 3$ \\
\hline $\mathrm{mmHg}$ & Alcohol & 15 & $68 \pm 2$ & $67 \pm 2$ & $67 \pm 2$ \\
\hline MAP & Placebo & 14 & $89 \pm 2$ & $88 \pm 2$ & $87 \pm 2$ \\
\hline $\mathrm{mmHg}$ & Alcohol & 15 & $85 \pm 2$ & $83 \pm 2$ & $82 \pm 2$ \\
\hline HR & Placebo & 14 & $63 \pm 3$ & $70 \pm 3$ & $79 \pm 5$ \\
\hline Bpm & Alcohol & 15 & $70 \pm 2$ & $73 \pm 2$ & $80 \pm 2$ \\
\hline MSNA & Placebo & 9 & $27 \pm 4$ & $32 \pm 4$ & $36 \pm 3$ \\
\hline bursts/min & Alcohol & 9 & $30 \pm 5$ & $37 \pm 4$ & $42 \pm 5$ \\
\hline MSNA & Placebo & 9 & $43 \pm 5$ & $47 \pm 4$ & $48 \pm 4$ \\
\hline bursts/100 HB & Alcohol & 9 & $43 \pm 6$ & $52 \pm 5$ & $53 \pm 5$ \\
\hline MSNA & Placebo & 9 & $14685 \pm 2442$ & $19951 \pm 2720$ & $26731 \pm 2617$ \\
\hline total area & Alcohol & 9 & $17384 \pm 3177$ & $24219 \pm 3985$ & $29742 \pm 4781$ \\
\hline FBF & Placebo & 13 & $1.7 \pm 0.2$ & $1.6 \pm 0.2$ & $1.5 \pm 0.2$ \\
\hline unit & Alcohol & 15 & $1.9 \pm 0.2$ & $1.7 \pm 0.2$ & $1.7 \pm 0.2$ \\
\hline FVR & Placebo & 13 & $59 \pm 5$ & $63 \pm 6$ & $64 \pm 5$ \\
\hline mmHg/unit & Alcohol & 15 & $51 \pm 4$ & $54 \pm 5$ & $54 \pm 5$ \\
\hline FVC $* 100$ & Placebo & 13 & $1.9 \pm 0.2$ & $1.9 \pm 0.3$ & $1.8 \pm 0.2$ \\
\hline unit/mmHg & Alcohol & 15 & $2.2 \pm 0.2$ & $2.1 \pm 0.2$ & $2.1 \pm 0.3$ \\
\hline
\end{tabular}

unit $=\mathrm{ml} / 100 \mathrm{ml} / \mathrm{min}$ 
Appendix C-1: Repeated Measures ANOVA for baseline measurements Baseline SAP

Within Subjects Effect

treatment

Source

treatment*drug

Baseline DAP

Within Subjects Effect treatment

Source

treatment*drug

Baseline MAP

Within Subjects Effect treatment

Source

treatment*drug

Baseline HR

Within Subjects Effect treatment

Source

treatment*drug
Mauchley's Test of Sphericity Mauchly's W Approx. Chi-Square

1.000

0.000

Test of Within-S ubjects Effects Type III Sum of Squares

3.902

$\begin{array}{rr}\text { df } & \begin{array}{r}\text { Mean } \\ \text { Square }\end{array} \\ 1.000 & 3.902\end{array}$

$\begin{array}{rr}\text { F } & \text { Sig. (1-tailed) } \\ 0.119 & 0.37\end{array}$

Mauchley's Test of Sphericity Mauchly's W Approx. Chi-Square

$1.000 \quad 0.000$

df

Sig. Huynh-Feldt

$\begin{array}{lll}0 & 1.000\end{array}$

Test of Within-S ubjects Effects Type III Sum of Squares

22.355

df
1.000

Mean

S quare

F Sig. (1-tailed)

$22.355 \quad 0.842$

0.18

Mauchley's Test of Sphericity Mauchly's W Approx. Chi-Square

$1.000 \quad 0.000$

$\begin{array}{rrr}\text { df } & \text { Sig. } & \text { Huynh-Feldt } \\ 0 & . & 1.000\end{array}$

Test of Within-Subjects Effects Type III Sum of Squares

15.073

df
1.000

Mean

15.073

F Sig. (1-tailed)

$0.753 \quad 0.20$

Mauchley's Test of Sphericity Mauchly's W Approx. Chi-Square

$\begin{array}{ll}1.000 & 0.000\end{array}$

df

Sig. Huynh-Feldt

1.000

Test of Within-S ubjects Effects

Type III Sum of Squares

df $\begin{array}{r}\text { Mean } \\ \text { Square }\end{array}$

F Sig. (2-tailed)

63.370

1.000

63.670

9.812

0.004 
Baseline MSNA
(bursts/min)

Mauchley's Test of Sphericity

Within Subjects Effect

Mauchly's W Approx. Chi-Square

df Sig. Huynh-Feldt

treatment

1.000

0.000

0

1.000

Test of Within-S ubjects Effects

Source

Type III Sum

of Squares

96.148

df
1.000

Mean

treatment*drug

1.000

Square

F Sig. (1-tailed)

$96.148 \quad 2.781$

0.05

Baseline MSNA (bursts/100HB)

Mauchley's Test of Sphericity

Within Subjects Effect

treatment

Source

treatment*drug

Baseline Total MSNA

Within Subjects Effect

treatment

Source

treatment*drug

Baseline FBF

Within Subjects Effect

treatment

Source

treatment*drug

\begin{abstract}
Mauchly's W
\end{abstract}
Approx. Chi-Square

1.000

0.000

Test of Within-S ubjects Effects Type III Sum of Squares

141.750

df
1.000

Mean

Square

141.750

1.724

F Sig.(1-tailed)

$724 \quad 0.10$

1.000
Mauchley's Test of Sphericity

Mauchly's W Approx. Chi-Square

1.000

0.000

df

Sig. Huynh-Feldt

0

1.000

Test of Within-Subjects Effects

Type III Sum

of Squares

df $\begin{array}{r}\text { Mean } \\ \text { Square }\end{array}$

F Sig. (1-tailed)

1.789E+07

$1.000 \quad 1.789 \mathrm{E}+07$

1.728

0.10
Mauchley's Test of Sphericity Mauchly's W Approx. Chi-Square
1.000
0.000

df Sig. Huynh-Feldt

0

1.000

Test of Within-Subjects Effects

Type III Sum

of Squares

0.023
Mean

S quare
F Sig. (1-tailed)

0.163

0.35 
Baseline FVR

\begin{tabular}{|c|c|c|c|c|c|}
\hline \multicolumn{6}{|c|}{ Mauchley's Test of Sphericity } \\
\hline Within Subjects Effect & Mauchly's W & Approx. Chi-Square & df & Sig. & Huynh-Feldt \\
\hline treatment & 1.000 & 0.000 & 0 & . & 1.000 \\
\hline \multicolumn{6}{|c|}{ Test of Within-S ubjects Effects } \\
\hline Source & $\begin{array}{r}\text { Type III Sum } \\
\text { of Squares }\end{array}$ & df & $\begin{array}{r}\text { Mean } \\
\text { Square }\end{array}$ & $\mathbf{F}$ & Sig. (1-tailed) \\
\hline treatment*drug & 17.859 & 1.000 & 17.859 & 0.199 & 0.33 \\
\hline
\end{tabular}

Baseline FVC

Mauchley's Test of Sphericity

Within Subjects Effect Mauchly's W Approx. Chi-Square 1.000

0.000

df

Sig. Huynh-Feldt

treatment

1.000

.

\section{Test of Within-S ubjects Effects}

Source

Type III S um
of Squares
$3.473 \mathrm{E}-06$

$\begin{array}{rr}\text { df } & \begin{array}{r}\text { Mean } \\ \text { Square }\end{array} \\ 1.000 & 3.473 \mathrm{E}-06\end{array}$

$\begin{array}{rr}\text { F } & \text { Sig. (1-tailed) } \\ 0.144 & 0.35\end{array}$

treatment*drug

$3.473 \mathrm{E}-06$

$1.000 \quad 3.473 \mathrm{E}-06$

0.144

0.35 
Appendix C-2: Repeated Measures ANOVA for blood pressures

$\triangle \mathbf{S A P}$

Effect

Treatment

Time

Treatment $*$ Time

Source
Treatment
Time
Treatment $*$ Time
Treatment $*$ Time * Drug

\section{Within Subjects}

\begin{tabular}{crrrr}
\multicolumn{2}{c}{ Mauchley's Test of Sphericity } \\
$\begin{array}{c}\text { Approx. } \\
\text { Chi-S quare }\end{array}$ & df & Sig. & Huynh-Feldt \\
Mauchly's W & 0.000 & 0 &. & 1.000 \\
1.000 & 167.270 & 20 & 0.000 & 0.288 \\
0.001 & 69.047 & 20 & 0.000 & 0.536 \\
0.062 & & & & \\
& & & & \\
Test of Within-S ubjects Effects & Mean & F ig. (1-tailed) \\
Type III Sum \\
of Squares
\end{tabular}

$\triangle \mathrm{DAP}$

Within Subjects Effect

Treatment

Time

Treatment $*$ Time

Source
Treatment
Time
Treatment $*$ Time
Treatment $*$ Time * Drug

\begin{tabular}{rrrrr}
\multicolumn{4}{c}{$\begin{array}{c}\text { Mauchley's Test of Sphericity } \\
\text { Approx. Chi- }\end{array}$} & \\
Mauchly's W & Square & df & Sig. & Huynh-Feldt \\
1.000 & 0.000 & 0 &. & 1.000 \\
0.001 & 162.545 & 20 & 0.000 & 0.328 \\
0.012 & 110.417 & 20 & 0.000 & 0.367
\end{tabular}

Test of Within-Subjects Effects

$\begin{array}{rrrrr}\begin{array}{r}\text { Type III S um } \\ \text { of Squares }\end{array} & \text { df } & \begin{array}{r}\text { Mean } \\ \text { Square }\end{array} & \text { F } & \text { Sig. (1-tailed) } \\ 2673.830 & 1.000 & 2673.830 & 19.781 & 0.000 \\ 10.327 & 1.968 & 5.246 & 0.274 & 0.379 \\ 62.708 & 2.203 & 28.470 & 3.264 & 0.021 \\ 45.451 & 2.203 & 20.635 & 2.366 & 0.049\end{array}$


$\triangle$ MAP

\begin{tabular}{|c|c|c|c|c|c|}
\hline \multirow[b]{2}{*}{ Within Subjects Effect } & \multicolumn{3}{|c|}{ Mauchley's Test of Sphericity } & \multirow[b]{2}{*}{ Sig. } & \multirow[b]{2}{*}{ Huynh-Feldt } \\
\hline & $\begin{array}{r}\text { Mauchly's } \\
\text { W }\end{array}$ & $\begin{array}{r}\text { Approx. Chi- } \\
\text { Square }\end{array}$ & df & & \\
\hline Treatment & 1.000 & 0.000 & 0 & . & 1.000 \\
\hline Time & 0.002 & 156.346 & 20 & 0.000 & 0.335 \\
\hline Treatment $*$ Time & 0.023 & 93.828 & 20 & 0.000 & 0.413 \\
\hline
\end{tabular}

Test of Within-Subjects Effects

Source
Treatment
Time
Treatment $*$ Time
Treatment $*$ Time * Drug

Type III

Sum of

Squares

2297.701

598.921

88.504

69.373

$\begin{array}{rrrr}\text { df } & \begin{array}{r}\text { Mean } \\ \text { Square }\end{array} & \text { F } & \text { Sig.(1-tailed) } \\ 1.000 & 2297.701 & 27.084 & 0.000 \\ 2.008 & 298.341 & 10.546 & 0.000 \\ 2.478 & 35.713 & 2.916 & 0.025 \\ 2.478 & 27.993 & 2.285 & 0.049\end{array}$

$\begin{array}{rrrr}\text { df } & \begin{array}{r}\text { Mean } \\ \text { Square }\end{array} & \text { F } & \text { Sig.(1-tailed) } \\ 1.000 & 2297.701 & 27.084 & 0.000 \\ 2.008 & 298.341 & 10.546 & 0.000 \\ 2.478 & 35.713 & 2.916 & 0.025 \\ 2.478 & 27.993 & 2.285 & 0.049\end{array}$

Sig. (1-tailed)

0.000

0.000

0.025

0.049 
Appendix C-3: Repeated Measures ANOVA for heart rate

$\Delta \mathrm{HR}$

\begin{tabular}{|c|c|c|c|c|c|}
\hline \multicolumn{6}{|c|}{ Mauchley's Test of Sphericity } \\
\hline & Mauchly's & Approx. Chi- & & & \\
\hline Within Subjects Effect & W & Square & df & Sig. & Huynh-Feldt \\
\hline Treatment & 1.000 & 0.000 & 0 & . & 1.000 \\
\hline Time & 0.000 & 205.027 & 20 & 0.000 & 0.274 \\
\hline Treatment $*$ Time & 0.011 & 111.207 & 20 & 0.000 & 0.345 \\
\hline \multicolumn{6}{|c|}{ Test of Within-S ubjects Effects } \\
\hline Source & $\begin{array}{r}\text { Type III Sum } \\
\text { of Squares }\end{array}$ & df & $\begin{array}{r}\text { Mean } \\
\text { Square }\end{array}$ & $\mathbf{F}$ & Sig. (2-tailed) \\
\hline Treatment & 1229.545 & 1.000 & 1230 & 14.825 & 0.002 \\
\hline Time & 12205.339 & 1.645 & 7420 & 119.257 & 0.000 \\
\hline Treatment $*$ Time & 96.019 & 2.069 & 46.417 & 2.305 & 0.108 \\
\hline Treatment $*$ Time $*$ Drug & 44.995 & 2.069 & 21.751 & 1.080 & 0.348 \\
\hline
\end{tabular}


Appendix C-4: Repeated Measures ANOVA for MSNA

\section{$\triangle$ MSNA bursts/min}

\begin{tabular}{lrrrrr}
\multicolumn{5}{c}{ Mauchley's Test of Sphericity } \\
Approx. Chi- & df & Sig. & Huynh-Feldt \\
Within Subjects Effect & Mauchly's W & Square & 0 &. & 1.000 \\
Treatment & 1.000 & 0.000 & 20 & 0.000 & 0.379 \\
Time & 0.002 & 84.597 & 20 & 0.000 & 0.531 \\
Treatment $*$ Time & 0.003 & 80.634 & &
\end{tabular}

Test of Within-Subjects Effects

Source

Treatment

Time

Treatment $*$ Time

Treatment $*$ Time * Drug Type III Sum of Squares 698.501 14049.910

56.723

41.724

df Square

$1 \quad 698.501$

$2 \quad 6178.816$

3.186

3.186

17.806

13.097

$\mathbf{F}$
2.311
117.767
0.693
0.510

Sig. (1-tailed)

0.074

0.000

0.285

0.344

\section{$\triangle$ MSNA bursts/100 HB}

\section{Within Subjects Effect}

Treatment

Time

Treatment $*$ Time

Source
Treatment
Time
Treatment $*$ Time
Treatment $*$ Time * Drug

Mauchly's
W
1.000
0.011
0.029

Mauchley's Test of Sphericity Approx. Chi-

Square
0.000
61.973
48.942

df
0
20
20

Sig.

0.000

0.000

Test of Within-Subjects Effects

Type III Sum of Squares 385.914 18620.876

155.472

131.529
Mean

$\begin{array}{rrrr}\text { df } & \text { Square } & \text { F } & \text { Sig. (1-tailed) } \\ 1.000 & 385.914 & 0.910 & 0.177 \\ 3.251 & 5727.526 & 74.564 & 0.000 \\ 4.028 & 38.600 & 0.974 & 0.215 \\ 4.028 & 32.656 & 0.824 & 0.258\end{array}$

Huynh-Feldt

1.000

0.542

0.671

0.258 
$\Delta$ Total MSNA

Within Subjects Effect
Treatment
Time
Treatment $*$ Time

\begin{tabular}{rrrrr}
\multicolumn{5}{c}{ Mauchley's Test of Sphericity } \\
Mauchly's & $\begin{array}{r}\text { Approx. Chi- } \\
\text { Square }\end{array}$ & df & Sig. & Huynh-Feldt \\
W & 0.000 & 0 &. & 1.000 \\
1.000 & 106.951 & 20 & 0.000 & 0.325 \\
0.000 & 100.994 & 20 & 0.000 & 0.304 \\
0.001 & & & &
\end{tabular}

Test of Within-Subjects Effects

Source
Treatment
Time
Treatment $*$ Time
Treatment $*$ Time * Drug

Type III Sum

of S quares

$1.992 \mathrm{E}+08$

$1.003 \mathrm{E}+10$

$9.348 \mathrm{E}+07$

$5.401 \mathrm{E}+07$
Mean

$\begin{array}{rrrr}\text { df } & \begin{array}{r}\text { Mean } \\ \text { Square }\end{array} & \mathbf{F} & \text { Sig. (1-tailed) } \\ 1.000 & 1.992 \mathrm{E}+08 & 0.634 & 0.219 \\ 1.952 & 5.138 \mathrm{E}+09 & 95.252 & 0.000 \\ 1.821 & 5.133 \mathrm{E}+07 & 0.771 & 0.231 \\ 1.821 & 2.965 \mathrm{E}+07 & 0.445 & 0.314\end{array}$


Appendix C-5: Repeated Measures ANOVA for forearm blood flows

\section{$\triangle \mathrm{FBF}$}

Within Subjects Effect

Treatment

Time

Treatment $*$ Time

Source

Treatment

Time

Treatment $*$ Time

Treatment $*$ Time $*$ Drug

\begin{tabular}{|c|c|c|c|c|}
\hline \multicolumn{5}{|c|}{ Mauchley's Test of Sphericity } \\
\hline $\begin{array}{r}\text { Mauchly's } \\
\text { W }\end{array}$ & $\begin{array}{r}\text { Approx. Chi- } \\
\text { Square }\end{array}$ & df & Sig. & Huynh-Feldt \\
\hline 1.000 & 0.000 & 0 & . & 1.000 \\
\hline 0.004 & 133.278 & 20 & 0.000 & 0.316 \\
\hline 0.102 & 54.266 & 20 & 0.000 & 0.668 \\
\hline \multicolumn{5}{|c|}{ Test of Within-Subjects Effects } \\
\hline $\begin{array}{r}\text { Type III Sum } \\
\text { of Squares }\end{array}$ & df & $\begin{array}{r}\text { Mean } \\
\text { Square }\end{array}$ & $\mathbf{F}$ & Sig. (1-tailed) \\
\hline 0.668 & 1.000 & 0.668 & 0.911 & 0.175 \\
\hline 7.989 & 1.898 & 4.209 & 15.850 & 0.000 \\
\hline 0.333 & 4.009 & 0.083 & 1.170 & 0.164 \\
\hline 0.086 & 4.009 & 0.022 & 0.303 & 0.438 \\
\hline
\end{tabular}

$\Delta F V R$

Within Subjects Effect
Treatment
Time
Treatment * Time

\section{Source}

Treatment

Time

Treatment $*$ Time

Treatment $*$ Time * Drug

\begin{tabular}{|c|c|c|c|c|}
\hline \multicolumn{5}{|c|}{ Mauchley's Test of Sphericity } \\
\hline Mauchly's W & $\begin{array}{r}\text { Approx. } \\
\text { Chi-S quare }\end{array}$ & df & Sig. & Huynh-Feldt \\
\hline 1.000 & 0.000 & 0 & . & 1.000 \\
\hline 0.028 & 85.145 & 20 & 0.000 & 0.507 \\
\hline 0.058 & 67.851 & 20 & 0.000 & 0.611 \\
\hline \multicolumn{5}{|c|}{ Test of Within-Subjects Effects } \\
\hline Type III Sum & & Mean & & \\
\hline of Squares & df & Square & $\mathbf{F}$ & Sig. (1-tailed) \\
\hline 580.244 & 1.000 & 580.244 & 0.862 & 0.181 \\
\hline 5043.282 & 3.045 & 1656.502 & 19.884 & 0.000 \\
\hline 194.336 & 3.664 & 53.044 & 0.908 & 0.228 \\
\hline 441.426 & 3.664 & 120.487 & 2.062 & 0.049 \\
\hline
\end{tabular}


$\Delta$ FVC

\begin{tabular}{|c|c|c|c|c|c|}
\hline \multicolumn{6}{|c|}{ Mauchley's Test of Sphericity } \\
\hline Within Subjects Effect & $\begin{array}{r}\text { Mauchly's } \\
\text { W }\end{array}$ & $\begin{array}{r}\text { Approx. Chi- } \\
\text { Square }\end{array}$ & df & Sig. & Huynh-Feldt \\
\hline Treatment & 1.000 & 0.000 & 0 & . & 1.000 \\
\hline Time & 0.006 & 123.620 & 20 & 0.000 & 0.335 \\
\hline Treatment $*$ Time & 0.124 & 49.595 & 20 & 0.000 & 0.730 \\
\hline
\end{tabular}

Test of Within-Subjects Effects

Source
Treatment
Time
Treatment $*$ Time
Treatment $*$ Time * Drug

Type III Sum

of Squares

0.000

0.001

7.456E-05

$2.468 \mathrm{E}-05$
Mean

df Square

$1.000 \quad 0.000$

2.012

4.380

0.000

1.702E-05

4.380

5.63E-06
F

2.676

10.874

1.921

0.636
Sig. (1-tailed)

0.057

0.000

0.053

0.326 
Appendix D-1: Post-hoc paired t-tests for baseline measurements

SAP (Alcohol)

Pairing

Pre-baseline vs Post-baseline

SAP (Placebo)

Pairing

Pre-baseline vs Post-baseline

DAP (Alcohol)

Pairing

Pre-baseline vs Post-baseline

DAP (Placebo)

Pairing

Pre-baseline vs Post-baseline

MAP (Alcohol)

Pairing

Pre-baseline vs Post-baseline

MAP (Placebo)

Pairing

Pre-baseline vs Post-baseline

HR (Alcohol)
95\% Confidence

Interval

$\begin{array}{rrrrrr}\text { Mean } & \text { Lower } & \text { Upper } & \mathbf{t} & \text { df } & \text { tailed) } \\ 4.797 & -9.443 & -0.150 & 2.210 & 14 & 0.022\end{array}$

95\% Confidence

Interval

$\begin{array}{rrrrrr}\text { Mean } & \text { Lower } & \text { Upper } & \mathbf{t} & \text { df } & \begin{array}{r}\text { Sig. (1- } \\ \text { tailed) }\end{array} \\ 5.860 & -9.693 & -2.027 & 3.279 & 14 & 0.003\end{array}$

95\% Confidence

Interval

\begin{tabular}{rrrrrr} 
Mean & Lower & Upper & $\mathbf{t}$ & $\mathbf{d f}$ & $\begin{array}{r}\text { tailed) } \\
4.653\end{array}$ \\
\hline & -8.851 & -0.456 & 2.378 & 14 & 0.016
\end{tabular}

95\% Confidence

Interval

$\begin{array}{rrrrrr}\text { Mean } & \text { Lower } & \text { Upper } & \mathbf{t} & \text { df } & \begin{array}{r}\text { Sig. } \\ \text { tailed) }\end{array} \\ 7.160 & -10.569 & -3.751 & 4.505 & 14 & 0.000\end{array}$

95\% Confidence

Interval

$\begin{array}{rrrrrr}\text { Mean } & \text { Lower } & \text { Upper } & \mathbf{t} & \text { df } & \begin{array}{r}\text { Sig. } \\ \text { tailed) }\end{array} \\ 4.700 & -8.055 & -1.345 & 3.005 & 14 & 0.005\end{array}$

95\% Confidence

Interval

$\begin{array}{rrrrrr}\text { Mean } & \text { Lower } & \text { Upper } & \text { t } & \text { df } & \begin{array}{r}\text { Sig. (1- } \\ \text { tailed) }\end{array} \\ 6.773 & -10.069 & -3.477 & 4.408 & 14 & 0.001\end{array}$


95\% Confidence

Interval

Pairing

Pre-baseline vs Post-baseline

MSNA bursts/min (Alcohol)

Pairing

Pre-baseline vs Post-baseline
Mean

5.187

Lower

Upper

$-7.799$

$-2.574$

t

df

Sig. (2-

tailed)

0.002

\section{5\% Confidence}

Interval

$\begin{array}{rrrrrr}\text { Mean } & \text { Lower } & \text { Upper } & \mathbf{t} & \mathbf{d f} & \begin{array}{r}\text { tailed) } \\ -5.985\end{array} \\ -12.516 & 0.547 & -1.996 & 12 & 0.035\end{array}$


Appendix D-2: Post-hoc Paired T-tests

\section{SMAP (Alcohol)}

\section{Pairing}

Pre $-5 \mathrm{mmHg}$ vs Post $-5 \mathrm{mmHg}$

Pre $-10 \mathrm{mmHg}$ vs Post $-10 \mathrm{mmHg}$

Pre $-15 \mathrm{mmHg}$ vs Post $-15 \mathrm{mmHg}$

Pre $-20 \mathrm{mmHg}$ vs Post $-20 \mathrm{mmHg}$

Pre $-30 \mathrm{mmHg}$ vs Post $-30 \mathrm{mmHg}$

Pre $-40 \mathrm{mmHg}$ vs Post $-40 \mathrm{mmHg}$

$\triangle$ S AP (Alcohol)

\section{Pairing}

Pre $-5 \mathrm{mmHg}$ vs Post $-5 \mathrm{mmHg}$

Pre $-10 \mathrm{mmHg}$ vs Post $-10 \mathrm{mmHg}$

Pre $-15 \mathrm{mmHg}$ vs Post $-15 \mathrm{mmHg}$

Pre $-20 \mathrm{mmHg}$ vs Post $-20 \mathrm{mmHg}$

Pre $-30 \mathrm{mmHg}$ vs Post $-30 \mathrm{mmHg}$

Pre $-40 \mathrm{mmHg}$ vs Post $-40 \mathrm{mmHg}$

\section{$\triangle \mathrm{DAP}($ Alcohol $)$}

\section{Pairing}

Pre $-5 \mathrm{mmHg}$ vs Post $-5 \mathrm{mmHg}$

Pre $-10 \mathrm{mmHg}$ vs Post $-10 \mathrm{mmHg}$

Pre $-15 \mathrm{mmHg}$ vs Post $-15 \mathrm{mmHg}$

Pre $-20 \mathrm{mmHg}$ vs Post $-20 \mathrm{mmHg}$

Pre $-30 \mathrm{mmHg}$ vs Post $-30 \mathrm{mmHg}$

Pre $-40 \mathrm{mmHg}$ vs Post $-40 \mathrm{mmHg}$
$95 \%$ Confidence

Interval

$\begin{array}{rrrrrr}\text { Mean } & \text { Lower } & \text { Upper } & \text { t } & \text { df } & \begin{array}{r}\text { Sig. } \\ \text { tailed) }\end{array} \\ 0.827 & -0.288 & 1.942 & 1.590 & 14 & 0.067 \\ 1.467 & -0.320 & 3.253 & 1.761 & 14 & 0.050 \\ 2.280 & 0.458 & 4.102 & 2.683 & 14 & 0.009 \\ 4.133 & 1.336 & 6.930 & 3.170 & 14 & 0.004 \\ 4.293 & 1.528 & 7.058 & 3.330 & 14 & 0.003 \\ 4.500 & 1.594 & 7.406 & 3.321 & 14 & 0.003\end{array}$

95\% Confidence

Interval

$\begin{array}{rrrrrr}\text { Mean } & \text { Lower } & \text { Upper } & \mathbf{t} & \text { df } & \begin{array}{r}\text { Sig. } \\ \text { tailed) }\end{array} \\ 0.960 & -0.451 & 2.371 & 1.489 & 14 & 0.084 \\ 2.160 & -0.432 & 4.752 & 1.787 & 14 & 0.048 \\ 3.600 & 1.019 & 6.180 & 2.992 & 14 & 0.005 \\ 5.587 & 1.353 & 9.820 & 2.831 & 14 & 0.070 \\ 5.727 & 1.850 & 9.603 & 3.168 & 14 & 0.004 \\ 5.633 & 1.793 & 9.474 & 3.146 & 14 & 0.004\end{array}$

95\% Confidence

Interval

$\begin{array}{rrrrrr}\text { Mean } & \text { Lower } & \text { Upper } & \mathbf{t} & \mathbf{d f} & \begin{array}{r}\text { Sig. (1- } \\ \text { tailed) }\end{array} \\ 0.453 & -0.440 & 1.346 & 1.089 & 14 & 0.148 \\ 0.653 & -0.464 & 1.771 & 1.254 & 14 & 0.116 \\ 1.187 & 0.035 & 2.338 & 2.211 & 14 & 0.022 \\ 2.873 & 0.844 & 4.903 & 3.036 & 14 & 0.005 \\ 3.353 & 1.110 & 5.592 & 3.212 & 14 & 0.003 \\ 3.730 & 1.239 & 6.228 & 3.210 & 14 & 0.003\end{array}$


$\Delta$ FVR(Alcohol)

\section{Pairing}

Pre $-5 \mathrm{mmHg}$ vs Post $-5 \mathrm{mmHg}$

Pre $-10 \mathrm{mmHg}$ vs Post $-10 \mathrm{mmHg}$

Pre $-15 \mathrm{mmHg}$ vs Post $-15 \mathrm{mmHg}$

Pre $-20 \mathrm{mmHg}$ vs Post $-20 \mathrm{mmHg}$

Pre $-30 \mathrm{mmHg}$ vs Post $-30 \mathrm{mmHg}$

Pre $-40 \mathrm{mmHg}$ vs Post $-40 \mathrm{mmHg}$

95\% Confidence

Interval

$\begin{array}{rrrrrr}\text { Mean } & \text { Lower } & \text { Upper } & \mathbf{t} & \mathbf{d f} & \begin{array}{r}\text { Sig. } \\ \text { tailed) }\end{array} \\ 1.529 & -3.679 & 6.737 & 0.630 & 14 & 0.270 \\ -0.797 & -5.421 & 3.827 & -0.370 & 14 & 0.359 \\ 0.906 & -3.331 & 5.144 & 0.459 & 14 & 0.327 \\ 7.381 & 0.595 & 14.167 & 2.333 & 14 & 0.018 \\ 5.204 & -4.477 & 14.885 & 1.153 & 14 & 0.134 \\ 6.866 & -0.083 & 13.814 & 2.119 & 14 & 0.026\end{array}$


Appendix E: Copyright clearance

Rightslink $®$ by Copyright Clearance Center

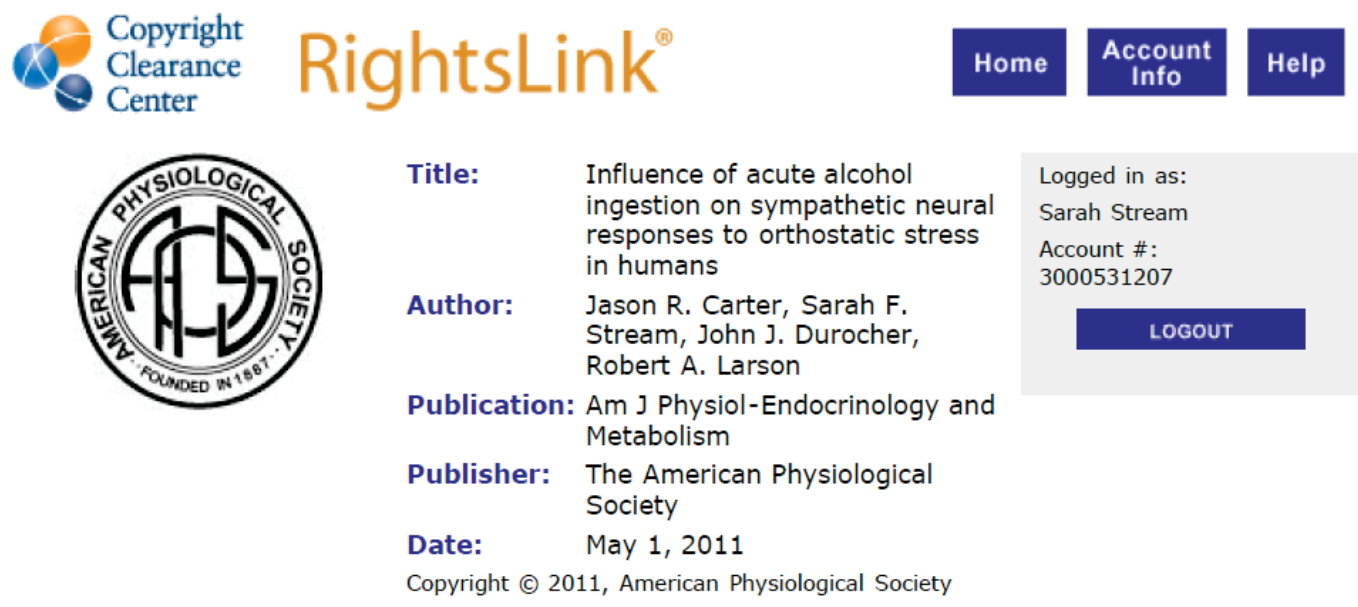

Permission Not Required

Permission is not required for this type of use.

\section{BACK CLOSE WINDOW}

Copyright (@) 2012 Copyright Clearance Center, Inc. All Rights Reserved. Privacy statement. Comments? We would like to hear from you. E-mail us at customercare@copyright.com

Figure 4.1 A screenshot of the American Physiological Society's copyright permission page. This can be found on their web page at http://www.theaps.org/mm/Publications/Copyright-and-Permissions

\section{Rights of Authors for Reuse of Content from their Articles}

Theses and dissertations. APS permits whole published articles to be reproduced without charge in dissertations, which may be posted to theses repositories. Full citation is required.

Figure 4.2 A screenshot of the American Physiological Society's copyright permission page stating the rights of authors to reuse published articles in theses. This can be found on their web page at http://www.theaps.org/mm/Publications/Copyright-and-Permissions 